University of Louisville

ThinkIR: The University of Louisville's Institutional Repository

Electronic Theses and Dissertations

8-2009

\title{
Hong Kong's cultural identity reflected in Jackie Chan's films.
}

Yajuan Ding 1969-

University of Louisville

Follow this and additional works at: https://ir.library.louisville.edu/etd

\section{Recommended Citation}

Ding, Yajuan 1969-, "Hong Kong's cultural identity reflected in Jackie Chan's films." (2009). Electronic Theses and Dissertations. Paper 352.

https://doi.org/10.18297/etd/352

This Doctoral Dissertation is brought to you for free and open access by ThinkIR: The University of Louisville's Institutional Repository. It has been accepted for inclusion in Electronic Theses and Dissertations by an authorized administrator of ThinkIR: The University of Louisville's Institutional Repository. This title appears here courtesy of the author, who has retained all other copyrights. For more information, please contact thinkir@louisville.edu. 


\title{
HONG KONG'S CULTURAL IDENTITY REFLECTED IN JACKIE CHAN'S FILMS
}

\author{
By \\ Yajuan Ding \\ M.A., University of Science and Technology Beijing, 2002
}

\begin{abstract}
A Dissertation
Submitted to the Faculty of the

Graduate School of the University of Louisville

in Partial Fulfillment of the Requirements

for the Degree of
\end{abstract}

Doctor of Philosophy

Department of Humanities

University of Louisville

Louisville, Kentucky

August 2009 
Copyright 2009 by Yajuan Ding

All rights reserved 


\title{
HONG KONG'S CULTURAL IDENTITY \\ REFLECTED IN JACKIE CHAN'S FILMS
}

\author{
By \\ Yajuan Ding \\ M.A., University of Science and Technology Beijing, 2002
}

A Dissertation Approved on

July 28,2009

By the following Dissertation Committee:

Dissertation Director 


\section{DEDICATION}

This dissertation is dedicated to my parents,

Mr. Jifa Ding and Mrs. Yonglan Zhang

who have believed in my dreams and supported me

to my husband

Mr. Keqing Li

who has supported me tirelessly in all aspects

as I pursued my Doctoral degree

and especially to my son

Siqi Li

who stimulates me with his sweet words and smiling face 


\section{ACKNOWLEDGMENTS}

I would like to thank Dr. Annette C. Allen, my dissertation director, for her unending patience in reading and commenting upon the drafts of my dissertation. Her encouragement, motherly concern and elegance have impressed me all along my study and life in the Beijing Ph.D. Program in Humanities of the University of Louisville in cooperation with Beijing Foreign Studies University for the past three years. She never fails to encourage me to fulfill my dream, especially during my one-year-and-a-half study in Louisville. I would also like to thank the other committee members, Dr. Mark E. Blum and Dr. Ying Kit Chan, for giving me inspiration and valuable suggestions and for reading and commenting upon the countless rough drafts of the dissertation. They proved extremely important in encouraging me to think and rethink about the issues in order to improve my work. I would give my heart-felt thanks to the outside reader, Dr. Joy Hart, who patiently reviewed the final copy of my dissertation and gave me valuable suggestions during my oral defense. I would especially like to thank the writing assistants of the Writing Center, especially Kelly Blewett, Stephen Strother and Ruth Miller, who have done a great job in helping me improve my academic writing skills, and the program assistant, Robin L Blackett, who patiently helps me 
print out my paper and gives me a warm welcome. Finally, I would like to thank my family (my parents, my brother, my sister-in-law, my husband and son) and my friends (my Chinese friends in China and in the U.S., and my American friends) who have been supporting and encouraging me to make my dream come true. Without your support and friendship, I cannot survive the thorny path of an aspirant academic in a foreign country. 


\section{ABSTRACT \\ HONG KONG'S CULTURAL IDENTITY REFLECTED IN JACKIE CHAN'S FILMS}

Yajuan Ding

July 28,2009

In the 1990s, especially the years before and after Hong Kong's return to the People's Republic of China in 1997, some celebrated and talented Hong Kong film stars, such as Jackie Chan, Yun-Fat Chow and Michelle Yeoh, sought their career success in the Western world, especially in Hollywood. By studying Jackie Chan's representative films produced in Hong Kong and in Hollywood before and after 1997, the author explores how Hong Kong's cultural identity is portrayed in his films produced in the Western world and in a city with a legacy of over a century of colonization. Moreover, the author also tries to explore whether or not the portrayal of Hong Kong's cultural identity in those films is influenced by historical and political factors, such as the handover in 1997, and other social, economic and cultural factors through analyses of the news articles published by a Hong Kong media organization, popular songs, films with other Hong Kong stars in leading roles and some relevant scholarly works produced around the year of the handover of Hong Kong from Britain to mainland China. 


\section{TABLE OF CONTENTS}

PAGE

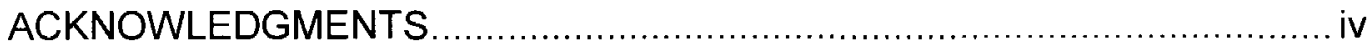

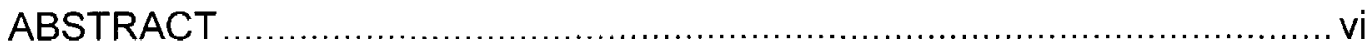

\section{CHAPTER}

INTRODUCTION

I. THE PURPOSE, SIGNIFICANCE, PERSPECTIVES, AND RESEARCH METHODS USED IN THE PRESENT RESEARCH.............................

II. KEY TERMS IN THE PRESENT RESEARCH ....................................15

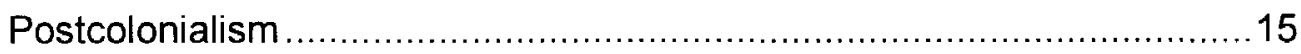

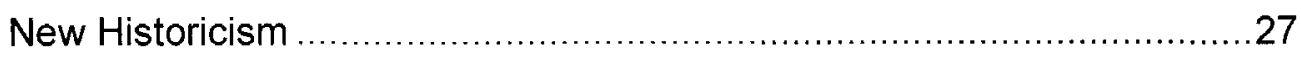

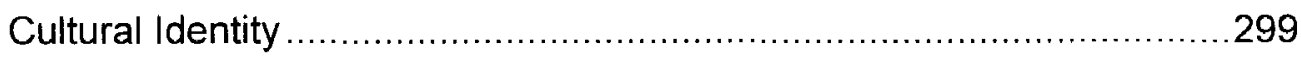

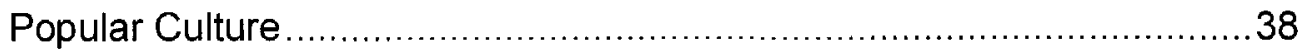

III. PHASES OF THE CONSTRUCTION OF HONG KONG'S CULTURAL IDENTITY

Phasese of the Construction of Hong Kong's Cultural Identity Demonstrated in Hong Kong Cinema .................................................54

Hong Kong's Cultural Identity Discussed in Scholarly Works .................78

Hong Kong's Cultural Identity Reflected in Popular Songs ......................91

Hong Kong's Cultural Identity Reflected in Mass Media .......................100 
IV. LITERATURE REVIEW OF HONG KONG'S CULTURAL IDENTITY REFLECTED IN JACKIE CHAN'S FILMS .............................................122

V. JACKIE CHAN'S HONG KONG FILMS ...........................................135

Jackie Chan's Hong Kong Films Produced Before 1997 ....................136

Jackie Chan's Hong Kong Films Produced After 1997 .......................145

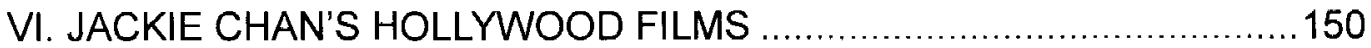

Jackie Chan's Hollywood Films Produced Before 1997 .......................152

Jackie Chan's Hollywood Films Produced After 1997 ...........................153

VII. POSTCOLONIAL AND NEW HISTORICAL READINGS OF JACKIE CHAN'S HONG KONG AND HOLLYWOOD FILMS ..........................156

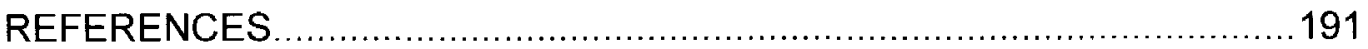

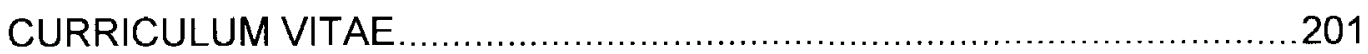




\section{INTRODUCTION}

It is well-known that Hong Kong was a part of the global system of colonization from the end of the Opium War and became one of the colonies of Britain after an unequal treaty signed between the British and Chinese governments in 1842. In the 1980s and the 1990s, Hong Kong witnessed a phase of historical transition after the British and Chinese governments signed Sino-British Joint Declaration in 1984. According to the Sino-British Joint Declaration, after the British handover of Hong Kong to the People's Republic of China on July 1,1997, Hong Kong, as a special administration (the Hong Kong Special Administrative Region, or HKSAR), would retain its previous capitalist economy under China's sovereignty, which was guaranteed through the implementation of the "one country, two systems" and "Hong Kong people ruling Hong Kong" policies. Scholars such as Eliza W. Y. Lee argue that the fact that China has the absolute final say on the sovereignty of Hong Kong results in the denial of the Hong Kong people's self-determination or voice in the negotiation process (13). Compared with other colonies of Britain, Hong Kong experienced totally different political and economic changes. Scholars believe these changes are responsible for Hong Kong residents' feeling of 
uncertainty as manifested in the debate about Hong Kong's present situation. Rey Chow regards Britain as an outgoing colonial power and China as an incoming authoritarian government and argues that the citizens of Hong Kong were deprived of their own voices by both British and Chinese governments and thus Hong Kong was in a situation of in-betweenness because of the "loss of voice between the patriotic rhetoric of China and the moral rhetoric of Britain (in claiming that it had the moral responsibility to take care of the interests of its colonial subjects)" (13). Lee believes that it is the feeling of political uncertainty concerning Hong Kong's sovereignty in the handover from Britain to the People's Republic of China that resulted in the 1980s and 1990s' massive migration of Hong Kong's well-educated and wealthy citizens, who are mainly composed of managers, entrepreneurs and professionals, to Western countries such as Canada, the United States, Australia and Britain (18). As described by Siumi Maria Tam, the "waves of emigration of Hong Kong people in the post-1984 and post 1989 periods" led to the appearance and existence of the so-called "astronaut families" (177). However, among those migrants, the most distinguished and attention-getting group of professionals was the film stars whose activities, behaviors and changes, especially in their private lives, are always the focus of the mass media and fan interest.

There has been an obvious trend of migration within the Hong Kong

\footnotetext{
1 Astronaut families: families in which one or more members of the immigrant family, mainly males, like astronauts, travel to and from the permanent base in home country or region and temporary space station in the host country where femaie members of the immigrant family and the offspring have set up a new household. See Lee (177)
} 
entertainment industry since the 1990s. Some distinguished and talented Hong Kong film stars have been making great efforts and trying to seek their career success in the Western world, especially in Hollywood-the world-famous center of film production—and are now involved in more and more Western film productions. For example, Jackie Chan, with the reputation as the best and most famous action film star in Asia, is well known to Americans with his Rush Hour series launched into the world film market after 1998. Yun-Fat Chow, who is well-known for his masculine and heroic screen figure in his Hong Kong films, starred in the Hollywood films The Replacement Killers, produced in 1998, Anna and the King and The Corruptor in 1999, and Bulletproof Monk in 2003. Another martial arts actor, Jet Li, who is of Chinese mainland origin, is famous for his Lethal Weapon in 1998 and Romeo Must Die in 2000. Also there is the handsome "action queen" Michelle Yeoh co-starring with Pierce Brosnan in Tomorrow Never Dies in 1997.

Dannern and Barry Long hold that the flow of Hong Kong film stars into Hollywood was mainly due to the unstable transition concerning the postcolonial situation of Hong Kong (Wang). Other researchers argue that Hong Kong's future was vague and uncertain upon its returning to mainland China after it had been governed and colonized by British imperial rule for more than one hundred years. Hong Kong residents, especially the celebrities, were confused and anxious about their future life and career achievements. Meanwhile, Hong Kong's unique timesaving and economical way of producing 
action films and comedies attracted the attention of Hollywood moviemakers (Wang). As some Hong Kong film stars have steered much of their career into Western film production, their performances and the images they shaped or created in their Western films may have shifted or changed accordingly. As a world famous city with a unique cultural, economic and political legacy, Hong Kong has been regarded as an internationalized ideal place for business and entertainment, especially for shopping. The cultural identity of Hong Kong has been undergoing different transformations in the past century, and changes especially emerge around the year of Hong Kong's return to the People's Republic of China. Hong Kong's cultural identity has been frequently reported by the mass media and discussed in literary and academic works in the past decades. In addition, it has been the main theme of different forms of arts and expressed and depicted vividly by artists in their works such as paintings in recent decades. The cultural identity of Hong Kong has also been demonstrated and reconstructed consciously or unconsciously by various forms of popular culture such as music, television and film. In this paper, I will use postcolonial theory to explore how Hong Kong's cultural identity is reflected in Jackie Chan's performances and in his Hong Kong and Hollywood films produced before and after 1997. Moreover, I will also examine the correlations of his presentation of the cultural identity of Hong Kong with the changes of holistic social, economic and cultural historical background from a new historical perspective. 
Jackie Chan has produced over one hundred films since he made his acting debut when he was eight years old in the film Seven Little Valiant Fighters (Big and Little Wong Tin Bar/The 7 Tyrants of Jiangnan, 1962). Because movies produced in different periods and locations are influenced by those periods and locations, they may differ in the performances, themes, plots, and the economic, social and cultural backgrounds. However, there may be some consistencies in these movies if they are produced by the same production companies or have the same actors or actresses as the leading protagonists. Therefore, new historicism is necessary to support the assumption of the correlations between the movies and the ages in which they were produced.

Traditionally, Jackie Chan's films cannot be regarded as representative of Hong Kong culture since most of his films are funny action films and therefore should be strictly categorized as popular culture, which by nature is excluded from the mainstream of art and highbrow culture. However, evidence shows that Jackie Chan's films are actually regarded as typical Hong Kong films. According to Poshek Fu and David Desser (2-3), the first success for Hong Kong action cinema in the Western film market was the Shaw Brothers' production Five Fingers of Death, released in America in 1973. Later, Bruce Lee became a Hollywood superstar and attracted international attention to Hong Kong cinema. Although his first attempts in Hollywood in the 1980s were not successful, Jackie Chan finally became a transnational superstar in the 
1990s and contributed significantly to the development of Hong Kong films in the international film market. In some sense, Jackie Chan's action films are believed to be a label of Hong Kong cinema. His performances are now accepted as representative of Hong Kong and the Chinese, especially in the Western entertainment industry, which is manifested by his household reputation in Western countries and the fact that he is one of few Chinese film stars whose name is engraved on the Hollywood Walk of Fame. In recent years he has been working as a prolocutor for Hong Kong and the Chinese. Moreover, it is the transnational appeal of Jackie Chan, together with two other transnational filmmakers John Woo and Wong Kar-wai, and the 1997 handover that drew more scholarly attention to Hong Kong cinema (Fu and Desser 2). Therefore, Chan's performances and films deserve to be studied. In Victory and Loneliness, Jinhua Xu says that Jackie Chan's films in some sense represent the culture of Hong Kong and the values of Hong Kong citizens as reflected by the detective Lee with whimsical ideas in City Hunter, who tries every means to save the little girl Su Yang's life (183-185). Xu notes that there is no doubt that the protagonist in the Dragon Fist is a vivid representation of the values of the youth of the 1980 s (50). Obviously the image seems to run in the opposite direction to the moral values of the old generations, but reflects the real nature of human beings and depth of culture.

Jackie Chan is not only a celebrated martial arts film star in Hong Kong, but also a household name in other Asian areas and countries such as 
Malaysia, Taiwan and Japan and a widely known action film star in Western countries, especially in Hollywood. His funny performances in his action films make him a super star among Chinese audiences all over the world. Furthermore, he wins the favor of audiences of different nations and nationalities; there are Jackie Chan fans even in the Sahara desert (Xu 83).

Another reason for taking Jackie Chan's films as examples to illustrate Hong Kong's cultural identity in the present research is that Jackie Chan's films are regarded as a new genre of action film. They are funny, exciting, adventurous and feature true to life stunts, and are fundamentally different from Bruce Lee's serious action films. In 1987, Jackie Chan was unprecedentedly awarded a special prize, Jin Ma Prize, the highest honor for actors and actress in Taiwan, which is well-known for its emphasis on art and refuses to classify action films into the genre of art or highbrow culture. The committee members of the Jin Ma Prize, based on the box office ticket sales of Jackie Chan's action films, acknowledged that action film is the only genre of Chinese film until now to be welcomed in the international film market ( $X u$ 96). It indicates that Jackie Chan's performances and achievements in film production are gradually accepted by critics of formal art and high culture.

Jackie Chan's contribution to Hong Kong cinema and Hollywood cinema and even world cinema is unequaled and unique, and therefore, he is not regarded only as a talented kung fu film star. In Hong Kong Cinema: the Extra Dimension, Stephen Teo says that Jackie Chan is "the star who most 
successfully continues the tradition of the kung fu action spectaculars which Bruce Lee brought to international prominence" (122). He further states that Jackie Chan "should be admired as one of the best of the purely physical performers in world cinema" and his fabulous stunts and "derring-do spirit have shown a face of Hong Kong cinema that is utterly irresistible" (134). Jackie Chan continues to preserve "Bruce Lee's tradition of kung fu as instinctive but disciplined art linked to a cultural and national identity" and the "overtones of nationalism of Lee's espousal of kung fu" in his movies (Teo 122). Therefore, it is feasible and practical to take Jackie Chan's movies as an example to explore the representation of Hong Kong's cultural identity. 


\section{CHAPTER I}

\section{THE PURPOSE, SIGNIFICANCE, PERSPECTIVES, AND RESEARCH METHODS USED IN THE PRESENT RESEARCH}

The purpose of the present research is to see how Hong Kong's cultural identity is reflected in Jackie Chan's performances and his films produced in Hong Kong and Hollywood before and after 1997. In addition, the paper also explores the correlations and influences of changes in cultural, economic and historical background on the representation of the cultural identity of Hong Kong in Jackie Chan's films by examining how the issue is discussed in scholarly works and portrayed in different forms of popular culture such as film, music and mass media.

The present research will be a pilot study on interpreting Jackie Chan's films. The significance of this research is reflected in the following aspects. Some film scholars in the academic world have used cultural critical theories in their analyses of films. However, the common practices and mainstream research methods in this field are to interpret films by using Western film theories such as text analysis, montage theory, experimental or avant-garde, or cultural theories such as Marxism, Structuralism, Poststructualism and 
Psychoanalysis. There are also a number of scholars discussing the cultural identity of Hong Kong by taking Jackie Chan's films as an example. But few scholars present a whole picture and comprehensive analysis of Jackie Chan's films to the readers to see how the cultural identity of Hong Kong is represented in his performances and films. Even fewer scholars explore the correlation of his presentations of the cultural identity of Hong Kong with the holistic historical environment, i.e. social, economic and cultural background, of the time when the films were produced and launched into the film market in Hong Kong or the Western world. The significance of this research also lies in its attempt to use New Historicism to interpret the relationship between the representation of cultural identity in films and social, political, cultural and historical factors, which is not very common in the field of film criticism. Furthermore, the research attempts to use the findings from forms of popular culture such as popular songs, mass media, in addition to scholarly discussion, to provide evidence to support the main theme of this paper-the cultural identity of Hong Kong reflected in Jackie Chan's films. Therefore, the present research may provide a novel research perspective or approach for academic research in the fields of both film criticism and Hong Kong studies.

Quantitative analysis and qualitative analysis will be adopted in the present research. Moreover, this paper will employ cultural critical theories such as Postcolonialism and New Historicism to explain in detail the representation of Hong Kong's cultural identity in Jackie Chan's performances 
and films.

The bar chart and Table 1 below show that of Jackie Chan's films produced between 1987 and 1996, 85.7\% were produced in Hong Kong and $10.7 \%$ were produced in Hollywood. However, during the period from 1997 to $2006,47.3 \%$ of Chan's films were produced in Hollywood, a much higher percentage than that produced in the previous decade. The figures in the two graphs clearly show Jackie Chan's tendency to seek his career success in Hollywood instead of Hong Kong. They also suggest that he pursued the internationalization or globalization of his performance career, which in some sense provides a good rationale for employing postcolonial theory.

Jackie Chan's Films Produced in 1987-1996 and 1997-2006

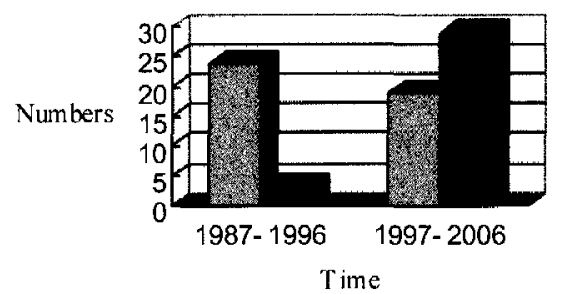

Films Produced in Hons Kong

- Films Produced in Holly wood

\begin{tabular}{|c|c|c|c|}
\hline Time Jackie Chan's Films & Total & $\begin{array}{l}\text { Films Produced } \\
\text { in Hong Kong }\end{array}$ & $\begin{array}{l}\text { Films Produced } \\
\text { in U.S. }\end{array}$ \\
\hline 1987-1996 & 28 & $24(85.7 \%)$ & $3(10.7 \%)$ \\
\hline $1997-2006$ & 55 & $19(34.5 \%)$ & $29(47.3 \%)$ \\
\hline
\end{tabular}

Table 1: Jackie Chan's films produced between 1987 and $2006^{2}$.

\footnotetext{
${ }^{2}$ Source : 6 Jan., $2007<$ http://p0000329.people.mov.cn/>
} 
In order to have a relatively full picture and elaborately illustrate how Hong Kong's cultural identity is reflected or represented in Jackie Chan's films, 23 films are used as samples in this research. The films, categorized on the basis of their production time and location, were selected by taking into consideration their representativeness and continuity of the main themes of the films, as well as the diversity of the themes and genres of the films. Group I includes eight Hong Kong films produced before 1997: Drunken Master/Drunken Monkey/Zuiquan (1978); Drunken Master II/Zuiquan II (1994); Project A/Pirate Patrol/A Jihua (1984); Project A II/A Jihua Xuji (1987); Police Story/Jingcha Gushi (1985); Police Story II/Jingcha Gushi Xuji (1988); Police Story III: Supercop/Jingcha Gushi III: Chaoji Jingcha (1992); Police Story IV: First Strike/Jingcha Gushi IV: Jiandan Renwu (1996). Group II contains five Hong Kong films produced after 1997 : Who Am I?Wo Shi Shui (1998); Gorgeous/Boli Zun (1999); New Police Story/Xin Jingcha Gushi (2004); Myth/Shenhua (2005); Rob-B-Hood/Baobei Jihua (2006). Because Jackie Chan had few opportunities to be involved in the film production in the Western world before 1997, only four Hollywood films are included in Group III: Battle Creek Brawl/The Big Brawl (1980); Cannonball Run (1980); Cannonball Run II (1983); The Protector (1985). Group IV is comprised of six Hollywood films released after 1997: Rush Hour I (1998); Rush Hour II (2001); Rush Hour III (2007); Shanghai Noon (2000); Shanghai Knights (2003); The Tuxedo (2002).

Series of Jackie Chan's films such as the Police Stories series, Project $A$ 
series and Rush Hour series are selected for inclusion in this paper. On the one hand, this way of selection can largely guarantee the continuity of the main themes of the films. It is true that those films are produced in different years, but they usually have the same actors or actresses as the protagonist and the same film producers. In addition, the plots of those films are more often than not connected with each other, although distinct and unexpected climaxes will appear in different episodes to excite the viewers or arrest their attention. On the other hand, the film series have slightly or dramatically different themes, plots, and economic, social and cultural backgrounds, which makes it easier to draw comparisons between the films to see the changes in such aspects as themes, performance styles and the backgrounds in different eras and the relationship between those aspects with the economical, political, social and cultural environmental elements of different times. There are also good reasons to select the films with different genres and diversity of themes. In general, producers or actors/actresses tend to produce or participate in the production of films of different genres. The same is true for the producers or actors/actresses to choose the themes of the films they produce or participate in. However, what matters most is that the selected films with different genres and diversity of themes can reflect the broadness of the films selected in the present research, the versatility of the producers or actors/actresses, and the tastes and focuses of a society. Moreover, such a selection of the films can help guarantee the reliability and the limitations of the present research. 
As mentioned above, the purpose of the present research is to explore how Hong Kong's cultural identity is reflected in Jackie Chan's Hong Kong and Hollywood films. Therefore, the author attempts to use postcolonism, new historicism and other related theories to examine the dialogues, pictures, symbols and themes in the aforementioned films as well as the performances of the actors or actresses to see how Hong Kong's cultural identity is portrayed in Chan's films produced in different periods and in both the Western world and in a city with a century-long colonial history. 


\section{CHAPTER II}

\section{KEY TERMS IN THE PRESENT RESEARCH}

\section{POSTCOLONIALISM}

Postcolonialism, a concept initially used by historians after World War II to designate the post-independence period, has been employed by literary critics since the late 1970 s to describe multifarious effects of European colonizers on the cultures and societies of the colonized. It has long been a controversial term that continually arouses disputes among scholars because of its prefix "post" and the nature of the term itself. The prefix "post," a source of vigorous debate, simply implies "after" colonialism, but actually that is not necessarily the case. On the one hand, as indicated by Bill Ashcroft, Gareth Griffiths and Helen Tiffin in Post-Colonial Studies-The Key Concepts, the term "post-colonial" per se was originally used to depict the cultural interplay within the colonized societies in literary circles, but it was later widely used to denote the subsequent experience of the former European colonies in aspects such as politics, language and cultures (186). On the other hand, the obscure and broad nature of the term postcolonialism fits it in diverse and wide analyses 
and studies of "European territorial conquests, the various institutions of European colonialism, the discursive operations of empire, the subtleties of subject construction in colonial discourse and the resistance of those subjects, and, most importantly perhaps, the differing responses to such incursions and their contemporary colonial legacies in both pre- and post-independence nations and communities" (Ashcroft, Griffiths and Tiffin 187). Therefore, postcolonial theory can be roughly categorized into analyses and studies of three levels of social conditions. First, the present situation of former colonies-cultural colonization has existed in these communities or societies after the ending of the military, political and economic ruling of Western colonizers. Second, the current societies of the Third World countries-some Third World regions and countries, including both the former European colonies and non colonies, have also to some extent experienced cultural colonization. Third, a world-wide situation-cultural colonization or cultural imperialism has permeated communities and countries all over the world after European expansion and colonization in the sixteen century up to and including the neo-colonization of the present day. One can see western influence almost everywhere and in every aspect. Cultures of the former colonized, Third World communities and societies, and minority groups in First World countries have been undergoing changes. As a result, what is European or European derived is considered superior, classic, masculine, advanced and standard, and regarded as the norm and the basis of human civilization which 
is manifested and made legitimate by Western culture, politics, science, law, music, art, and literature. What is non-west, especially Asian, African and Latin American, is regarded as subordinate, inferior, feminine, and is depreciated accordingly. Postcolonialism is in fact a cultural discourse of the intellectuals of the former colonies and the Third World and those who live in the colonies of both the First and Third Worlds, and it reflects those intellectuals' cultural concerns and preferences.

On the whole, postcolonial studies focuses on the cultural dimension of such societies and communities, but it is also integrated into the studies emphasizing the historical, political, sociological and economic aspects upon which European imperialism still has an enduring impact. Undoubtedly, as a current popular colonial discourse theory especially in North America and Europe, postcolonial theory examines the continuing infiltration and control of the former colonizer over its ex-colonies and third world countries with their hegemony in politics and economics, especially in the aspects of culture, knowledge and values. Postcolonialism focuses on the protest against Eurocentrism and the cultural hegemony of those developed Western countries over the developing countries, aiming at restoring their national cultures to their original places from the margins and even striving to become new cultural centers. The world-wide influence of postcolonial theory generally includes two aspects: west and non-west. In the west, what matters is how western people look at the non-western world, that is, how occidentals 
understand the real non-west in the contradictory and unifying dynamic system of knowledge and power. Since it is a theory based on and developed from western ideology, the intellectual reflection and radical changes in thinking patterns it brings about, particularly in the academic circle, seems to be overwhelming as well as normal. In the non-west, postcolonial theory inspires non-westerns to rethink their own cultures and reflect on the modernization process experienced in their communities and societies after melting into the unifying world history.

The publication of Edward Said's Orientalism was a milestone in the formation of postcolonial theory. Postcolonial theory has been further developed by such influential critics as Gayatri Spivak and Homi Bhabha. Postcolonial theory emphasizes that non-western cultures are shadowed, written by westerners in a western way and dominated by the western discourse of "others." It means that, when western people look at the non-western world, what they see is something similar to what they see in a mirror. The image is obscure and sometimes distorted and blurred, thus westerners can only have a specious image and assumption of non-western people, not their real image and the reality of how they perceive the world and themselves. By comparing themselves with the images in the mirror, that is, the images of oriental, occidentals define themselves positively and appreciatively, having no negative and pejorative characteristics.

Since European imperialism expanded its territory and power in the 
nineteen century, more than half of the communities and countries world-wide were once dominated by European or European derived powers, and were subjected to the imposition of European values and cultures. Therefore, the differences between oriental and occidental were exaggerated and magnified. The image of orientals in the eyes of westerners is stereotyped and degraded in a way which others the oriental. To occidentals, oriental people are "others," belonging to disparate groups or races. As a result, when the occidentals describe orientals, they generally use the following negative or pejorative adjectives: inferior, unfledged, dishonest, naïve, effeminate, savage, cruel, evil, cunning, promiscuous, perversive, incompetent, incapable of being independent (Young 2). They furthermore think Orientals require "parental rule of the west for their own best interests," as indicated by Robert J.C. Young in his Postcolonialism-A Very Short Introduction (2). As Said points out, the "Orient is seen as the occident's other," and representations of the orient in many works dealing with orientalism are not objective or accurate representations of the orient, but one constructed or envisaged by Westerners. He argues that the "other" is conceived by the West to confirm its "self." Therefore, "orientalism" is in fact a reflection of the cultural hegemony of imperialism. In Orientalism, Said claims that the "Orient has been represented as the binary opposite of the West," through descriptors such as "timeless," "strange," "irrational," "feminine," "degenerate," "lustful," etc. (McLeod 40-50). Westerners give positive self-definition and achieve a sense of pride by using 
appreciative adjectives procured by comparing them with the negative characteristics of the imaginary image of the oriental they've produced in the process of military colonization and ensuing cultural and economic colonization.

A vivid analogy to postcolonialism is feminism: women are always the objects to be observed, not the subjects who look, and in a society dominated by men they are "others," who belong to a distinct category, a non-men category, and are always subordinated and subjugated to men. Women do not enjoy the same rights in political and economic aspects, and they are deprived of the right to decide and even are disfranchised in some societies. However, in a patriarchal community or society, women become more and more aware of their positions within the status quo, and some are provoked to react and rebel against the oppression and discrimination they undergo. The situation of the oriental in postcolonialism is similar to that of women in feminism. Like women, orientals are always the objects to be observed and seen as others by the occidental. As a theoretical framework, postcolonial criticism attempts to perceive the operations of colonialist and anticolonialist ideologies from political, economical, social, cultural and psychological perspectives, concerning not only the resistance of the colonized against the dominating European cultural imperialism but also the ideological forces that lead to the assimilation of colonizers' values and cultures among those colonized (Tyson 419). 
The fact that many formerly colonized people speak, read and write English in formal settings such as school, government and business manifests the residual influence of dominant European cultures on the subjugated peoples and societies. Such influence is furthermore reflected in the previous colonized society: many formerly colonized people still use English words in daily communications, having English names and film subtitles. There is also an indication of the inherent antagonism between the formerly colonized and the dominating European culture in the fact that indigenous peoples prefer and persist in using local languages at home and in daily conversations. However, the integration and resistance between the culture of the colonizer and that of the colonized are difficult to identify and also not easy to separate into different segments or entities because European cultures and values have been deeply embedded and assimilated into every corner of the daily lives of the subjugated people since the beginning of European colonization. People of the dominated communities and societies have been psychologically confused about their own cultures and values and those of the dominating powers. Colonizers' propaganda about their advanced technology as well as the positive characteristics of their cultures such as being superior, moral, honest, and kind have attracted and influenced the colonized, resulting in a "psychological 'inheritance' of a negative self-image and alienation from their own indigenous cultures, which had been forbidden or devalued for so long that much precolonial culture has been lost" (Tyson 419). Colonial subjects' 
traditional ways of thinking and living, however, have been major psychological forces for preserving local languages and traditions. Colonial subjects have mixed feelings about accepting and resisting the dominating European cultures and social systems or maintaining their native, indigenous, precolonial cultures and societies. They have inquiries about who they are, what their language is, and what and where their home is. Such a dynamic psychological and social interaction is the main concern of postcolonial criticism.

The problem of cultural identity, which is usually represented in postcolonial literature, often arouses heated discussion in postcolonial studies. To begin with, we should first know the key term "colonialist ideology," because the reactions to it comprise the origin of postcolonial identity. Colonial ideology, that is, colonial discourse, is based on the premise that westerners believe themselves to be superior over the original residents of the land they invaded. Therefore, as discussed in the pervious paragraphs, only European or European derived culture is the apotheosis of the civilized and sophisticated world, and is believed to be the norm for the subjugated to emulate and follow suit. Everything of the colonized such as religion, literature and customs is not worth considering and appreciating, and therefore, will be devalued and ignored. European powers see themselves as the center of the world while the rest remain at the margins. Europeans judge those who are different from them as less fully human "others," dividing the world between "us" - the civilized west and "them"-the savage non-west, the "others" (Tyson 420). 
Unfortunately, after years or centuries of colonization, Eurocentric colonial ideology has been entrenched in the psychological, economic and social dimension in the ex-colonial societies because the colonized and their offspring have received education and doctrine from European colonizers. On the one hand, they conceive that what is European is superior and advanced, as inculcated repeatedly and constantly by the west; then they imitate westerners' dress, speech, behavior and lifestyle, which is described by the west as mimicry, while they depreciate and feel shameful of their "inferior" native culture and race and "underdeveloped" technology. Postcolonial theorists claim that colonial subjects often have double consciousness, a consciousness or way of "perceiving the world that is divided between two antagonistic cultures: that of the colonizer and that of the indigenous community" (Tyson 421). It is believed that double consciousness or double vision often leads to the sense of insecurity about oneself even when one is on his homeland, a notion which is portrayed by Homi Bhabha and other postcolonialists as "unhomeliess." You don't feel you are at home even in your own home because everything that seems to be familiar to you is actually what distances you. The native language, lifestyle, way of thinking, culture, custom, etc. make you have a sense of being at home because they have been accompanying you and haunting around you since you were born. However, they also alienate you from where you are because you find you have some different things inside and outside acquired through education and life 
experience that make you have a feeling of not belonging to the indigenous culture and land. The confusion of your cultural identity puts you in a state of psychologically homeless refugee.

Hong Kong experienced British colonization for one hundred and fifty years before it was returned to mainland China in 1997. Despite its return to the motherland, Hong Kong is still influenced by its former colonizer's conquest, colonization and domination over its land, cultural identity and economy. The British colonizer retreated from Hong Kong; however, we still can see its subsequent influence in ideological, political, economic, psychological and cultural dimensions in Hong Kong society. After the handover of Hong Kong from Britain to mainland China, Hong Kong retains its capitalist economy and carries out "one country, two system" political policy. The relative independence in economic and political dimensions, together with industrialization, commercialization and previous colonialization, has led to Hong Kong people's egotism, indifference to politics and partiality for Westernized lifestyle. They continue to value everything Western. Although Mandarin, Cantonese and English are all languages used in Hong Kong, many are proud of their fluent use of English while distaining to speak Mandarin. Hong Kong's colonial state makes possible a hybridized culture. The education Hong Kong people receive enables them to speak, write and think in English; furthermore, they perceive Western culture as superior compared with their local culture and Chinese culture due to their Anglicized education. During the 
transitional periods, especially the initial years after the signing of the Sino-British Joint Declaration in 1984, many Hong Kongers felt unsure and unsafe about their future career and life. They had a sense of loss, yearning and mourning for the supposed golden past. Some of the professionals and enterprisers even migrated to Western countries such as Australia, the United States, Britain and Canada.

Under the colonial subjugation of British imperialism, Hong Kong was transformed from an originally small precolonial seaport which lacked convenient transportation and natural and human resources to a prosperous, world-famous international metropolitan city. In "Introduction: Gender and Change in Hong Kong," Eliza W.Y. Lee argues that, with the approach of the handover of Hong Kong from the British colonizer to mainland China, the 1980 s and 1990s's Hong Kong witnessed a critical historical transition in its economic, political, social dimensions caused by internal and external factors (3-8). The interaction of globalization, postcolonial and Chinese legacies contributed a great deal to the transition and formation of the cultural identity of Hong Kong under the significant historical context of the colonial modernity shaped by the interpenetration of the colonial state, the capitalist economy, and Hong Kong Chinese society. The three elements-colonial state, the capitalist economy and the Hong Kong Chinese society_feed on each other, that is, each element supports each other's operation, fosters the development of other elements by providing the context, or changes the institutional nature 
and structure of the other elements. The social and economic situations were selectively influenced or untouched by the colonial state. For example, the influence of the colonial state on social affairs helps perpetuate women's subordinate positions in such aspects as public policy and actions. Research on the history of Hong Kong's economy shows that the power relations between entrepreneur and the colonial state were the driving forces underlying the development of capitalist society. Lee further takes the two features of Hong Kong society-familialism and individualism, which she believes to have developed specifically in relation to the colonial state and the capitalist economy-as examples to illustrate the changing nature of the Chinese society in Hong Kong. The colonial state is believed to be the real cause of the formation of Hong Kong Chinese familialism which is characterized by individuals relying on familial networks as their safety nets. In turn, familialism helped construct the instrumental ideology of the Hong Kong Chinese who view the existence of the state and society as the means to strengthen the material interests of the individuals and their family members, which leads to "low social participation rate, a lack of civic-mindedness, and low class-consciousness" in the society (Lee 7). Another aspect of economic individualism is reflected in Hong Kongers' sense of self. Hong Kong people believe that intrinsic factors, rather than extrinsic factors, determine their life changes. That is, they believe that the efforts of individuals, not the structural and institutional forces beyond their control, play a significant role in bettering 
their social and economic status.

It is widely accepted that Hong Kong has long been regarded as a "cultural desert" (Fu 199), and the blurred or even distorted cultural identity of Hong Kong during this political and economic transition period needs reinvestigation and rethinking. Hong Kong has been a major concern for postcolonial studies because of its unique features.

\section{NEW HISTORICISM}

In Critical Theory Today, Lois Tyson states that New Historicism is a literary theory which holds that a literary text or an artifact is not an isolated creation, but a result of the interaction of some extrinsic issues such as the historical circumstances and politics of the era in which the literary text is written or the artifact is produced, the philosophical and theological milieu or the author's personal experiences and his frame of mind (281-295). New historicists focus more on the historical background of the literary text or artwork in discussion and the interplay between the literary text or artwork and historical contexts such as the life or intentions of an author in writing a literary text or painting a work. New historicists claim that any given event is generated from a culture, and in return it also affects that culture. That is to say, "all events-including everything from the creation of an artwork, to a televised murder trial, to the persistence of or change in the condition of the poor-are 
shaped by and shape the culture in which they emerge" (Tyson 284). Jonathan Culler believes that New Historicism was vigorously developed in Britain and the United States in the 1980 s and 1990s. He says that the focus of the theorists in the field of new historicism in both Britain and the United States was centered on the Renaissance, while British Renaissance specialists influenced by Foucault accentuated the "historical constitution of the subject" and the "contestatory role of literature" (126). American new historicists put less emphasis on the "hierarchy of cause and effect" because it can reflect the association between "texts, discourses, power and the constitution of subjectivity" (Culler 126). Some scholars such as Stephen Greenblatt did not see literature as a manifestation or representation of social reality but as "one of several sometimes antagonistic practices" because what they emphasized was "how Renaissance literary texts are situated amid the discursive practices and the institutions of the period" (Culler 126). The dialectic relationship between "subversion" and "containment" has been the main concern of the new historicism. For example, new historicists will ask questions such as "how far do Renaissance texts offer a genuinely radical critique of the religious and political ideologies of their day and how far is the discursive practice of literature, in its apparent subversiveness, a way of containing subversive energies?" (Culler 126). 


\section{CULTURAL IDENTITY}

The concept of cultural identity and function of the subject or self has been the focus of theoretical debates in cultural studies and social theory in recent years. In identity theory, self is defined as a multifaceted social construct that is associated with and determined by the roles of people in a society and varies accordingly due to different roles people play in a given social community. Self is generally believed to be a product of social interaction and many people are gregarious and prefer to interact with each other in different groups. It is the interaction between people that helps define who they are. The gregarious nature of people suggests that a person may have distinct selves in different social contexts. Identity, therefore, as a key concept in identity theory, is defined by the associations between social structure and individual action (Hogg, Terry and White 2). Sheldon Stryker views identity as "internalized expectations derived from roles embedded in organized networks of social interaction" (1083). Modern thinking on the topic of self involves whether the self is something given or made as well as whether the self should be viewed in individual or social terms. Modern thinking provides the following perspectives on the self: 1) a well-expressed inner core and something inner and unique; 2) something determined by origins and social attributes such as male or female or American or Australian, 3) or something that has a changing nature and is defined by different subject positions in a society, such as boss rather than a worker (Stets and Burke 
224-38; Stryker 1084-99). Lili Zhu argues that identification means to know "Who am I?" and the real "I"/self is constructed in the process of communication with others (50). Poshek Fu holds that, in a broad sense, identification exists when we compare ourselves with others and in a colonial context, "the colonizer, in Sartre's words, 'has been able to become a man through creating slaves and monsters' out of natives-lazy, incompetent, and primitive" (200). Traditional views of identity regard identity as the most stable, unchanged and continuous reference and significant frame of a nation, a collective real self which can be traced to the source from the history of a nation. From postmodern perspective, identity, on the other hand, is a continuously changing and constructed process, having no fixed definition. The two different views of identification are sometimes transitional, exchanging, contradictory and ambiguous.

Identity is also a central theme in artistic texts. For example, in literature, Jonathan Culler mentions that the mainstream modern tradition has "treated the individuality of the individual as something given, a core which is expressed in word and deed and which can therefore be used to explain action: I did what I did because of who I am, and to explain what I did or said you should look back at the 'I' (whether conscious or unconscious) that my words and acts express" (104-5). What concerns scholars most in studying the topic of subject in literature are the following questions or problems: "What am "I," which factors or circumstances determine one's identity?; the association of 
the "individuality of the individual" and the identity of that individual as a member of a group, and to what extent an individual, "the 'I' that I am, the 'subject', an agent who makes choices rather than has choices imposed on him or her?" (Culler 105). However, compared with the exploration of identity in novels, which can use particular cases to express a general claim while keeping the generalizing force implicit, theoretical treatment of identity may seem less productive (Culler 107). When group identity is the central theme of a novel, it is very common that the novel will "frequently explore how the demands of group identity restrict individual possibilities" (Culler 108). Therefore, with the "individuality of the individual" as the central focus, novels often "construct an ideology of individual identity whose neglect of larger social issues critics should question" (Culler 108). For instance, you may argue that "Emma Bovary's problem is not her foolishness or her infatuation with romances but the general situation of women in her society" (Culler 108). However, the most important significance of literary works is that they can create or construct an identity for the readers as well as make identity a theme. Literature has long been regarded as a good source to give readers diverse and sometimes fantastic experiences and enable them to imagine themselves in similar situations and thus make them attempt to imitate or feel in certain ways. Culler argues that literary works often "encourage identification with protagonists by showing things from their point of view" and holds that literary works such as poems and novels present to readers identification which 
"works to create identity: we become who we are by identifying with figures we read about" (108-109). The mechanism of identification in literature is believed to corrupt the youth because in a sense it encourages the youth to imitate protagonists in novels or films. For example, young people may imitate the characters' way of living and thinking, and even their hairstyle and habits. They may run away from home to escape the reality of life and experience adventurous life in deserts or metropolitan cities. The same is true in films. It has long been argued that films, like literature, frequently create stereotyped identities in different times such as heroes or heroines for the audience, especially the young people to imitate or follow.

The term "identity" is also a topic which arouses heated discussion in the literature of Taiwan, Hong Kong, Macau, East Asia and Western countries. Identity, as a concept, involves not only the awareness of the construction of identity in an individual and a group, but also concerns the cultural factors and real living situations of the individual and the group. It is closely associated with the political and cultural ecology of certain countries and regions as well as the social and historical vicissitudes experienced in modern Chinese history and contemporary China. In recent years, the concept of identity has switched from the original psychoanalytic category to a broader cultural research field with more complicated connotations which include diverse topics such as political identity, state identity, ethnic identity, cultural identity, gender identity and class identity (Zhu 1). 
Correspondingly, the term "cultural identity" is also a relatively complex concept which is hard to define. Stuart Hall believes that identity is the name given to the different ways a person is positioned by, and positions himself within, descriptions of his position. Jun Wang holds that cultural identity is a self-awareness of the existence of the history of a nation and the self-identity of a nation and national spirit. In Writing Diaspora, Rey Chow discusses this concept from the perspective of "seeing" and "being seen." She discusses on how China, especially the marginal Chinese culture, the passive object, is "being seen" by the hegemony of westerners, and the dominant subject of "seeing," in the discourse environment of western hegemony. She holds that to understand the relationship between the "center" and the "periphery" by observing the connection of subject and object is a fundamental theoretical dimension of postcolonial culture.

However, Rey Chow's view on the Chinese is somewhat biased. She believes that Hong Kong's postcolonial state is quite different from that of other areas or countries. She argues that Hong Kong is an in-betweenness of British and Chinese government, and therefore, the postcolonial situation of Hong Kong is a kind of double negation, i.e., Hong Kong cannot be subjugated to Chinese nationalism or nativism just as it could not succumb to British colonialism (Chow 94; Zhu 207). She believes that the concept of China should be questioned when Hong Kong is broken off from Britain, no differently than India when it was broken from Europe. Although both Hong Kong and 
India were under the colonization of Britain, Hong Kong is different in that it cannot keep its independence or self-determination through Chinese nationalism or Chinese native culture without weakening or disregarding the unique history of Hong Kong at the same time. Meanwhile, mainland Chinese have considered Hong Kong culture to be too westernized, and, therefore, cannot be treated as a real Chinese culture. Thus, Chow draws a conclusion that Hong Kong, instead of keeping the oversimplified and contradictory "resistance of colonized over colonizers," has to throw off both the influence of Chinese and British history and construct its own identity (Chow 98; Zhu 207). However, considering the inseparable and inherent consanguineous relationship between Hong Kong and mainland China culturally, geographically, and nationally, one should acknowledge that the cultural identity of Hong Kong cannot be separated or isolated completely from that of mainland China.

But the most important factor we should consider when talking about the cultural identity of Hong Kong is that Hong Kong has a double cultural identity-Hong Konger and Chinese-because of Hong Kong's unique cultural heritage and distinct colonial history. It is indubitable that Hong Kong was industrialized and capitalized successfully under British colonization. After the historical transition, Hong Kong maintains its capitalist system through the implementation of specifically designed economic and political policies for the sake of a stable society and a prosperous economy. However, it is impossible to talk about the identity of Hong Kong without considering the substantial 
cultural ties between Hong Kong and mainland China. Hong Kong and mainland China are linked by such factors as race, lineage and language, although they have distinct cultural practices and geopolitical situations. One of the most noticeable testimonies is the language. Both Hong Kongers and mainlanders speak Chinese, although many Hong Kongers prefer to speak Cantonese, a dialect of Chinese. What's more, Hong Kong and mainland China share the Chinese cultural traditions and historical legacies. They share same moral values, norms, and customs situated within a larger Chinese discourse. An unassailable fact is that Hong Kong has been a place for colonial officials, foreign merchants, missionaries, and migrants from mainland China since it became a British colony a century ago. Fu argues that many Hong Kong local residents never stopped identifying themselves with "the mainland, particularly Canton, as their homeland from which they traced their male ancestries, historic memories, and cultural practices," even under British colonization (214).

Hong Kong's status within Chinese society has also changed substantially in the past hundred years. Some of the changes or vicissitudes helped foster the formation of a local cultural identity in Hong Kong. The foremost factor in the formation of a local identity was World War $I I$ as indicated by $\mathrm{Fu}$ in the following paragraph:

"In the shadow of the China-centered discourse of nationalism engendered by the modern Chinese state and cultural elite, with their 
chauvinistic undertones, wartime was also an ambivalent moment to construct a local identity. Hong Kong's marginalization in the Chinese national imagery generated contempt and attacks on Cantonese film culture, thereby disempowering and suppressing all the local voices." (Fu 220)

In the war time, Hong Kong was regarded as a "cultural desert" (Fu 199) and a mixture of eastern and western culture by mainland elites and held a degraded place. The world war forced many intellectuals to migrate from the mainland to Hong Kong for refuge. They refused to learn the local "exotic" dialect and thought they were superior to the locals. On the other hand, the Hong Kong locals who were classified as huaren (Chinese) were treated by the British colonizer as an inferior group and racial Others, and they were denied a role in the public sphere through colonialist discourse. In fact, Hong Kongers were "socially marginalized and systematically depoliticized" (Fu 213). Another contribution to the formation of local cultural identity in Hong Kong comes from the population composition of Hong Kong residents. Among the native population, Hong Kong local-borns increased from 26 percent in 1921 to 32.5 percent in 1931 , which made Hong Kong become a "distinct geopolitical space with its specialty of historical and social formations," and together with the peripheral position to the mainland Hong Kong became a "possible site for the articulation of a local identity" (Fu 214). However, in the 1930s, hybridized culture, British colonization and the increased local-born Hong Kongers 
contributed to shaping an incipient yet ambiguous local identity. The formation of a local identity in Hong Kong can also be traced back to the establishment of the People's Republic of China since it led to another influx of mainlanders mainly composed of entrepreneurs, filmmakers and professionals. As a result, the 1950 s and 1960s witnessed the start of industrialization and modernization of Hong Kong. The most important factor which influenced the shaping of a local identity is assumed to be the signing of the Sino-British Joint Declaration and the handover of Hong Kong from Britain to mainland China in 1997. Hong Kong experienced a major change in this historical period. Some residents migrated to Western countries because they felt nervous and uncertain about their future although Hong Kong retained its capitalist economy and enjoyed a special political arrangement of "one country, two systems" under the sovereignty of China. However, Hong Kong was still marginalized by the West and the East, by the British and the Chinese. Many of Hong Kong's residents were denied British citizenship and were not considered patriots and nationalists. However, the marginalized situation of Hong Kong also offered some advantages. For example, Hong Kong enjoyed economic and relative political freedom. To some extent, Hong Kong has become the colonizer of the mainland and other Asian areas and countries. For example, what is Hong Kong or Hong Kong derived is regarded as fashionable and superior by many mainlanders. Hong Kong businessmen generally have concubines during their stay in some cities of mainland China, as discussed in Chapter 4. 


\section{POPULAR CULTURE}

Popular culture as a term is hard to define since it is closely related to other forms of cultures and the concept of ideology, and what's more, the two words comprising the term have multiple meanings. First of all, the term popular culture is always defined by mentioning explicitly or implicitly other forms of cultures such as folk culture, mass culture, dominant culture and working-class culture (Storey 1). The definition of popular culture becomes more complicated because of the polysemic nature of its two components, "popular" and "culture." According to John Storey, popular culture covers two of the three definitions of "culture:" culture as "a particular way of life," which refers to "the development of literacy, holidays, sport, religious festivals" and culture as "signifying practices," which refers to "the works and practices of intellectual and especially artistic activity" (2). Based on the definition given by Raymond Williams, mentioned in Storey's Cultural Theory and Popular Culture: An Introduction, the word "popular" has four meanings: "well liked by many people," "inferior kinds of work," "work deliberately setting out to win favor with the people" and "culture actually made by the people for themselves" (6). Therefore, there are many complex interpretations of the meaning of the term popular culture when we combine "culture" with "popular," which makes it difficult to give a clear and accurate definition of the term "popular culture." The difficulty also lies in the fact that the term popular culture has a closely correlative relationship with the term "ideology," a term which is believed to be 
a crucial concept in the study of popular culture. In cultural analysis, the three terms "ideology," "culture" and "popular culture" generally have overlapped meanings and therefore they are often used interchangeably. However, there exists a conceptual space between the terms "culture" and "ideology." The difference between the two words is that "ideology" includes a political dimension while "culture" does not. It is necessary to discuss in detail the concept of ideology because of its similarities to culture and popular culture as a conceptual category. Here, only the meanings of the term "ideology" closely related to the study of popular culture are considered. One definition of ideology suggests that some cultural texts and practices tend to present masked, distorted or concealed images of reality to the audience which may result in false consciousness in the mind of the audience (Storey 3 ). It is believed that such distortion or concealment of the images of reality work in the interests of those who have power against the interests of the subordinated class (Storey 3). For example, capitalist ideology may help conceal the reality of the dominant class' exploitation or oppression of the powerless. The concealed nature of such distortion lies in those who are in dominating positions in a society and who do not regard themselves as exploiters or oppressors. What's important here is that the subordinated powerless also do not realize or think they are oppressed or exploited. Another definition of the term "ideology" suggests that cultural texts such as television, pop songs and feature films always present to the viewers a particular image of the world, and 
cultural texts are biased because they offer "competing ideological significance of the way the world is or should be" (Storey 4). Therefore, popular culture is said to be "a site where 'collective social understandings are created;' a terrain on which 'the politics of signification' are played out in attempts to win readers to particular ways of seeing the world" (Storey 4; Hall 36).

Based on the above analysis, Storey outlines the following six definitions of popular culture given from different perspectives. The first definition of popular culture is very basic and simple. It says that popular culture is "simply culture which is widely favoured or well liked by many people" (Storey 6). However, the quantitative index in this definition seems to refer to a broader concept since it apparently does include high culture, which is generally acknowledged to have distinct scope and standards. The second one attempts to define popular culture as the residue from which high culture is filtered. Popular culture is understood as a mass-produced and commercialized culture that fails to be categorized into high culture, the aesthetic creations of individual artists. The third definition of popular culture is given from the mass culture perspective. In this sense, popular culture is perceived as a culture featuring extreme commercialization and mass production for mass consumption. Under this framework, the audience of popular culture is a "mass of nondiscriminating consumers" (Storey 8). Popular culture has been seen as identical with American culture by some cultural critics within theoretical mappings of popular culture. A fourth definition of popular culture is seen from 
its sources. It contends that popular culture originates from the people. Therefore, it should be regarded as an authentic culture of the people. The fifth definition of popular culture is given by the Italian Marxist Antonio Gramsci from the perspective of political analysis. Gramsci's definition puts more emphasis on the concept of hegemony, a term used by Gramsci to refer to "the way in which dominant groups in society, through a process of 'intellectual and moral leadership,' seek to win the consent of the subordinate groups in society" (Storey 10). Scholars who approach popular culture by using neo-Gramscian hegemony theory see popular culture as "a terrain of ideological struggle between dominant and subordinate classes, dominant and subordinate cultures" (Storey 11). The last, but not the least, definition of popular culture is given in the terms of postmodernism. It is claimed that in postmodern culture the line between popular culture and high culture is blurred since the "authentic" and the "commercial" cultures are highly interpenetrated and assimilated into each other. No matter what the definition of popular culture is, the common feature is that popular culture is definitely a product of industrialization and commercialization which originates from Britain. What's important is that the forms of popular culture gradually climb up to the center stage in our life, and as Geoffrey Nowell Smith indicates: "the separate existence of a distinctive popular culture in an oppositional relation to high culture is not in question" (Storey 15). In the study of popular culture, it is very common that different scholars will approach it from different theoretical 
perspectives and put emphasis on different aspects of the popular culture landscape. For example, some may focus on the study of texts such as "popular fiction, television, pop music, etc." while others may center on the study of such lived cultures or cultural practices as "seaside holidays, youth subcultures, the celebration of Christmas, etc." (Storey 15).

No matter what definition is given to popular culture, no one will doubt the significance of popular culture in the lives of people in a society. The commercial nature of popular culture makes possible the superiority or popularity of popular culture over high culture in a society. One of the most important functions of popular culture is to express what people need and want. In other words, popular culture gives "voice to the culture of marginalized groups" (Culler 42), especially at the early stage of its development. Therefore, the study of popular culture has significant meanings. On the one hand, the significance of studying popular culture is to narrate the momentous moments or events and record or catch the current ideology of a society instead of portraying or reflecting the lives of aesthetes and professors. Popular culture is a way to express the prevailing values or portray the lives of ordinary people; that is, to give voice to the culture of common people. On the other hand, the significance of studying popular culture is reflected by the underlying force: to see "how people are shaped or manipulated by cultural forces" (Culler 43). Popular culture is believed to be made from mass culture and reflects the authentic expression of value. It is "made from cultural resources that are 
opposed to it and thus is a culture of struggle, a culture whose creativity consists in using the products of mass culture" (Culler 43). Various forms of popular culture such as films and music are believed to be the most direct, influential and effective ways to reflect what ordinary people are concerned about in their daily lives. On the one hand, popular culture reveals the values and perspectives most strongly represented and accepted within a society. On the other hand, popular culture helps disseminate and perpetuate those prevailing views and perspectives in a given society. As a result, it is not difficult to explain why some scholars often explore the trends in a society by analyzing popular cultural elements such as films and music.

When studying popular culture, scholars often adopt different cultural theories such as structuralism, post-structuralism, Marxism, postmodernism, etc. Only the theoretical frameworks which are frequently used to interpret films will be adopted in this paper. One of the theories commonly used by scholars in studying popular culture is structuralism, together with poststructualism. Structuralists include such figures as "Louis Althusser in Marxist theory, Roland Barthes in literary and cultural studies, Michel Foucault in philosophy and history, Jacques Lacan in psychoanalysis, Claude Lévi-Strauss in anthropology and Pierre Macherey in literary theory" (Storey 58). The common ground for these scholars is Swiss linguist Ferdinand de Saussure's linguistic theory which they use to approach texts and practices in their fields. According to Saussure, language is composed of signifier, signified 
and sign. The signifier refers to the inscription of an object, the signified refers to the concept or mental image of that object, and signifier and signified constitute the sign. There is no specific reason or rationale for a given signifier to produce a certain signified. The relationship between them is loose and arbitrary, and the meaning of a word can only be pinned down within a specific context. Different signifiers in different languages may yield the same signified. Even the same signifier may produce different signifieds in different contexts. For example, "dog" in English and "gou" in Chinese both can produce the same signified: four-leg canine creature. The word "letter" may have different signifieds as one can find in the dictionary the different meanings it produces in different contexts. Therefore, Saussure believes that the relationship between signifier and signified is established on the basis of convention or cultural agreement, not of any fixed rules. According to Saussure, meaning comes from the "difference" and "relationship" between the signifier and the signified, and it is also a "result of a process of combination and selection." For example, the signifiers "red" and "green" are not necessarily the signified "stop" and "go" respectively, and if we use "red" to mean "go" and "green" to mean "stop," it may also work. So it is the difference and relationship between the signifier and the signified that makes the system work. Moreover, the meaning of a sentence will be changed by substituting a word or adding a word or words to the sentence. For example, the meaning of the sentence "He watched the game today" will be changed if we change the sentence into "He watched the 
game at home" or "Yesterday he watched the game in the stadium." To a structuralist, it is the language that helps us perceive the world (Storey 59). Saussure's division of language into langue and parole also contributes significantly to the development of structuralism. Langue is perceived from the social perspective: it refers to "the system of language; the rules and conventions which organize it," whereas parole is to the language used by individual (Storey 60). Therefore, langue is regarded as the structure of a language and parole as the performance of language. The underlying rules and conventions-the structure-of cultural texts and practices make the meaning — the acts of parole—possible.

Based on Saussure's linguistic theories, such Structuralists as Claude Lévi-Strauss, Will Wright and Roland Barthes developed their own theories which they use to approach the texts and practices in popular culture. Lévi-Strauss finds that different forms of cultural and social practice such as manners, cooking and modes of dress, like language, can express different meanings (Storey 61-2). He further finds that, underlying the vast heterogeneity of myths, there is a homogeneous structure and myths are structured in terms of "binary oppositions" such as "culture/nature, man/woman and good/bad." Will Wright, on the basis of Lévi-Strauss' structuralist methodology, attempts to interpret the Hollywood Western from a similar but different perspective. Instead of emphasizing the mental structure, he focuses on the way the myths of a society convey to the audience through the structure 
of those myths. According to his findings, the Hollywood Western presents to the readers "a symbolically simple but remarkably deep conceptualization of American social beliefs" by way of many stereotyped narrative patterns such as "The hero enters a social group," "The hero is unknown to the society" and "The hero is revealed to have an exceptional ability" (Storey 62). Barthes approaches the implicit texts and practices in popular culture by using the process of signification, "mechanisms by which meanings are produced and put into circulation" (Storey 64). His Mythologies is believed to be the most important attempt to use Saussure's semiology in the study of popular culture. Saussure believes that language is a system of signs comparable to a system of writing since such signs as "the alphabet of deaf mutes," "symbolic rites," "polite formulas" and "military signals" can convey meanings to the readers, and therefore, he develops "semiology," a theory which he uses to study the meaning of signs (Saussure 16; Storey 65). Barthes adds a second level of signification to Saussure's schema of signifier/signified=sign and develops his semiological model for reading popular culture. He argues that it is possible that the sign "dog" - the primary signification or denotation—produced at the primary level of signification can become the signifier at the secondary level of signification and then can produce a secondary signification (connotation)- "an unpleasant person." He further states that it is the secondary signification or connotation that produces myth-an "ideology understood as a body of ideas and practices, which by actively promoting the 
values and interests of the dominant groups in society, defend the prevailing structures of power" (Storey 65). However, the polysemic nature of signs makes it possible that the same sign may be interpreted differently by different readers in different locations, historical contexts and cultural backgrounds. For example, the same image may have different connotations to readers of different age groups even in the same historical and cultural context. According to Barthes, image can be read differently from different reading positions. It can be seen as a symbol for something from the position of those who produce myths, as an 'alibi' for something from the position of a specific reader or as the very presence of something from the position of the "reader of the myths" (Storey 66). To John Storey, an image can also be read from a fourth reading position, that is, from the perspective of a mythologist, and then produces what Barthes calls a "structural description." Storey states that "it is a reading position which seeks to determine the means of ideological production of the image, its transformation of history into nature" (68). That is to say, an image is used to naturally evoke a concept of something in the mind of the readers. The relationship between the image and the concept of the given object has been "naturalized" and there is no need for detailed or explicit explanation since the image may allude the presence of the other.

When a reader sees an image, the social knowledge stored in his or her brain makes possible the move from denotative meanings to connotative meanings. Such knowledge, the shared code of the readers, may vary in 
different historical and cultural background. That means, in different cultures, the same image may have different interpretations. The same is true in different historical periods. Cultural differences means differences such as "class, race, gender, generation or sexuality" as mentioned by Storey in his book Cultural Theory and Popular Culture-An Introduction (71). It is also well explained by Barthes:

Reading closely depends on my culture, on my knowledge of the world, and it is probable that a good press photograph (and they are good, being selected) makes ready play with the supposed knowledge of its readers, those prints being chosen which comprise the greatest possible quantity of information of this kind in such a way as to render the reading fully satisfying. (Barthes 29 ; Storey 71 )

As we can see from what Barthes says above, the interpretation of an image or text is influenced by various factors. Such factors may include a person's cultural, national and aesthetic background. Therefore, good images are those which can foresee the shared code (conscious or unconscious) of the readers. Here the individual image, like parole, is equivalent to individual utterance, and the shared knowledge, like the langue, is equal to the rules and conventions of a language.

However, to poststructualists Barthes's denotation is no longer neutral. They believe that meaning is temporal and unstable and think that denotation, like connotation, constitutes part of the production of myth or ideology and they 
suggest that signifiers can produce more signifiers. Unlike structualists, poststructualists focus more on how people use language and the correlation between language and other social and cultural practices. Michel Foucault believes that institutions use discourse as an instrument to exert their power over the powerless through a "process of definition and exclusion, intelligibility and legitimacy," that is to say, certain discourses or discursive formations, which consist of "a body of unwritten rules, and shared assumptions, which attempt to regulate what can be written thought, and acted upon in particular field," can determine the way the language is articulated and expressed (Storey 78). Based on Friedrich Nietzsche's view on knowledge as a weapon of power, Foucault demonstrates in detail "how power operates through discourse and how discourses are always rooted in power" as follows: "power produces knowledge...power and knowledge directly imply one another...there is no power relation without the correlative constitution of a field of knowledge, nor any knowledge that does not presuppose and constitute at the same time power relations" (Foucault 27; Storey 78). The "power-knowledge" theory is often used to approach texts and practices. For example, in Orientalism, Edward Said explains "how a Western discourse on the Orient-'orientalism' - has constructed a 'knowledge' of the East and a body of 'power-knowledge' relations articulated in the interests of the 'power' of the West" (Storey 78). Said argues that the truth of a discourse "depends less on what is said and more on who is saying and when and where it is said" 
(Storey 78). Said holds that it is Europeans who created the word Orient and therefore he uses the term "Orientalism" to refer to the "relationship between Europe and the Orient, in particular, the way 'the Orient has helped to define Europe (or the West) as its contrasting image, idea, personality, experience' (Storey 78; Said 1-2). What's more, Said attempts to show how Europe identifies itself and gains confidence by contrasting itself with the Orient. According to Said, Orientalism is in fact a way for Westerners to dominate, restructure, and have authority over the Orient, which is manifested by one of the stereotyped imperial fictions depicting how white colonizers show their authority over the jungle and its inhabitants because of the "supposed power of their racial heredity" (Storey 79). A classic example to illustrate how Foucault's "power-knowledge" relations and Said's Orientalism theory are used in the study of the popular culture is to see how Hollywood films portray the Vietnam War. It is ironical that the Vietnam War, the most unpopular war in the eyes of Americans, has become the most popular "when measured in discursive and commercial terms" (Storey 80). The Vietnam War has been depicted in Hollywood films based on Western accounts. As Storey states:

"Hollywood as a 'corporate institution' deals with Vietnam 'by making statements about it, authorizing views of it, describing it, by teaching it'. Hollywood has 'invented' Vietnam as 'contrasting image' and a 'surrogate and ... underground self' of America" (Storey 80).

The war is still the war, but it is not portrayed on the basis of historical 
reality but according to American's interpretation or supposition. Therefore, Hollywood presents to America and the world the "truth" of the war and an "authentic" Vietnam which increasingly becomes many Americans' knowledge and real experience of Vietnam and the Vietnam War. In fact, Hollywood films on the Vietnam War produce a powerful discourse on Vietnam, and the American's "knowledge" of the war, and the "power-knowledge" relations established on this "knowledge," are discursive. Storey argues that "Even when Hollywood appears to be critical of American involvement in Vietnam, it is always critical within a discursive practice which ultimately works to contain such a criticism, to redirect it into the procedures and protocols of Orientalism" (80).

The present research focuses on the study of film, which is a form exactly categorized into popular culture. Traditionally, popular culture has not drawn much attention of academic researches since it has not been regarded as highbrow culture. However, it is obvious that the influence of popular culture on the lives of modern people and the society has been increasing, especially in recent decades. More scholars than ever have become interested in the study of popular culture and its impact on our life and society. Therefore, understanding popular culture, its features and how scholars approach popular culture has great significance for this research. On the one hand, knowing more about popular culture can help us understand the significance of the present research in culture studies. On the other hand, it helps us know the 
differences and similarities between the present research and the research done by other scholars, since the present research will employ the aforementioned concepts or theories such as postcolonialism and new historicism to explore how the cultural identity of Hong Kong is reflected in Jackie Chan's Hong Kong and Hollywood films. 


\section{CHAPTER III}

\section{PHASES OF THE CONSTRUCTION OF HONG KONG'S CULTURAL IDENTITY}

The issue of cultural identity has been debated heatedly in recent years, especially in the Taiwanese and Hong Kong academic world. Hong Kong became the focus in the study of cultural identity because it experienced a historical transition in the late twentieth-century. Some scholars explore the cultural identity of Hong Kong by employing different literary works or films or other related materials. Others use the specific literary works of an author or films produced by an actor or actress to illustrate the representation of the cultural identity of Hong Kong. The cultural identity of Hong Kong is not only discussed in the academic field; it is also portrayed or constructed in different forms of popular culture such as film, music, television and mass media. However, there are always some distinct voices when it comes to the cultural identity of Hong Kong. Some scholars think that Hong Kong, like any other region of China, has a similar or identical cultural identity as China because it exists within a larger Chinese discourse. Others argue that there exists a unique cultural identity of Hong Kong because of the uniqueness of its history. 
Undoubtedly, the construction of cultural identity is a complicated process. It is particularly true in this case since Hong Kong has over a century of colonial history and underwent a unique historical transition in the context of Chinese nationalist discourse and globalization. In this chapter, the author attempts to explore the formation of the cultural identity of Hong Kong by examining the films produced in Hong Kong in the twentieth-century. This is possible because it is the nature of visual arts to reflect the prevailing trends or values of a society. The author also expatiates on some scholarly works and other forms of popular culture such as popular songs and news articles published in a Hong Kong newspaper from the 1930 s to the present to further discuss the issue of Hong Kong cultural identity.

\section{PHASES OF THE CONSTRUCTION OF HONG KONG'S CULTURAL IDENTITY DEMONSTRATED IN HONG KONG CINEMA}

In recent decades, Hong Kong cinema has been in a leading position in the world of Chinese movies, which are mainly produced in Hong Kong, mainland China, Singapore and Taiwan in recent decades. As a former British colony, Hong Kong enjoys more economic and political freedom than mainland China and Taiwan, a fact which made a great contribution to the development of Hong Kong as the base of film production in East Asia. What's more, Hong Kong cinema has been playing an important role in the world film industry in 
the past decades, which is well manifested by the fact that Hong Kong, in addition to Hollywood and Bollywood, is claimed to be the world's third film industry base. Hong Kong cinema is also famous for its unique feature of film production-a short production cycle. In order to cater to the needs of the audience, Hong Kong films are highly commercialized, which in turn makes them popular around the world. In fact, as Fu indicates, Hong Kong has been "a significant part of the Chinese cinema" since the 1900s and "a dynamic site of disparate discourses and practices that center particularly around the notion of mass culture" (200) since the early 1920s. However, before the Second World War, Hong Kong cinema had been seen by mainland intellectuals as inferior, frivolous and vulgar, especially compared to the cinema of Shanghai, which was believed to be the "Hollywood of the East" at that time (Fu and Desser 1; Fu 200). The development of the Hong Kong film industry can be traced back to the 1920 s and 1930 s when many elite filmmakers migrated from mainland China to Hong Kong as refugees. Because of its peripheral position to mainland China, its unique colonial history and the historical transition between the 1980s and 1990s, the identity of Hong Kong has been a major theme in Hong Kong cinema, which is reflected in the following statement from The Cinema of Hong Kong: History, Arts, Identity edited by Poshek Fu and David Desser: "Because of its deep local roots and linguistic affinity with the colonial audience, Cantonese cinema has lent itself since the 1930 s to the exploration, articulation, and projection of a Hong Kong identity 
vis-à-vis the mainland mentality" (2). In the aforementioned book, scholars such as Poshek Fu and Ping-kwan Leung try to examine how films portray the identity of Hong Kong by exploring the films produced there from the 1930 s to the 1990s. After reviewing the academic literature of those scholars on films, the author finds that diverse social, cultural, economic, and political factors have contributed significantly to the formation of the cultural identity of Hong Kong. Several stages of the construction of the cultural identity of Hong Kong can be identified after exploring the films produced in Hong Kong between the 1930 s and the 1990s.

The first attempt to construct a local cultural identity of Hong Kong can be traced to the 1930s. An ambivalent and hybrid Hong Kong local identity was first constructed by cinema during the initial years of the Second World War, and was fostered by the social and geopolitical differences between Hong Kong and mainland China magnified by the war and the double marginality of Hong Kong which resulted from Chinese nationalism and British colonial discourse (Fu 200-1). In "Between Nationalism and Colonialism: Mainland Emigres, Marginal Culture, and Hong Kong Cinema 1937-1941," Poshek Fu makes a detailed analysis of wartime cinema and its historical context to explore the causes of Hong Kong's marginality and the formation of a collective Hong Kong local identity. He believes that, due to its geopolitical and cultural uniqueness, the imagery of Hong Kong as a "cultural desert" (199) and a marginal population within Chinese culture, which is integral to the "Central 
Plains syndrome" (da Zhongyuan xintai) ${ }^{3}$, can be traced to the 1920 s, when some mainland intellectuals migrated to Hong Kong for refuge because it was not a combatant British colony until Japanese military forces invaded it in 1941. The newly-settled mainland intellectuals not only felt uncomfortable with the local dialect, but also belittled the hybridized culture. They thought the local Cantonese was an "exotic" language and regarded the local multi-culture as a marginalized culture, a mixture of Westernization, feudalism, colonialism and provincialism. What's more, the mainland scholars depreciated Hong Kong cinema's frivolity, vulgarity and box-office driven system. They deprecated Hong Kong cinema's lack of artistic significance or social meaning and took pride in the cinema of mainland China, especially Shanghai cinema. However, Hong Kong, which superseded Shanghai as the "Hollywood of the East" after the "Communist takeover," has been playing an important role in the Chinese cinema because of its uniqueness in such aspects as artistic and financial interactions since its beginning around the 1990s (Fu and Desser 1, Fu 200). But the first years of World War II accelerated the marginalization of Hong Kong in the Chinese geocultural imagination and magnified the social and cultural differences between Hong Kong and mainland China, which was believed to contribute significantly to the shaping of a collective local identity. The marginalized and alienated nature of Hong Kong resulted not only from

\footnotetext{
3 The Central Plains Syndrome: By the 1930s, the Nationalist government and the Communists, in pursuing their anti-imperialist agenda, had reformulated and celebrated the "old idea" of a primodial identity for all Han Chinese of a shared origin in the north China plain. This Central Plains syndrome represented a hierarchy of cultural differentiation derived from geographic, territorial, and cultural boundaries between the mainland core and the outlying periphery. See Fu (208)
} 
the British colonizers but also from the mainland cultural elites. On the one hand, Hong Kong was treated by the British colonizers, who had an inherent and bred-in-the-bone superiority over Asians, as untrustworthy and unworthy racial Others, as manifested by the fact that Hong Kong Chinese were deprived of the right to defend the colony. On the other hand, because of the contamination of British colonization and its peripheral location and "exotic" dialect, Hong Kong was depreciated by mainland intellectuals as a slavish and decadent land, a "cultural desert" (Fu 199). Fu believes that the aforementioned sociocultural differences and double marginality were the driving forces for the formation of an ambivalent sense of hybrid identity, which continues to prevail in Hong Kong society today: Hong Kongers were "caught in between identification with past and the present, with the centralizing nationalism of the mainland and the hybrid tradition of Hong Kong" (201).

During the war time, many mainland Mandarin-speaking film practitioners fled from the previous prosperous and glamorous Shanghai to Hong Kong—the so-called "haven of tranquility" (Fu 201)—for refuge. However, they were reluctant to learn the local Cantonese since they had an ingrained superiority complex and therefore disregarded the local culture. In the eyes of these mainland filmmakers, the colony's sociopolitical culture was inferior and unworthy, and Hong Kong cinema was technologically and artistically backward, superstitious, escapist, racy and low budget. The image of Hong Kong as an inferior, vulgar and alien cultural space was further strengthened 
by the shoddy, frivolous and feudal films produced in a rough way in a very short time due to such factors as low budget, lack of studio space, and star's deficient filming time. Hong Kong was alienated by the mainland diasporas not only in cultural discourses but also in publications such as the Nationalist-sponsored Yilin by way of expressing and promulgating nationalist discourse. Meanwhile, mainland filmmakers actively produced some patriotic films such as The March of Guerrilla (Youji jinxingqu, Situ Huimin, 1938) and Homeland (Baiyun guxiang, Situ Huimin, 1940) (Fu 210). In addition to disseminating and fostering patriotism and nationalism, the films mentioned above were created to mobilize Hong Kong people to participate in the defense of China and awaken them to rebel against and escape from the colony. Fu believes that The March of Guerrilla is a typical film that reflects the marginalization of Hong Kong. He assumes that, although there is no direct reference, Rong Xiaoyi, a woman raped by foreign invaders, is a representation of the marginalized Hong Kong since women have been traditionally regarded as "others" in male-dominated society, and their identities and subject positions have been generally denied in the patriarchal Chinese discourse (211-2). Therefore, the raped woman portrayed in the film is actually presented to the readers as an allegorical signifier of the marginalization and sacrifice, a symbol of the "ultimate victimization of the Chinese state" (Fu 211), which is sufficient to arouse or kindle the countrymen's patriotism and nationalism. 
Two Southern Sisters, which Fu believes to be the most representative film that constructed an "ambivalent, hybrid local identity" (217) of Hong Kong by using the conventional nationalism discourse, is a Cantonese film played by entirely local film stars and directed by Hong Kong-born young filmmakers. Twin sisters, separated at birth, coincidentally fall in love with the same man. Chow Wen-ying, the eldest, grows up wealthy on the mainland while her sister Hsiu Dip stays with her poor father and step mother in an outlying island. The elder sister Wen-ying is rich, well-educated, confident, fearless, patriotic, active and supportive in the cause of Chinese defense, while the younger sister Hsiu Dip is diffident, timid, passive, indecisive, vulnerable, helpless, old-fashioned, and lacking modern consciousness, nationalism and patriotism. However, they have to make a difficult choice regarding their marriage upon their happy reunion. After careful thinking, Wen-ying determinedly returns to the mainland to support Chinese resistance, and the younger sister, without knowing her elder sister's choice, decides to sacrifice her love. Both of them intend to sacrifice their love for the sake of each other's happiness, without considering their father and the artist they fall in love with. Fu argues that such a choice is in fact an allegory of the construction of identity of Hong Kong (218). To him, such a choice indicates that a woman, who is generally slighted and alienated in the traditional Chinese patriarchal discourse, is granted a subject-position, which can be regarded as a symbol of the ideological subversion of the Central Plains syndrome. It is further seen as an allegorical 
construction of Hong Kong identity because of the marginalized imagery of women in the context of Chinese nationalism. As Fu said in his paper:

Indeed, the melodramatic and dichotomous ending of Two Southern Sisters dramatized a vision of local identity that was marked by a double marginality. Marginalized by British colonialism and Chinese nationalism in a wartime situation, Hong Kong was unsure and tentative in defining (and thereby asserting itself......this film did not consciously engage in evoking a collective memory of Hong Kong or mapping an alternative discourse surrounding its colonial situation. Rather, just as Wen-ying returned to the mainland and Hsiu Dip stayed on to marry her lover, the film projected an ambivalent hybridity in the imagery of Hong Kong, highlighting the double marginality that framed it. Unable to identify fully with either British colonialism or with Chinese nationalism, both of which shunned it as inferior and suspicious, Hong Kong appeared to be positioned uncomfortably in between Chinese tradition and Western lifestyle, moral commitment to the "homeland" that was China and emotional attachment to the home that was Hong Kong. (Fu 219)

As is allegorized by the distinct mentality of the two twin sisters-one chooses to be loyal to her motherland and Chinese nationalism and the other prefers to stay in the British colony, the cultural identity of Hong Kong is constructed to be an ambivalent and hybrid one, fluctuating between 
nationalism and local consciousness, and between tradition and modernity. It is also a doubly marginalized identity as mentioned above: on the one hand, Hong Kong locals were denied military service because they were treated as racial Others by the British colonizer and most Hong Kong people had been denied British citizenship yet ruled by Britain until the handover on July 1, 1997; on the other hand, Hong Kong was estranged and neglected by the grand Chinese discourse of nationalism and patriotism.

The second phase of constructing a local cultural identity of Hong Kong can be traced back to the 1950 s and the 1960 s. By carefully examining the films, Ping-kwan Leung believes that a clear and distinct urban culture of Hong Kong has been shaped since 1949, especially in 1960s. Two significant historic events are believed to have great influence on the formation of Hong Kong's cultural identity. One is the establishment of the People's Republic China in 1949, which is assumed to be the beginning of enlarging the difference between a socialist China and a capitalist colonial city. It results in a large number of wealthy immigrants, such as entrepreneurs, from the mainland to the outlying colonized island. Another historic event that helps shape the cultural identity of Hong Kong is believed to be the notorious Cultural Revolution from 1966 to 1976 which took place in mainland China. During this period, Hong Kong local filmmakers made an effort to use unique artistic forms and cultural imagination to express, define, or rethink a local cultural identity. Like the films produced in the 1930s, those produced in the 
1950 s continued to focus on the theme of city and country, putting more emphasis on shaping Hong Kong as a modernized, industrialized and commercialized urban space since the 1950 s witnessed the modernization of Hong Kong. However, these films also tend to highlight the "actual political choice imposed on the people between staying in Hong Kong and returning to mainland China" and the choice between the city and the country has "become the first crucial issue in defining the cultural identity of Hong Kong" (Leung 228). Leung argues that films produced in this period are generally categorized into three styles in terms of the way they depict the cultural identity of Hong Kong. Space is Gold (Cunjin chitu), the first episode of Kaleidoscope (Renhai wanhuatong, 1950), is a typical film in which Hong Kong was depicted negatively as an urban space with greedy, selfish residents living in poor, unfavorable and crowded community under capitalist economy. Leung holds that such a negative depiction of the image of Hong Kong urban space implies China's nonrecognition of an independent cultural identity of Hong Kong. The second type of films such as A Hymn to Mother (Cimu Song, 1956) positively pictured Hong Kong as an ideal place for people to live: "lawful, just, rational, and dynamic" (Leung 231). The third type, unlike the other two types of films, neither criticizes the negative side nor glorifies the positive side of the urban city. Instead, it tries to depict an ambivalent attitude toward the city in a neutral, funny, and sarcastic way and attempts to reveal the reality of life in a commercialized and industrialized city in which humorous and sympathetic 
citizens struggle for life. A good example for the representation of an ambivalent cultural identity of Hong Kong in the 1950s is vividly portrayed in the third episode of "Broker Lai" series, entitled Mis-setting the Love Trap (Baicuo Mihunzhen, 1950), by the combination effect of the following three elements-the alme, the song named "Wonderful, Glamorous Hong Kong," and the postcards shots of Hong Kong scenery. The lyrics of the song and the images shown on the postcards not only depict an attractive modernized city but also reveal the loneliness and helplessness of urbanites and the dark side of an industrialized and commercialized city.

However, it is from the 1960 s that Hong Kong Cantonese filmmakers consciously evoke and construct a collective cultural identity of Hong Kong in a colonial context. In the 1960s, Hong Kong was influenced tremendously by Western cultures in many social aspects such as language, music, literature, movies, TV programs, books and magazines, the way of living and thinking of Hong Kong people, especially that of young generations. Hong Kong was also influenced at the societal level including the infrastructure and superstructure of Hong Kong society. Therefore, the 1960 s is believed to be a crucial age for the shaping of a local cultural identity of Hong Kong. Matthew Turner, curator of the exhibition Designing Identity: Hong Kong 60 s held in 1994, concludes that the Hong Kong government committed itself to consciously evoking and establishing a new public image of modern and Westernized Hong Kong (Leung 233). This government shift occurred during the Cultural Revolution in 
mainland China. Attempting to construct a unique identity of Hong Kong, the Hong Kong government organized a series of events such as the Hong Kong Festival and Miss Hong Kong Pageant. However, it is not necessarily the case for literary works and films to unanimously foster and disseminate such an image of Hong Kong as the government designed and expected. For example, Teddy Girls (Feinu zhengzhuan, 1969), on the one hand, presents vividly Hong Kong people's desire to identify themselves with Western values by dynamically portraying young girls' fascination with Western fashion. On the other hand, it also never forgets to remind people of the deep-rooted traditional values and local life. A Purple Stormy Night (Zise fengyuye, 1968) is claimed to be a representative film that mainly focuses on fostering Hong Kong's Chinese heritage. The story explores the contrast between western and eastern musical aesthetics. The plot follows a musician enjoying overnight fame with his music recommended by a western lady to a western performance group. He then becomes fascinated with Western aesthetic concepts, neglecting and temporarily forgetting the traditional Chinese music. However, it is the legacy of Chinese music that attracted him and enabled him to produce musical pieces full of passion and momentum in the past. Fortunately, he finally realizes the ideological preconception and comes back to his mentor. He is devoted to being a moral and faithful husband of his mentor's daughter and continues to glorify his beloved national aesthetics. The motif of the film is apparently to evoke people's consciousness of the Chinese ethnic role and 
cultural identity and to emphasize Chinese aesthetic concepts and moral values. However, it elaborates more on the musician's fascination with exotic concepts of beauty and abstraction. In fact, the Western moral values and artistic standards the white girl Purple Swallow represents are not denied but fostered in a subtle way. It seems to imply that it is hard to disregard the hybrid nature and define an unmixed cultural identity of Hong Kong "by means of solely Western or Chinese models" (Leung 236).

The third golden age for constructing a local cultural identity of Hong Kong is said to be the 1970 s. During this period, the so-called Hong Kong New Wave Directors, who were born after the war, had grown up in Hong Kong but received education in Western countries, engage in constructing a distinct representation of Hong Kong and its culture. It is widely accepted that the 1970s witnesses a mature stage of conscious construction of the cultural identity of Hong Kong because of the efforts of the new generation of directors. They are devoted to forming a unique image of Hong Kong culture in their films, consciously differentiating it from that designed by the local government and from that of mainland China. Instead of fostering the cultural identity of Hong Kong conceived by the local government, Allen Fong's documentary drama Song of Yuen Tsau Chai (Yuanzhouzi zhi ge, 1977) concerns social issues neglected by previous generations of directors and consciously portrayed an image of urban space (Leung 237-8). Like the films produced in previous decades such as Street Angel, filmmakers of the 1970 s continue to center on 
the binary opposition between the city and the country. They actively reveal the reality of urban residents and consciously construct the ever-changing cultural identity of the city from different perspectives. For example, Hong Kong is described by Tsui Hark as a "crowded, violent, no-way-out urban space" (Leung 239) in his film Dangerous Encounter of the First Kinds (Diyi leixing weixian, 1980) and the news clips of Hong Kong's unrest in the late 1960s appear at the end of this film present to the viewers in an actual context of political and social disorders, indicating courageous attempts of the directors to frame a reality of Hong Kong urban space. Allen Fong's Father and Son (Fu zi qing, 1981) presents a different picture. It not only exhibits to the audience the social issues his predecessors experienced but also focuses on the local-born Hong Kong people's efforts and desires for pursuing study in Western countries to favor the taste of younger generation of directors. However, no matter what aspects are emphasized in the films produced in the 1970s, a mixed cultural identity of Hong Kong is undoubtedly revealed to the viewers: it is a land of cultural hybrid that is formed in the conflicts and interaction between Chinese traditions and Western values (Leung 239-40). This hybrid nature of Hong Kong culture is vividly depicted by Ann Hui in his The Secret (Feng jie, 1979), in which the Western District of Hong Kong represents not only "all the traditional customs and superstitions, old values, and morals upheld in the neighborhood by the older generation without much doubt," but also included "modern university students, medical doctors in 
training, modern-style parties, and their evolving lifestyles" (Leung 241).

The period between the 1980 s and the 1990 s is assumed to be the fourth phase of the construction of the cultural identity of Hong Kong. The 1980s and 1990s' Hong Kong films mainly focus on the locals' anxiety and uncertainty about their identity and future life. Two historical events are widely believed to have great impact on the anxious concern of Hong Kong people. One is the signing of Sino-British Joint Declaration in 1984, and the other is the return of Hong Kong from Britain to mainland China in 1997. Some of the films produced during the aforementioned historical transition periods are generally read in an allegorical way. One of the representative films is The Boat People (Touben nuhai, 1982), a film originally made by leftist filmmakers but eventually transformed by Hong Kong director Ann Hui and script writer Qiu Gangjian, also known as Tai An-Ping Chiu. The film portrays the reality of the terrible postwar life of the Vietnamese under a totalitarian government from the perspective of journalists. It is believed that the suspicious attitude and merciless criticism towards the desolate decline of the Vietnam society demonstrated in the film aims at fustigating the Hanoi government. However, it seems to echo Hong Kong people's desperate and terrified concern for their life after 1997. Unexpectedly, the film receives a big financial achievement and is acknowledged by the audience and film critics as an allegorical imagery of Hong Kong after 1997. The success of the film indicates that the film well expresses the identity crisis prevailing in Hong Kong society during the 
historical moment.

However, Hong Kong cinema in the mid-1990s changed slightly from previous allegorical presentation of Hong Kong identity to a more practical examination or exploration of the actual situation of Hong Kong culture. A good example is Ann Hui's Summer Snow (Nuren shishi, 1995). In this film, a couple and their parents-in-law lived in two independent but adjacent buildings of different styles built in different ages, but they had to pass through stairs to visit each other. Leung assumes that the unique arrangement and layout of the architecture of Hong Kong portrayed in this film demonstrates the director's successful attempts to illustrate allegorically the complex negotiation between the old and the new, between Chinese traditions and Western lifestyle (248). In Derek Yee Tang Shing's C'est la vie, Mon Cherie (Xinbuliaoqing/Endless Love, 1993), diverse and exotic music is assumed to indicate the hybrid culture of Hong Kong.

Postcolonial nostalgia was another theme of Hong Kong cinema's efforts to construct a local cultural identity in the years after 1984 and before 1997 . Postcolonial nostalgia, as Natalia Chan Sui Hung defined in her "Rewriting History: Hong Kong Nostalgia Cinema and its Social Practice," has two interpretations. On the one hand, it refers to "the social phenomenon that has arisen since the mid-1980s. Nostalgia, in its various forms of practice (e.g., filmmaking, fashion, popular music, literary, and historical writings), has initiated a significant trend in which the social feelings of discontent, 
depression, and yearning for the past have been found," and on the other hand, it relates to "such cultural issues as the 1997 handover, rewriting history, cultural identities, and collective memory of the past that are dominant in both literary and cultural artifact in the transitional period" (252). Most Hong Kong people felt anxious and uncertain about their future in the 1980s and the 1990 s. At the same time they were dissatisfied with the present society and slightly resistant to the current social, economic and political realities, which resulted in their yearning and mourning for the golden past; which was generally referred to as the 1930 s, the 1950 s and the 1960 s. As a result, this prevailing nostalgic feeling becomes the dominating motif of Hong Kong cinema, which vividly reflects Hong Kongers's search for and reconstruction of a local cultural identity and a revision of history. Nostalgia, including personal nostalgia and collective nostalgia ${ }^{4}$, is in fact a process of searching for or redefining identity, trying to find "Who we are? What we are about? And whither we go," and it is a way of "rewriting or reinventing the history of the past, a revision of the present, and a speculation of the future" (Chan 264). Standly Kwan's Rouge (Yanzhikou, 1987), as Leung and Chan discuss, is a typical nostalgia film which best reflects Hong Kongers's concern at that historical moment and their searching for a local identity (Leung 243; Chan 255). The plot follows that Ruhua, a prostitute of the1930s who commits suicide with her lover, comes to the human

\footnotetext{
${ }^{4}$ Hung elaborates on the differences between personal nostalgia and collective nostalgia: "Personal nostalgia: as Davis explains, maintains itself on the levels of personal memory and individual retrospection of the past; Collective nostalgia: locates itself on the social level in which collective identities, memories, histories, and consciousness or unconsciousness are invoked. In terms of its social meanings, nostalgia is a collective search for identities; it marks epochs and rewrites the history. It creates a kind of sentiment in which the remembered past can be "filtered, selected, arranged, constructed, and reconstructed from collective experience." (264).
} 
world in the 1980s since she can't find her lover in the underworld. She is shocked by the changes: the places she remembered from the 1930 s are completely changed or converted into buildings for other purposes in the 1980s - the brothel is converted into a kindergarten, for example. People of the 1930 s become disabled or senile in the 1980s. The sharp contrast between the two eras presents a trace of history and a sense of loss-a loss of the city's golden colonial past that could never come back. In the course of yearning for the golden past and recalling the old and sweet memories, people enjoy short happiness and forgot the unpleasant present and the hopeless future. Nostalgic films are not only seen as entertainment but also offer a much-needed escape. Chan believes that the nostalgic films produced in the 1980s are a critical and direct response to the 1997 handover. He states: "the yearning for yesterday in nostalgia film serves not only as a possible way for the people of Hong Kong to escape the uncertainty brought about by the 1997 issue but also as an alternative form of the colony's history" (257). Such nostalgic films as Lee Rock, To be Number One, and He Ain't Heavy, He is my Father visually express Hong Kongers's yearning for the past, especially the 1950 s and the 1960 s, which is allegorically regarded as the golden age of colonial history. The aforementioned films realistically reproduce a collective memory of the golden past and a collective identity crisis. Furthermore, they allegorically demonstrate a prevailing fear of Hong Kong people about their uncertain future after the 1997 reunification. By portraying the two protagonists 
as admirable heroes, Lee Rock, and To be the Number One present to the audience the history of the 1960s with golden color. The two films emphasize the positive aspects of the society such as brotherhood and personal loyalty which has been highly valued in Chinese society. However, they neglect all the other negative social problems such as crime and poverty. In these films, the past is depicted as a simulacrum, like a beautiful but unreal dream which can not be reached. On the one hand, the nostalgic films are regarded as effective means to express the resistant attitudes of the local citizens to the official documents signed by British and Chinese government. On the other hand, they also function as an outlet for the filmmakers, who were born or grew up in the 1950 s and 1960s, to reminisce about their personal experiences and memories of the past, which to some degree represent collective memories and retrospections of Hong Kong's past.

It is interesting to note that in the mid-1990s, a new trend in the representation of the cultural identity of Hong Kong cinema emerged. Continuing to use romantic love to allegorically allude to the relationship between Hong Kong and mainland China, however, the representation of the cultural identity of Hong Kong in Hong Kong cinema took on a more flexible feature. Some films depicted a "fluid, deterritorialized, transnational, and mobile mechanism of national affiliation" (Lu 276) as illustrated by two typical films named Comrades, Almost a Love Story (Tian mimi, 1996) and Happy Together (Chunguang zhaxie, 1997) which are discussed in detail in Sehldon 
H. Lu's Filming Diaspora and Identity: Hong Kong and 1997. The two films analyzed by Lu envisage the cultural identity of Hong Kong from a new perspective by elaborating on the private lives of ordinary Hong Kong citizens. As Lu discusses in his article, at the very beginning of Comrades, Almost a Love Story when the leading male protagonist Xiaojun migrated from mainland China to Hong Kong, it was easier for him to identify himself with China when he heard the Chinese national anthem. However, it was not only difficult for him to identify himself with China but also not easy for him to keep a marriage with his previous mainland fiancée after he had been struggling for his tough life in Hong Kong together with Li Qiao, an earlier female migrant from the mainland. The previous easily identified cultural and national security was gradually fragmented because he had to renegotiate his identity in the new circumstances. Ironically, it was not the Chinese national anthem but a Taiwanese popular singer Deng Lijun's "Sweet Love" (Tian mimi) that made Xiaojun unexpectedly encounter Li Qiao on a New York street, which Lu argues that it was the "popular, deterritorialized, pan-Chinese songs of a Taiwanese singer more than the national anthem that reunite ethnic Chinese and Hong Kongers into some sense of communal bonding" (278) in a foreign land. Happy Together tells a story of two gay lovers' experience in an exotic place. Although the love-hate stories portrayed in the two aforementioned films are of two different types, Lu believes that both of them allegorically refer to the relationship between Hong Kong and China (Lu 276-82). The two films, under 
the grandeur historical context of national unity and Chinese sovereignty of Hong Kong, describe an unstable and insecure status of Hong Kong Chinese and the efforts of their pursuing a perpetual homeland and identity. However, unlike the postcolonial nostalgia films which only indulge in reminiscing the golden past of colonial history and exaggerate the uncertainty and anxiety of the future of Hong Kong and Hong Kong people, the film Happy Together suggests a more ambivalent relationship between Hong Kong and China and meanwhile presents to the audience a hope for the new beginning for the future life after 1997 (Lu 282). In "Buying American, Consuming Hong Kong: Cultural Commerce, Fantasies of Identity, and the Cinema," Gina Marchetti holds that Wong Kar-wai's Chungking Express (Chongqing Sinlin 1994) well demonstrates the complex nature of Hong Kong culture-a "bricolage of American pop culture, British colonialism and Asian commerce" (Fu and Desser 10). The mixed culture is vividly exhibited by the protagonist's outlandish attire: the blonde tresses disguises her as Marilyn Monroe-an American superstar; yet she has an Asian face; her dark glasses and raincoat wearing in neither particular sunny nor raining days remind the audience of some nature of the British. After a detailed analysis, Marchetti finds that the film endeavors to center on the shifting identity of Hong Kong and attempts to depict Hong Kong as a transnational and global city. Although there is no direct reference to the handover, Marchetti believes that the "film's mood, themes, and overall sensibility" (290) remind the audience of the 1997 handover. 
Therefore, the film is generally read as an allegory of 1997 . He holds that commodity, which is believed to be a source of identification, plays an important role in understanding the situation of Hong Kong as a "postcolonial, postcapitalist, postmodern environment" (Fu and Desser 10).

The fifth phase of the construction of the cultural identity of Hong Kong is assumed to begin in 1997, the year of Hong Kong's reunification with mainland China. In the year of the handover, the Chinese government attempted to arouse and construct a nation-wide unanimous cultural identity and nationalistic, especially among Hong Kong people, by providing a grandeur Chinese nationalism discourse through such nationalism films as The Opium War (Yapian zhanzheng, 1997), and The Red River Valley (Honghe Gu, 1997) which were screened repeatedly during that historical transition period. The two films produced by mainland filmmakers with big production budgets were advertised and screened in mainland China and Hong Kong to celebrate the reunification of Hong Kong with mainland China. The epic film The Opium War depicts the commissioner Lin Zexu as a historical hero figure who destroyed the opium trade of Britain in China. It is screened not only to celebrate the victory of anti-colonialism but also to arouse collective consciousness and enthusiasm for nationalism of both Hong Kong people and mainlanders. The subject matter of The Opium War retells a favorite nationalistic memory: Lin Zexu and his followers stimulated and added momentum to the nationalistic and anti-imperialistic overtones which culminated in the formation of the 
People's Republic of China in 1949. Therefore, it is of special significance to commemorate and celebrate the handover of Hong Kong from Britain to mainland China. Leung believes that The Opium War is made to uphold the myth of national unification (249). The film The Red River Valley describes how the Chinese/Tibetan people resisted the British imperialism within the territory of China in early twentieth-century. The film accentuates that Tibet is part of China and, and the relationship between Tibet, China and Britain. The victory of China over British imperialism is easily to be read by the audience and critics as an allegory of the relationship between Hong Kong, mainland China and Britain. It is necessary to mention another film named The Soong Sisters (Songjia huangchao, 1997) which was coproduced by mainland and Hong Kong filmmakers. Since the film reflects the political intricacies and expounds upon the inseparable consanguine relationship between mainland China, Hong Kong and Taiwan by telling the story of the three Soong sisters, Soong Ailing, Soong Qingling and Soong Meiling, who were separated and settled down in the three different parts of China after several historical vicissitudes, it contributes a lot to strengthening the consanguinity of Hong Kong and Taiwan with mainland China. The author believes that the three films aforementioned not only provide background of unity, sovereignty and nationalism, but also recall, especially at the critical historical time, that Hong Kong, as well as Taiwan, is part of China and shares the same cultural heritage and traditions, and help strengthen the nationalistic awareness of Hong Kong people. 
However, Hong Kong cinema continues to use the popular theme of nostalgic romance to remind people of the good old days in the colonial past and to allegorically refer to the ambiguous and inseparable relation between Hong Kong and mainland China. One of the representative films is Mabel Cheung's City of Glass (Boli zhi cheng, 1998). In this film, the secret lovers Raphael and Vivian, who met and fell in love with each other in Hong Kong University in the colonial 1970s, died in a tragic car accident in London on the eve of the year 1997 . Their children gradually learned their parents' beautiful and painful love stories and dream yet to be accomplished in the course of searching for their parents past. However, to the surprise of the audience, in the end, the two children of the Raphael and Vivian fell in love with each other as their parents did when they were young, which implied a promising hope for the future relationship between Hong Kong and mainland China.

Leung assumes that, due to the highly commercialized operation and less concern on social issues of Hong Kong films, it would be hard to "claim any conscious postcolonial awareness in films produced before and after 1997" (249). Although individual film's production in fact experience more restrictions than before due to the economic depression in Hong Kong after the reunification of Hong Kong with mainland China, there were still some films attempting to explore a changing cultural identity of Hong Kong by examining various minority communities such as gay and prostitute communities, which were neglected by previous directors as reflected in Yu Lik-wai's Love Will Tear 
Us Apart (Tian shang ren jian, 1999) and Fruit Chan's Made in Hong Kong (Xianggang zhizao, 1998).

\section{HONG KONG'S CULTURAL IDENTITY DISCUSSED IN SCHOLARLY WORKS}

Culture identity has been not only an unfailing theme of Hong Kong cinema, but also a heated topic illustrated or discussed in scholarly works in recent years. Most of these debates focus on the actual situations of Hong Kong and life and ideological changes of Hong Kong people in the 1980s and 1990s. Gender and Change in Hong Kong: Globalization, Postcolonialism, and Chinese Patriarchy, edited by Eliza W. Y. Lee, explores Hong Kong women's changing identities and agencies under the historical setting of colonial modernity shaped by the interpenetration of colonial state, the capitalist economy, and the Hong Kong Chinese society from the perspectives such as political participation, the situation of working-class and professional women, sexuality, religion and international migration. In the introduction of this book, Lee provides a detailed and comprehensive analysis of the context of Hong Kong society, especially in the 1980 s and the 1990s. She emphasizes the significant role of globalization, postcolonialism and Chinese patriarchy in the transition and formation of the cultural identity of Hong Kong. Lee makes a detailed analysis of two typical characteristics of Hong Kong Chinese 
society—familialism and individualism—to illustrate that Hong Kong has been experiencing a changing nature in its Chinese society under the direct influence of colonial state and the capitalist economy. On the one hand, Hong Kong Chinese familialism fostered by the colonial state promotes the formation of an instrumental ideology of Hong Kong people. They attach great importance to material values, which they believe are stimulated and strengthened by the existence of the state and society. Therefore, Hong Kong people seldom participate in social activities, lack civic-mindedness and have low class-consciousness (Lee 7). On the other hand, economic individualism engendered by the capitalist development under colonialism fosters a strong and unique sense of self. Hong Kong people value the role of intrinsic factors more than that of extrinsic factors in achieving their social and economic success. That is, they believe the efforts of the individuals, not the structural and institutional forces that are beyond their control, dictate their life chances and are the real source of the improvement of their social and economic status. Hong Kong's unique market economy is developed in a unique colonial state context and fosters the formation of marketization and rationalization of the society. As a result, the marketization of the society breeds prevalent individualistic social ethos that stresses the apolitical and impersonal nature of the market. Individuals enjoy the freedom of choices, and regard free competition among individuals as a symbol of a just society. The desire for material interest and the instrumental approach to all aspects of social life 
constitutes a modern consciousness of Hong Kong society, which results in a pervasive lack of a sense of obligation to the society and focuses on personal gains in all facets. Lee then concludes that in a sense "the colonial modernity has produced individualistic colonial subjects who have subjectively internalized the rationalistic market norms and lack a sense of political community" (8).

Lee further discusses in detail the origin and nature of globalization and its influence on shaping cultural identity. Scholars such as Featherstone believe that the globalization process is "an extension of global cultural interrelatedness," which generates both "cultural homogeneity and disorder" and leads to "transnational cultures (third cultures)" (Lee 8). Cultural globalization is also involved in a two-way assimilation and amalgamation of the local and the global. To cultural theorists, globalization is involved in a process of redefining identities and expanding the "realms of self-definition but also cause the fragmentations and conflict identities" (Lee 9). The above theories about globalization can be well manifested by the subtly changed identity of Hong Kong. The historical handover of Hong Kong from Britain to mainland China on July 1,1997, resulted in redefining the cultural identity of Hong Kong, mainly because of the expediential arrangement of political and economic systems. The two policies "one country, two systems" and "Hong Kong people ruling Hong Kong" has been implemented in Hong Kong since the historical transition with Hong Kong's preserving its capitalist system under 
the sovereignty of the People's Republic of China. Hong Kong has been believed to be denied its right of self-determination and its discourse power and put in a marginalized position in the main Chinese society since the day China claimed the sovereignty of Hong Kong. However, some scholars argue that Hong Kong did not experience decolonization as expected after the historical handover. Rey Chow believes that Hong Kong was in-between two colonizers, Britain and China, and insists that Hong Kong had undergone a new form of colonization since its economic and political development was controlled by the socialist Beijing government, with the preserved previous framework of a colonial institution. But Kuan-Hsing Chen and other local scholars deem that Hong Kong, because of its special economic and political arrangement after the historical moment of national reunification, acts as an internal colonizer in less developed regions or countries in Asia, as manifested by the word "Northbound," a term used by Ho-Fung Hung, which refers to Hong Kong's colonization of mainland China in economic and cultural aspects (Lee 16). In "Discourse on Baau Yih Naai (Keeping Concubines): Questions of Citizenship and Identity in Postcolonial Hong Kong," Ka-Ming Wu takes the phenomenon of Hong Kong men's Baau Yih Naai in mainland China as an example to illustrate that this practice actually functions as an internal colonization, not as a peripheral or subaltern nation state.

Nonetheless, the political changes also brought about many changes in social and political structures of Hong Kong, as many social forces initiated 
concern over the city's future development and new political groups were formed. One of the most important issues that permeated in the political agenda of these groups was the issue of national identity. A heated debate on the real meaning of being Chinese and patriotic and on the local Hong Kong identity was aroused because any dissidents of the "one country, two systems" would be silenced by China's nationalism and patriotism. In addition, the promise of "Hong Kong people ruling Hong Kong" evoked the discussion on what the postcolonial political system should be like. Thus, colonial resistance, which is embodied by one's Chinese identity, together with the shaping of a local Hong Kong identity, constitutes a part of the postcolonial subjectivity (Lee 13).

Under the historical contexts mentioned above, the 1980s and 1990s witnessed a migrating trend and the formation of diasporic and transnational identity, as is well depicted by Siumi Maria Tam in her "Empowering Mobility: 'Astronaut' Women in Australia." Envisioning an economic and political uncertainty of Hong Kong after the handover, many Hong Kong residents, mainly composed of upper class people such as managers and entrepreneurs, migrated to Western countries such as Australia, Canada and the United States. Their instrumental ideology makes them place familial interests above societal well-being or political loyalty and prefer a flexible citizenship ${ }^{5}$, which is

\footnotetext{
5 The term "flexible citizenship" is used to describe Hong Kong migrants by Aihawa Ong as "the strategies and effects of mobile managers, technocrats, and professionals seeking to both circumvent and benefit from different nation-state regimes by selecting different sites for investments, work, and family relocation" (112) See Ong, Aihawa. "On the Edge of Empires: Fliexible Citizenship among Chiense in Diaspora." Positions: East Asia Cultures Critique 1,3: 745-78. 1993
} 
a good manifestation of individualism and familialism in the context of globalization. Tam elaborates on how women become the mainstream in the making of flexible citizenship. The wives of many Hong Kong families migrating to Western countries settle down in the new host countries, constituting a new diasporic and cosmopolitan Chinese identity and acting as agents in the construction of transnational identities by observing and sticking to Chinese and Hong Kong convention and customs in combination with some Western varieties in their daily life, while their husbands continue to stay and work in Hong Kong. In the quest for a national identity and a local Hong Kong identity, women also strive to represent some voices for Hong Kong women by advocating that feminist issues should be integrated into the postcolonial institutions (Lee 12-14). In the 1980s, women's groups proliferated in Hong Kong, focusing on gender equality, and more and more women obtained the opportunities to receive tertiary education and participate in feminist activities. Some talented women even participated in electoral activities during the historical transition.

However, the most notable and representative scholar in the heated discussion of the cultural identity of Hong Kong may be Rey Chow. Chow, growing up in the 1960s and 1970s in Hong Kong (which she believed to be a "classic immigrant city," and a "junction between diaspora and homeland" [20]) occupies a unique position in theorizing China since she received her education both in the British colonial and American institutions and has been a 
professor in the Comparative Literature Program at the University of California, Irvine. Rey Chow's works such as Women and Chinese Modernity and Writing Diaspora have a great and enduring influence on the cultural studies in Taiwan, Hong Kong and Western countries as is manifested by frequent quotations and references of her views on Hong Kong culture and the perspectives she used in her writing. She is regarded as the most widely-accepted Hong Kong critic and prolocutor of Hong Kong culture in North American institutions. In Writing Diaspora, Chow attempts to interpret contemporary Hong Kong culture from a postcolonial perspective and tries to create or self-write a marginal and third culture which is in some sense subversive to the dominating culture by making an analysis of Hong Kong films, popular music and literary works. In this book, her argument mainly focuses on two points. On the one hand, she thinks the central issue of self-writing of Hong Kong culture is that China and Hong Kong are contradictory to each other because she believes that Hong Kong is colonized by the former. Therefore, she argues that, in order to construct an independent Hong Kong cultural identity, "Chineseness" or nationalism must be deconstructed first. On the other hand, she believes that the construction of cultural identity of Hong Kong rests with the literary works produced by local Hong Kong literary professionals, which are subversive to the dominating Chinese culture.

The cultural identity of local people is often rewritten gradually without cognizance in a colonial society and as a result the local people often do not 
have explicit awareness of their cultural identity. A glimpse of the confusion of the cultural identity of Rey Chow herself can shed light on the state of the awareness of cultural identity of Hong Kong people. Chow believes that the cultural identity of the people of her age is complicated and even emotionless because it can not remain stable and unchanged by identifying and sustaining a given cultural value, which is very different from her ancestors who perceived and maintained a clear and specific cultural identity. She insists on regarding herself as a Chinese, but she feels that she dissociates between two different identities, which puts her in an embarrassed situation: her original Hong Kong identity and her later westernized identity. She feels that she, as a Hong Konger, lives in the political conflict between Britain and China. She doubts the nation where Hong Kong identity is rooted because, to Hong Kong people, language, especially Chinese, embodies cultural identity and value. However, it is obvious that the Chinese language has an inferior position in Hong Kong colonial society, not only in the societal level but also in the daily life. Weilian Ye (365) believes that the superiority of English not only provides an advantage to the people who use it by strengthening their life chances, but also results in the indigenes' inferiority to their own culture and language. Moreover, under the impact of the superiority of the English language over the local language, the intellectuals unwittingly identify themselves with the culture of the colonizer, that is, the colonial ideology is internalized in their struggle for living, which is termed "Culture Inauthenticity" by Renato Constahtino (Ye 365). 
According to Chow, Hong Kong's colonial situation is a kind of double negation because Hong Kong is an in-between of British and Chinese government, and it cannot be subjugated to Chinese nationalism or nativism, just as it couldn't succumb to British colonialism in the past century. She further argues that Hong Kong cannot keep its independence only through Chinese nationalism or Chinese nativism without damaging or disregarding Hong Kong history. Meanwhile, Hong Kong culture is not regarded as real Chinese culture as is manifested by the fact that it has been depreciated by mainland China as an over-Westernized one. Chow argues that the first concern for Hong Kong if it intends to construct its own identity and self-write its history is to decolonize Chinese convention as well as British. She regards China/Chineseness as "other," which she believes should be resisted if Hong Kong reconstructs its culture.

However, Lili Zhu (207) believes that it is apparent that Chow misunderstands postcolonialism when she considers both Britain and China as colonizers in the course of decolonization since the unique colonial and postcolonial feature of Hong Kong cannot eliminate its postcolonial universality, and what's more, the decolonization of the suzerain is different from the autonomy of the regions within the territories of China. In fact, "Chineseness" is a notion of culture in a broad sense-a concept which is based upon, bound to, Chinese cultural essence and has a referentiality of modernity, comprising all of the cultures of the Chinese minorities. It is not only a culture deposited 
and formed after a long centuries-old history, but also a spirit construction experiencing gradual and continuous changes. Therefore, it is not a single and fixed notion, but a historical notion comprising multicultural essences, including both the regional and the exotic. Under the context of globalization, Chineseness provides a new space for reflection for Western modernity. However, Zhu argues that Chow misconstrues Chineseness since she insistently deems Chineseness as other, as is manifested as follows:

The people of Hong Kong can sacrifice everything they have to the cause of loving 'China' and still, at the necessary moment, be accused of not being patriotic_-if not being 'Chinese' enough...... 'Chineseness'...lies at the root of a violence which works by the most deeply ingrained feelings of "bonding" and which-even at the cost of social alienation-diasporic intellectuals must collectively resist (Chow 24-25).

However, Zhu believes that Chow misapprehends or distorts what "Chineseness" is. She thinks that in the above quotation Chow totally repudiates "Chineseness." Chineseness/China is completely homogenized, simplified and stigmatized, and national identification is uniformly regarded as "bonding." In fact, Chineseness is narrated by Chow as a rigid, stubborn, hegemonic and terrible "other" that never changes and develops, and the issues of China and the West, Hong Kong and Western colonizer are completely neglected. Moreover, in order to exaggerate the terribleness of 
"Chineseness," she deliberately portrays Hong Kong as a vulnerable victim full of patriotism while portraying Chineseness as a haughty and hegemonic "other" and enacting "violence." However, when Chow uses "hybrid" and "orphan" to describe Hong Kong to exaggerate its vulnerability, it seems that she forgets that the hybridity and marginality of Hong Kong actually have their own edges. Leung not only acknowledges the superiority and reference value of modern Hong Kong to mainland China, but also warns that Hong Kong people should not regard themselves as vulnerable victims since there is a possibility for the victims to become tyrants, as demonstrated by some Hong Kong people's attitudes towards Vietnamese migrants, Philippino maids and the new migrants from mainland China (146; Zhu 215). Yaowei Zhu says that the identity of Hong Kong has been in an embarrassed situation. On the one hand, Hong Kong benefits from Western capitalism. On the other hand, it also resists the colonization of Western countries. Therefore, Hong Kong is eager to identify its Chinese identity, but at the same time it also worries about losing the right of self-determination after its return from Britain to mainland China after 1997. In fact, there is interaction between Hong Kong and mainland China in many aspects, especially in economic and cultural respects. Hong Kong culture and economy have been functioning as a colonizer to mainlanders since the 1980s. It is well known that Hong Kong's popular culture celebrities such as Jin Yong, Zhou Xingchi, Cheng Long (Jackie Chan) and Beyond have tremendous influence on the young mainlanders. 
Postcolonial theorists who advocate the hybridity of culture believe that culture is the accumulation of diverse cultures and the development of culture is in fact a process of absorbing the varieties. Hong Kong has been transformed into a cosmopolitan city and an image of Hong Kong combined with western and Chinese ideologies has been shaped after one hundred and fifty years of colonization. According to Ping-Kwan Leung, compared with other regions or countries with colonial history, the identity of Hong Kong is more complicated (157). Undoubtedly, to foreigners, Hong Kong people are Chinese. However, to people from mainland China or from Taiwan, it seems that Hong Kong people are exotic. Weilian Ye explains that, on the one hand, Hong Kong culture is part of Chinese culture because Hong Kong is a city of China (362). But on the other hand, Hong Kong culture is not real Chinese culture because it is not completely the same as Chinese culture. The same is true of the national consciousness and sense of participation in Chinese history of Hong Kong people. According to Stuart Hall, cultural identity is "far from being eternally fixed in some essentialised past, they are subject to the continuous 'play' of history, culture and power" (qtd. in Luo 211; Zhu 213). After over a century of colonization and the reunification of Hong Kong with mainland China, Hong Kong has been experiencing changes and development in all aspects including its cultural identity. However, it seems that Chow, blinking at the edges of Hong Kong in both the Western and Eastern world, envisages a Hong Kong with a third culture, neglecting its hybidity, marginality and 
in-betweeness.

According to the research conducted by Yincong Ye, the transition of nationalism and colonialism in the 1950 s and the 1960 s gave rise to the issue of Hong Kong identity and society, which is created by way of narrative and wording techniques borrowing from nationalism and colonialism (Ye 14; Zhu 213). Nativism is not completely depreciated by Chinese nationalism or compressed by colonialism. On the contrary, nativism gradually becomes a process of cultural hybridization under the context of national and colonial narrative. As an imaginary society, Hong Kong itself is also a place of history construction where different forces compete with each other. Hong Kong's nativism is not formed independently and it is impossible to be a culture enclave which gets rid of national culture and rejects exotic culture. With the realization of the reunification of Hong Kong to its motherland, the relationship between Hong Kong and mainland China becomes closer and closer, which makes Chow's self-writing Hong Kong-a third culture-look more unreal. Zhu holds that identity is a continuously changing and developing construction process (215). Therefore, self-enclosure or returning to the previous colony is not the way out for Hong Kong. What Hong Kong needs is not simply to reject but to be open to, communicate, interact and compete with Western cultures, non-western cultures, and the diverse cultures of different areas of mainland China. 


\section{HONG KONG'S CULTURAL IDENTITY REFLECTED IN POPULAR SONGS}

If the scholarly works show the concern of cultural identity of Hong Kong in the academic world, what is reflected in some contemporary popular songs sung by Dayou Luo (a Taiwaness singer, who now bases his work in Hong Kong) and other popular singers can be said to be the embodiment of Hong Kong's ordinary people's concern about their cultural identity.

Music has been used by the Chinese government as an effective way to arouse nationalism and patriotism since the establishment of the People's Republic of China in 1949. No one doubts the power of music in evoking human beings' diverse emotions. Julia Kristeva says music takes us to "the limit of the system of the sign," and due to its "transliguistic feature," music provides us "a means of suggesting what goes beyond" (qtd. in Chow 152). As discussed by Rey Chow (149-50) in her Listening Otherwise, Music Miniaturized, which is included in the book Writing Diaspora, sonorous and cadenced music is especially regarded as the most successful way of kindling people's national and patriotic enthusiasm by using class struggle, the basis for the official culture of a nation-state, as the foundation. For example, musical pieces such as "International Song," "Dongfanghong [The East is Red], "Meiyougongchandang Meiyou Xin Zhongguo [There Would be No New China without the Communist Party]" have been widely used by the Chinese government as standardized music for official celebrations to invoke patriotism and nationalism. 
Unlike official state culture, the power of popular songs is to express or voice what ordinary people think and are concerned about, especially in a highly commercialized and industrialized international city like Hong Kong where economic and political systems are different from those implemented in mainland China. To the native-born Hong Kong people, what is their original identity? Is it the imperial culture of Britain or traditional Chinese culture? These questions have been haunting Hong Kong people since British and Chinese government signed the Joint Declaration in 1984. During the crucial transitional period, many popular songs had been created to reflect Hong Kong people's concern and mixed feelings about their identity.

The popular songs sung by Dayou Luo, Yida Liu (Tats Lau)and Yaoming Huang (Anthony Wong Yiu Ming) clearly demonstrate the power of music to express and harmonize populist emotions during the historical transition period. The most representative songs which can reflect the social consciousness and political awareness of Hong Kong ordinary people may be Dayou Luo's Huanghou Dadao Dong/Queen's Road East (1991) and Shoudu/Capital (1992). The composition of the songs, including the lyrics, and the use of both English and Chinese in the lyrics and the music, reveals the hybrid nature of Hong Kong culture and society, as can be seen in the lyrics of the two songs shown below:

\author{
皇后大道东 [Queen's Road East] \\ 皇后大道西又皇后大道东
}


[Queen's Road West and then Queen's Road East]

皇后大道东转皇后大道中

[Queen's Road East to Queen's Road Central]

皇后大道东上为何无皇宫

[Why is there no palace in the Queen's Road East]

皇后大道中人民如潮涌

[Crowds of People are rushing in the Queen's Road Central]

有个贵族朋友在硬币背后

[There is an aristocrat on the back of the coin]

青春不变名字叫做皇后

[Who is the forever youthful Queen]

每次买卖随我到处去奔走

[Every time she goes with me for all my business transactions]

面上没有表情却汇聚成就

[No facial expression but full of achievements]

知己一声拜拜远去这都市

[Confidant just to say goodbye and leave the city]

要靠伟大同志搞搞新意思

[Must rely on the great comrade to do some innovations]

照买照卖楼花处处有单位

[Buy and sell the real estate as speculation as usual]

但是旺角可能要换换名字 
[But the name of Mong Kok may be changed]

这个正义朋友面善又友善

[The righteous friend is so kind and amiable]

因此批准马匹一周跑两天

[That he sanctions the horse race two days a week]

百姓也自然要鬥快过终点

[Common people are also preparing to race to the end]

若做大国公民只须身有钱

[To be a citizen of a great nation, all you need is to have money]

知己一声拜拜远去这都市

[Confidant just to say goodbye and leave the city]

要靠伟大同志搞搞新意思

[Must rely on the great comrade to do some innovations]

冷暖气候同样影响这都市

[Both cold and warm climate influence the city]

但是换季可能靠特异人士

[But changing the season may need superman]

空即是色色即是空空即是色即是色即是空

[Emptiness is the same as the material world; The material world is the same as emptiness; Emptiness is the same as the material world; The material world is the same as emptiness] 这个漂亮朋友道别亦漂亮 
[This friend is beautiful and her goodbye is also beautiful] 夜夜电视萤幕继续旧形象

[The old image still appears every night on TV]

到了那日同庆个个要鼓掌

[On that day everyone should applaud]

硬币上那尊容变烈士铜像

[The esteemed face is changed to a bronze martyr]

知己一声拜拜远去这都市

[Confidant just to say goodbye and leave the city]

要靠伟大同志搞搞新意思

[Must rely on the great comrade to do some innovations]

会有铁路城巴也会有的士

[Will have railway, bus and also taxi]

但是路线可能要问问何事

[But the route may ask what will happen]

(Luo and Jiang; Trans. Ding, Yajuan and Chan, Ying-kit)

The song Queen's Road East (1991) shown above tells the story and the vicissitudes of a street of Hong Kong and its surroundings, which feature a mixture of Western and Chinese style. It vividly portrays the dilemmatic and embarrassed situation of Hong Kong between British colonizer and mainland China. In this song, the street name "Queen's Road East" and the Queen Elizabeth's image on one side of the coin which was circulated in Hong Kong 
before 1997 are used as metaphors of British colonialization. Such words as "weida tongzhi [great comrade]," "qihou [climate]," "teyi renshi [superman]" and "luxian [route]," which are frequently used official words of Chinese government, allegorically refer to mainland China. The lyrics clearly show the ambivalent attitudes of the Hong Kong people towards leaving the British colonization and the sovereignty of China. “知己一声拜拜远去这都市[Confidant just to say goodbye and leave the city]" implies the nostalgia of the Hong Kong people towards the golden past. The use of "知己," which means "very close friend" in Chinese, and "一声拜拜[just to say goodbye]," shows that Hong Kong people are reluctant to part with British control. The two sentences in the lyrics “百姓也自然要鬥快过终点 [Common people are also preparing to race to the end]" and “若做大国公民只需身有钱 [To be a citizen of a great nation, all you need is to have money] vividly portray the uncertainty and anxiety of Hong Kong people about the coming handover. Ordinary people also have to be well-prepared in advance in case the policies will be changed. Some migrate to other areas or countries and others sell their belongings because no one feels for sure what will happen after the handover. But you don't have to worry if you are wealthy. Furthermore, the composition of the lyrics is perfectly arranged, neat and compact; the metaphors of Britain and mainland China are used alternatively and comparatively, and the two singers Dayou Luo and Zhiguang Jiang sing the song in a humorous and conversational way. The lyrics as well as the tone, voice and vocal arrangement of the singers indicate 
a sarcastic and playful attitude of the perplexed Hong Kong people towards their situation. All the above features present to the listeners a vivid picture of the postcolonial status of Hong Kong and emphasize the embarrassed situation of Hong Kong under the two political powers during the historical transition period.

In addition to using the official words of the Chinese government as metaphors to ironically and playfully express the social consciousness and political awareness of Hong Kong people during the transitional period, the song Capital accentuates the hybrid culture of Hong Kong by using Mandarin, Cantonese and English in its lyrics and the dilemmatic inbetweenness of Hong Kong. The feature is clearly shown in the lyrics shown below:

(Sing in Mandarine)

首都 万里河山千代人物

[Capital, million miles of river and mountain, thousand generations of historical figures]

\section{首都 万世乾坤青云路}

[Capital, millions of universes and roads to high positions] (Sing in English)

首都 capital; 首都 capital; 首都 capital; 首都 capital (Sing in Cantonese) 皇天 一朝解放 股票数字任飞舞

[The Empire, once liberated, stock rocketing] 


\section{后土 改做地盘 段段划成黄金路}

[The territory, converted into land, each piece will be a road to gold] 皇天 一朝解放 高干大楼在拥抱

[The Empire, once liberated, high-ranking officials hug high buildings] 后土 改做地盘 段段是繁荣跑道

[The territory, converted into land, each piece will be a road to prosperity]

(Luo and et al; Trans. Ding, Yajuan and Chan, Ying-kit) The postcolonial feature of the song Capital (1992) is embodied through the various phonetic systems and the inter-semioticity of the lyrics. The three different pronunciation systems-Mandarin, English and Cantonese-are used not only to reflect the hybrid nature of Hong Kong but also represent three distinct cultures and values: Mandarin has been regarded as the established and authentic Chinese culture; English is the embodiment of the exotic and the Western cultures and values; and Cantonese represents the local dialect which has been depreciated by mainland scholars as frivolous, lowbrow and vulgar language. The subtle, crafty and skillful use of the words and the composition further implies the marginality of Hong Kong. It is marginalized not only by British colonizers but also by the authentic Chinese culture.

It is interesting that one of the popular songs produced and sung in 1993 
by mainland singer Ai Jing offers a picture of Hong Kong from the perspective of mainlanders. Lu claims that the lyrics and music of Ai Jing's "Wo de 1997 [My 1997]" have "captured the heart and feelings of the mainlanders in ways that official pronouncements could not" (274). In the eyes of the narrator in the song, the meaning of Hong Kong's return to mainland China in 1997 is reflected vividly and concretely in the following lyrics:

When will it be possible to go to Hong Kong

without a visa and a stamp

Let me go to this dazzling world give me a stamp

1997 please come quickly! What does Yaohan look like?

1997 please come quickly! So I can go to Hong Kong

1997 please come quickly! So I can stand in Hung Hom Coliseum

1997 please come quickly! So I can go with him to see the midnight show

1997 please come quickly! So I can see how the cloths of in Yaohan are actually are

1997 please come quickly! So I can go to Hong Kong

1997 please come quickly! So I can stand in Hung Hom Coliseum

1997 please come quickly! So I can go with him to see the midnight show

(Trans. Lu 275)

To "1," a mainlander, Hong Kong is an exotic and "dazzling" world and a 
shopping heaven. In the eyes of "I," the return of Hong Kong in 1997 means everything: people from mainland China can travel freely to Hong Kong without "a visa and a stamp" and enjoy everything in Hong Kong as she or he does in any other place in China (Lu 276). From the picture of Hong Kong envisaged by the mainlander "I," we can see the fact that Hong Kong has been marginalized and alienated by the people from mainland China.

\section{HONG KONG'S CULTURAL IDENTITY REFLECTED IN MASS MEDIA}

The cultural identity of Hong Kong has been a focus in scholarly works and has been portrayed in music and films as discussed above. In this section, by examining news articles on the topic of the cultural identity of Hong Kong selected from one of Hong Kong's newspapers, South China Morning Post, I will attempt to explore how the cultural identity of Hong Kong is discussed by journalists. In addition, I will attempt to examine the trend of news coverage in the past decades. News is generally regarded as a way of recording the most important experiences and events happening in the world. Serving as the disseminators of information to common readers, journalists take pride "in their independence and in professional norms of objectivity" (Page 20). They claim that they convey to readers unbiased or impartial descriptions of certain events with value-free language, although some journalists may take stands in reporting news. Therefore, it is possible and feasible to explore the 
experiences of human beings or ideological trends in a given society by studying the news. The reason I choose South China Morning Post (SCMP) as the major news resource for the present research is that it claims to be the "leading English newspaper in Hong Kong and Greater China" since it was first established on November 6, 1903.

Both quantitative and qualitative approaches are adopted in the present research. The sample news stories of this research consist of two groups. The first group includes news stories selected from South China Morning Post downloaded from the database Lexis-Nexis Academic Universe and the search terms (natural language) are "Hong Kong cultural identity" with "identity" in the headline. The second group includes news stories from the same news source mentioned above, and the search terms (natural language) are also "Hong Kong cultural identity" but with "identity" in the byline. The news stories in both groups are selected from January 1, 1930 to May 1, 2009, since the first attempt of the construction of the cultural identity of Hong Kong has been traced to the 1930 s. This cultural construction is reflected in the films produced in the 1930s as discussed in the first part of this chapter. The first group consists of 17 news stories after ruling out 11 duplicates and 19 irrelevant articles. The second group contains 8 news stories, excluding 1 duplicate and 13 irrelevant ones. Thus, the actual sample of this research consists of 25 news stories. From Table 2 we can see that there are no news articles on the topic of the cultural identity of Hong Kong between the 1930s 
and 1980 s, which indicates that the issue of cultural identity had never been a main concern for Hong Kong people from the 1930 s to the 1980 s, even though China and Britain signed the Sino-British Joint Declaration in 1984. There are 3 in the first group and 0 in the second group on the same topic from 1991 to 1996, indicating that the issue of the cultural identity draws attention to Hong Kong people but it is not a major concern for them at that time. And there are 14 and 8, respectively, in the first group and second group from 1997 to 2009 , accounting for $88 \%$ of the total. The dramatically increased number of the news articles on the topic of the cultural identity of Hong Kong after 1997 indicates that the issue arouses more interest in the public after Hong Kong's return from Britain to mainland China.

The analysis of the figures in Table 3 indicates that Hong Kong people have never stopped thinking of their cultural identity since 1992 and that they have been constantly concerned about it since the 1997 handover. Table 2 shows that 17 news articles, which accounts for $68 \%$ of the total, have "identity" in the headline. The relatively high percentage indicates that the issue of identity is of great significance in the life of Hong Kong residents. Journalists often carefully choose the words they use in the headline to draw the attention of the readers to focus on their discussion since headlines generally recapitulate and summarize the news stories. Concise and categorical wording of headlines makes it easier to capture the attention of the readers immediately. (Zuo 3; Wu 267-272). 


\section{Table 2}

The Number of the News Stories of First and Second Group selected from South China Morning Post (From January 1, 1930 to May 1, 2009).

\begin{tabular}{|l|l|l|l|}
\hline Decades & 1930s-1980s & $1991-1996$ & $1997-2009$ \\
\hline First Group & 0 & 3 & 14 \\
\hline Second Group & 0 & 0 & 8 \\
\hline
\end{tabular}

\section{Table 3}

The Number of the News Stories of First and Second Group selected from South China Morning Post (From January 1, 1930 to May 1, 2009)

\begin{tabular}{|c|c|c|c|c|c|c|c|c|c|c|}
\hline Number & 91 & 92 & 93 & 94 & 95 & 96 & 97 & 98 & 99 & \\
\hline First Group & & 1 & & & 1 & 1 & 2 & 1 & 1 & \\
\hline Second Group & & & & & & & & & & \\
\hline Number & 00 & 01 & 02 & 03 & 04 & 05 & 06 & 07 & 08 & 09 \\
\hline First Group & 1 & 1 & 1 & 1 & 3 & & 1 & 1 & & 1 \\
\hline Second Group & & 2 & 2 & & 1 & & & 2 & 1 & \\
\hline
\end{tabular}

The cultural identity of Hong Kong reflected in the three articles 
published before 1997 takes on the following three characteristics. First of all, upon the upcoming of the handover, Hong Kong people felt uncertain about their future and desire to have an articulated identity, which is well illustrated by the article written by a political pollster and columnist, Citi Hung Ching-tin, in 1992. According to Hung, empirical studies show that Hong Kong people were "suffering an identity and purpose crisis" (13). They worried about the transition of sovereignty, as shown in the statement "there may lie the smooth transition to Chinese sovereignty and China's smooth transition to modern times" (Hung 13). Hong Kong people desired to have a clearly defined identity and expected Hong Kong to have "a soul on the cultural and historical plane" that guaranteed its development with "ferocity and lucidity, compassion and authority" (Hung 13). Upon the end of 150 years of colonization and the forthcoming handover, many people thought it was time for Hong Kong to reconstruct its identity. The desire for a well-defined identity was further demonstrated by people's expectation of the last governor of Hong Kong, Chris Patten, to address in his speech "Hong Kong's peculiar aspirations-an identity in a cultural and historical context." Chris Patten was also expected to give Hong Kong people "a sense of themselves, an identity that reaffirms their values and direction" (Hung 13). Unfortunately and ironically, even the governor himself had never a comprehensive understanding of what a Hong Kong identity would be like until his term of office was over. However, a sense of "we Hongkongers" had been claimed to take shape among Hong Kong residents, especially among the 
young and well-educated people, which was reflected by the surveys conducted by Hong Kong Polling and Business Research. The surveys also showed that Hong Kong people were not satisfied with the exclusion of them from the decision-making process.

The uncertainty and anxiety continued to haunt Hong Kong people in 1995. Alice Cairns' article shows that the artistic works of some artists are influenced by a collective uncertainty and anxiety of Hong Kong residents. A Shanghai-born Hong Konger admitted that his artistic works were inspired by issues related to the 1997 handover. He said that "Here in Hong Kong, we are looking to 1997 conscious that on the one hand it is natural for Hong Kong to go back to China, and at the same time we are all afraid it may not turn out well. Much of my inspiration comes from this apparent contradiction" (Cairns 6 ). The second characteristic of the cultural identity of Hong Kong before 1997 is that Hong Kong people feel that they are marginalized by mainland China. The marginalization lies in that China only acknowledges the uniqueness of Hong Kong in the economic dimension. In other aspects, China has been "doing everything within its power to "thwart Hong Kong's development in accordance with Hong Kong's internal logic and drives" (Hung 13). The third characteristic is the hybrid nature of Hong Kong culture. On the one hand, this hybridity is reflected in the works exhibited in Hong Kong Designers Association (HKDA) Design Show, which was held in 1996. The representative one is Alan Chan's works, which embody a "juxtaposition of seemingly contradictory Chinese and 
Western cultures" (Herd 5) On the other hand, as is discussed in Deborah Herd's news report, the unique colonial history makes Hong Kong a bilingual society, which in turn enables its subjects to think in both ways-Eastern and Western simultaneously, which is believed to be basis of local artists in their creative products.

Compared with the three articles published before 1997, the cultural identity of Hong Kong reflected in the 22 news articles issued after 1997 take on new features, especially those published in the years after the millennium. An analysis of the 22 articles also shows that Hong Kong people pay much attention to the issue of identity when there is a big event, which is well manifested by the increased number of articles addressing the topic in 1997 , 2001 and 2002, 2004, and 2007. It seems that those years are milestones in Hong Kong history and the construction of Hong Kong cultural identity. July 1 , 1997 witnesses the historical handover, July 1,2001 is the $70^{\text {th }}$ anniversary of the Japanese invasion in 1931, and in the following year, few Hong Kong people are aware of the anniversary; there is a rally for social justice and for political reasons on July 1, 2003, which evokes more attention of Hong Kong people to their identity; July 1, 2007 is the 10 years anniversary of Hong Kong's return to the motherland.

As the time goes on and the transition has been going smoothly, it seems that Hong Kong people feel more comfortable concerning their identity as Chinese in a larger Chinese discourse than before, which is seemingly 
predicted by the two articles published in 1997. In fact, Wendy Kan's article which was entitled "Identity Crisis No Longer a Problem" is not an article directly addressing the Hong Kong people's identity. However, it seems to present to the readers a vista and hope for the future and to analogically picture a process of identification that Hong Kong people may experience in their searching for an articulated identity in the future. The article is about how a Chinese growing up in a Western society feels about his Chinese identity in both Western and Chinese discourses. Due to his poor mastery of Chinese language and limited knowledge of Chinese cultural traditions, the narrator often feels confused when Westerners laugh at his claiming to be Chinese. He has inherited traditional Chinese values-"a strong work ethnic, discipline, respect for authority"-and acquired "cultural education, values and sense of Chinese identity" at home. However, he has neither acknowledged "the influences of Western culture," nor his "ignorance of certain aspects of Chinese culture" (Kan 2). His experience of growing up in a Western society and having Chinese values and cultural background acquired at home and a sense of Chinese identity enable him to live peacefully and at ease, although he sometimes feels to be alienated.

In the early years of the post-1997 era, Hong Kong seems to be lost in searching for its identity, especially in such aspects as education and the development of the city. An article written by David Saunders published in 1999 shows that the officials of Hong Kong government are keen on turning 
Hong Kong into a city of Western style. It seems that every official coming back to Hong Kong from overseas feels "obliged to offer their thoughts on how to transform the city into the Manhattan/London/Las Vegas/Milan of Asia" (Saunders 16). However, Saunders reminds us of not forgetting the fact that "Hong Kong is still one of the world's great cities" (16). Therefore, there is no need for Hong Kong to imitate others. The education of Hong Kong also stands at the cross of the road in embracing Westernization or Chinese heritage. An article published in July of 2001 says that "since a country's education system springs from a clear and commonly accepted philosophical base, Hong Kong needs to define its identity and goals instead of relying on Band-Aids of buzzwords, clichés, slogans, and acronyms" (Pujadas 5). It further elucidates that "Education and culture feed off each other, and SAR [Special Administrative Region] is wavering at a cultural crossroads. Should it deny its Chinese heritage in favour of westernization, or should it renounce the coloniser and cleave to the motherland? It is common for these disparate elements to collide within the educational spectrum, two philosophies" (Pujadas 5).

The unawareness of Hong Kong people to the $71^{\text {st }}$ anniversary of Japan's invasion arouses another wave of the attention of the public to the issue of the cultural identity of Hong Kong. Research findings show that the number of Hong Kong people who identify themselves as Chinese or Chinese in a broad sense is increasing. However, Chris Yeung's "Kong Kong's identity 
still an open question," published on September 22, 2002, provides contradictory evidence. Yeung argues that the indifference of Hong Kong people to the $71^{\text {st }}$ anniversary of Japan's invasion, one of the most significant events in the history of China in the 1930s, seems to "contradict findings of surveys that indicate more Hong Kong people are identifying themselves as Chinese" (Yeung 8). Yeung further explains her statements with the findings of a poll conducted by the University of Hong Kong. The result of the poll shows that, of the 1,000 respondents, people who identify themselves as Hong Kongers remain stable at $51 \%$, while those who identify themselves as Chinese have increased from $38 \%$ in a similar poll conducted in 1997 to $48 \%$. According to pro-Beijing legislator Yeung Yiu-chung, the increase may result from the "positive developments such as Beijing's successful bid to host the Olympic Games in 2008 and China's entry into the World Trade Organization" (Yeung 8). However, Yeung argues that Hong Kong people have mixed identities. The findings of the poll conducted by Hong Kong Transition Project in late 2001 show that 45 per cent of the respondents regard themselves as Hong Kongers, 22 per cent identify themselves as Chinese, and 26 per cent consider themselves Hong Kong Chinese (Yeung 8).

Based on the findings of a research study, a researcher concludes that the majority of Hong Kong people still identify themselves as Hong Kongers. Yeung further mentions that "various opinion polls have also indicated a growing trend of 'feel good' sentiments among people towards Chinese 
leaders and the mainland's social and economic outlook" (8). The aforementioned data, as Yeung argues, is a reflection of a "thin line of historical, ethnic and cultural affiliations" rather than of the "emergence of a strong bond of identification with the socialist country," which may be caused by the big difference between Hong Kong and mainland China (8). In recent years, more and more Hongkongers move to mainland for "greener pastures" and Hong Kong students spend their summer experiencing the campus life in the universities of the mainland. Yeung concludes as follows:

...the flourishing of ties and exchanges with the people across the border over the past few years has brought about changes to the perception of Hong Kong people towards the mainland. Public perceptions of the mainland have become complex. People see it as a place where both opportunities and crises exist, and react to developments with both hope and despair. There will only be more complexities and subtleties in the question of identity of Hong Kong people as both sides of the border are undergoing drastic changes within their societies and in their interface (8).

However, Mark O'Neill's "One of the Family_Hong Kong's identity is merging with mainland even as Beijing says the SAR plays a distinctive and vital role," which was published on July 8,2002 , emphasized the integration of Hong Kong with mainland China. O'Neill says that "Hong Kong has always had strong cultural ties with its hinterland across the border" (2). In the post-1997 
era, those cultural ties have been remarkably strengthened rather than diminished, as companies become aware of their increasing reliance on the highly developed mainland cities such as "Guangdong, Shenzhen and Zhuhai" (2). O'Neill argues that the economic differences between Hong Kong and mainland China have been increasingly narrowing and the integration of Hong Kong with the mainland has become "an economic force that cannot be ignored" (2). To the Beijing government, Hong Kong still has its uniqueness, having a distinct identity from other cities in mainland China. O'Neill also mentions that the perceptions of mainlanders towards Hong Kong had been changing after more and more mainlanders visited Hong Kong. To the mainlanders, the "stereotypee image of a city oozing modernity and super-wealth, of drunk American sailors with a girl on each arm and loud British policemen with beer bellies, is gone" (O'Neill 2). The ignorance and the lack of awareness of the media and ordinary Beijing people towards the handover anniversary of the previous year indicate the diminution of the distinctiveness of Hong Kong as well as the smooth transition.

The July 1 rally which began in 2003, which may result from the discontents with political policies and social problems, seems to be a turning point for the development of Hong Kong cultural identity. For the first time in history, Hong Kong people actively take a subjective role. In an article published in May of 2004, Edith Terry argues that Hong Kong identity is "in the process of being found" after having been missing for the past seven years, 
despite the fact that, as most observers agreed upon, Hong Kong experienced a decline after the handover due to "an unholy combination of regional and global financial crises, poor governance and self-absorption." The identity of Hong Kong experienced a change from the old one to a new one. Terry believes that the old identity of Hong Kong was "of taipans and tycoons, with a British potentate genially overseeing the market melee, more like an investment banker than a governor-general." To Terry, the new identity is as follows:

Hong Kong's new sense of self has been growing like kudzu vines in a wild mountain valley, sending out exploratory shoots here, there and everywhere. The new Hong Kong is Chinese, tolerant and political, although a bit of a lightweight when it comes to such things as the arts, creative design and deep thinking, maybe Hong Kong, like a Honolulu with skyscrapers, is simply too rich in physical beauty to nurture the dark mental spaces inhabited by artists. Or perhaps it is just a matter of time before the artists, writers, creative designers and people of the mind take root here" (13).

However, the transformation from the old to the new is not dramatic but quiet and slight, which is lit by the following surface indicators. The first indicator is that more businesspeople become involved in discussing politics in the public sphere than they did before. The second indicator is the dramatically increased public meetings on various issues "ranging from governance and 
constitutional reform to the future of Victoria Harbours" (Terry 13). The third indicator is the increased attention of the Hong Kong government to the public's responses. In addition to the aforementioned surface indicators, Terry says there is also "a new-found dignity." This dignity is "based on the good faith and civility of last year's pro-democracy march on July1, and its positive outcomes, which have included a new dialogue between Hong Kong's previously ostracized democrats and Beijing" (13).

Christine Loh's "Hong Kong's Search for Identity" published on June 24, 2004 , a few days before the coming July 1 rally of that year gives us more evidence of the awareness of Hong Kong people towards an articulated cultural identity. Loh holds that the rally is a result of the conflict of different cultures between Hong Kong and mainland China. The "one country, two systems" and "Hong Kong people ruling Hong Kong" policies promised a stable political and economic future for Hong Kong people and guarantee a 50-year unchanged lifestyle (Loh 15). However, culture is not the same as lifestyle. It is always changing. In the 1960s, with Hong Kong becoming an international city and one of the world's largest economic centers, a unique local identity was created, and at the same time, the differences of the lifestyle between Hong Kong people and the mainlanders also augmented gradually. Hong Kong people were faced with an identity crisis: to be British subjects or Chinese patriots or to embrace Chinese culture or Western civilization. In the 1970s, Hong Kong society differs from that of mainland China in such aspects 
as "rule of law, individual liberty and a determination to stamp out corruption" (Loh 15). In the 1980s, identity was the main concern of many of the activists of young pressure-group movement. Loh concludes that it is therefore not a surprise to learn that few Hong Kong people identify with the mainland even after the reunification (15). In fact, Hong Kong has diverse identities, as Loh says "The Hong Kong "lifestyle" today is a blend of multiple identities-a mixture of Chinese and Western; Cantonese and other Chinese regional identities; individualistic and communal; Buddhist and Christian; capitalist and class conscious; and free versus constrained" (15). Loh further argues that Hong Kong identity is still a heated and controversial issue (15). Hong Kong people have never been given a chance to assert their own identity in the past. Therefore, they still have to think about their identity. Loh thinks that how mainlanders see Hong Kong people and how Hong Kong people see themselves should be taken into consideration:

There is also the issue of how the mainland sees Hong Kong. Does it regard Hong Kong people as perverted by western values, lacking in Chinese cultural understanding and ruthlessly opportunistic? Does it see an assertion of Hong Kong's local cultural identity as a drift towards separatism and independence? The identity of Hong Kong people can be described as a collective imagination. It is consciously being shaped by how the people see themselves. The recent articulation by a group of scholars and professionals of Hong 
Kong's 'core values" is an example of this continuing attempt. The pursuit of a democratic culture has become very much part of the local imagination, and hence the Hong Kong culture. The coming July 1 rally is a part of the making of that identity (15).

In "Essence of a city" which was published on December 4, 2004, Andy Cheng attempts to stress the diversity of Hong Kong cultural identity resulted from its unique history, as illustrated in the following statements of Alex Hui Yat-chuen (a curator of The University of Hong Kong's Museum and Art Gallery):

...the unique part of the city's cultural heritage comes from its history since $1841 \ldots$ the pre-colonial part is really not much different from the rest of China at the time.... but since 1841, in a way, Hong Kong has been a new frontier for new immigrants. They came from all parts of the world and tried to build their lives and homes here... in fact, the uniqueness of Hong Kong's culture is in its fusion and diversity, we have colonial heritage and western experience on the one hand, and Chinese traditional values with Hong Kong practices on the other (16).

The issue of Hong Kong cultural identity continues to be a heated topic in the following years after the July 1 rally in 2003 , especially in 2007 , the $10^{\text {th }}$ anniversary of the handover. In "Who Are We?" an article published on June 11, 2007, Clarence Tsui says that "the demonstration on July 1,2003 , instilled into 
many a Hongkonger a communal spirit and local consciousness that had been more or less ambivalent, or even absent, in the past" (12). In an article published in October of 2007, Denise Hung and Ambrose Leung claim that "the first decade after the handover had seen a growing sense of national identity in the community" (6). They further argue that if Hong Kong people "make their life and career plans from the perspective of national development, both individual citizens and the community at large will surely have a brighter future" (6). They say that the Hong Kong government will "promote education on national identity through channels such as classroom teaching, teachers' education, extra-curricular activities and exchanges among young people from the mainland" (6). For example, schools will be encouraged to have flag teams, perform "national flag-raising ceremonies" and provide more opportunities for the young to take mainland study trips and participate in exchange programs (Hung and Leung 6). They hold that the success of 2008 Beijing Olympics present an "excellent opportunity to promote education on national identity" (Hung and Leung 6).

In the most recent article in this research which was published on March 30, 2009, Anthony Cheung argues that the confidence crisis that Hong Kong has been experiencing reflects "a deeper sense of uncertainty and lack of direction," and some commentators even say that "Hong Kong is no longer Hong Kong" (11). Meanwhile, Hong Kong still enjoys privileged advantages because of its "financial-hub status" (11). Hong Kong experienced great 
changes in different dimensions such as economy and culture in the past 150 years of colonization and in the post-1997 era. Hong Kong identity has been transformed from a "barren rock" through "an inglorious colonial history" into a world famous metropolitan city, with its people "taking pride in its freedoms and rule of law" (Cheung 11). Hong Kong culture expanded its influence "throughout the Chinese diaspora through its unique Cantonese cultural and lifestyle forms-Hong Kong movies, Canto-pop music, television soap operas and Hong Kong-style cuisine and café food" in the 1980s (Cheung 11). With its advantaged geopolitical background and colonial history, Hong Kong "eventually overtook its regional rivals to become a premier financial centre, ranking with London and New York." Although Hong Kong had been treated as "a political dwarf" in the years before the handover, it still represented "institutional superiority and vibrancy" because of its economic achievements and advanced civil society and its legal and administrative systems, which Hong Kong had taken pride and strived to "preserve and safeguard" (Cheung 11).

However, as argued by Hung and Leung. Hong Kong culture has gradually lost its lustre with the decreasing influence of Canto-pop and local movies on the market. It is further deteriorated by the death of some local superstars such as Leslie Cheung Kwok-wing and Anita Mui Yim-fong, which is a signal of the "end of a golden era" (Hung and Leung 11). What makes it worse is that the economic advantage of Hong Kong seems to lose its edge 
over some cities of mainland China, as Hong Kong is believed to gain economic support from the mainland and is overtaken by some mainland cities such as Shanghai and Guangdong. Hung and Leung contend that it is useless for Hong Kong to yearn for the golden past, since what matters most for Hong Kong people is whether "they can maintain the necessary institutional capacity, and willpower and imagination" to "reinvent a new city from the old one" and whether they can look at things in a new perspective (11).

Among all the other news articles included in this research, it is worth noting the one written by Greg Torode which was published on January 5 , 2001. This article can give us some clue on how Americans perceive Hong Kong identity, especially in the post-1997 era, since it will be important in analyzing how the cultural identity of Hong Kong is reflected in Jackie Chan's Hollywood films. Torode believes that Chris Jackson, the Director-General of Hong Kong Economic and Trade Office in Washington DC, has "played a unique role in trying to shape the United States' perception of Hong Kong" (14). Chris Jackson held that the issue for Hong Kong was to "continue to be a separate identity while recognising the full importance" of the place of Hong Kong within "the sovereign People's Republic of China" Torode (14). He further contended that the anxiety of Hong Kong people had "come down considerably," but what should not be forgotten was that "the general impression in the United States is that Hong Kong's unique status is beginning to lose its luster," and that impression was largely acquired from the media 
(Torode 14). As Jackson said:

...to the average American there is a tendency to think that Hong Kong has gone back to China, and therefore it loses its identity... among the broader American public there is insufficient understanding of Hong Kong as a separated entity, as a model of what the WTO is about, as an opportunity for American business, and that is what we really need to emphasize both from Hong Kong and in the US (Torode 14).

The cultural identity of Hong Kong has been discussed in scholarly works and in different forms of popular culture such as film, music and mass media. Due to its 150 years of colonial history, the uniqueness of its economic and political systems and its peripheral position in geographic, cultural and political dimensions in a larger Chinese discourse, Hong Kong experienced different stages in searching for its identity from the 1930 s to the 1990 s and in the post-1997 era. The changes in the formation of the cultural identity of Hong Kong are closely associated with the historical periods, especially significant historical events, which will unavoidably influence the ways scholars or artists discuss or portray Hong Kong in their works. In this paper, the author uses New Historicism theory and the findings of the above discussion to examine the correlation between the historical events and the portrayal of the cultural identity of Hong Kong in Jackie Chan's Hong Kong and Hollywood films.

Cultural identity is in some sense an everlasting topic since it seemingly 
never stops changing. With the increasingly complicated interaction between different cultures, more and more people become aware of their cultural identity. However, it is not easy to define the cultural identity of a person, a group or even a society in the context of globalization. Scholars such as Rey Chow and Eliza W.Y. Lee and other professionals such as filmmakers and popular singers have been trying to explore the cultural identity of Hong Kong in different forms. This research only discusses the issue of the cultural identity of Hong Kong reflected in some scholarly works and some different forms of popular culture such as film, music and mass media. The major subject of the present research is film, which is regarded as a major form of popular culture. Moreover, it is Jackie Chan, together with two other international film stars, that drew the attention of academic research, as mentioned above. Therefore, it is necessarily to know the perspectives of scholars on the issue of Hong Kong's cultural identity and how other forms of popular culture portray the cultural identity of Hong Kong. From the discussion in the above sections, we can see that scholars such as Rey Chow and Lili Zhu have done some research on the issue of the cultural identity of Hong Kong. They examine the issue from different perspectives and some of their viewpoints are incisive and thought-provoking, which contributes significantly to the understanding and construction of an articulated cultural identity of Hong Kong. However, they have their own limitations. First of all, scholars such as Chow fail to give a comprehensive understanding of the issue. It seems that Chow only focuses 
on the disadvantages of the marginalized Hong Kong culture while ignoring its advantageous facets. For example, she insists on the denial of Hong Kong's self-determination or voice in the negotiation process because of the absolute sovereignty of mainland China over Hong Kong and the peripheral situation of Hong Kong culture in the context of Chinese discourse. However, she forgets the freedom and independence that Hong Kong enjoys and the colonization of Hong Kong over the mainland and other regions in Asia. In addition, it seems that she also forgets the inseparable cultural affiliation between Hong Kong and mainland China. Another limitation is that scholars, unlike the film producers, cannot envision or construct a cultural identity of Hong Kong in their scholarly works. More often than not, they also cannot capture the trend of the major concern of the society immediately as the journalists or popular singers do. 


\section{CHAPTER IV}

\section{LITERATURE REVIEW OF HONG KONG'S CULTURAL IDENTITY REFLECTED IN JACKIE CHAN'S FILMS}

As discussed in the previous chapter, the issue of the cultural identity of Hong Kong has been a heated topic in scholarly works and in different forms of popular culture such as film and music, mainly because of the historical mutation in the 1980s and the 1990s. Because of its nature as a visual art, film has become a mainstream form of popular culture which is frequently used to construct or present the cultural identity of a given society or ethnic group. As mentioned above, it is Jackie Chan, together with two other transnational filmmakers, that drew scholarly attention to Hong Kong cinema. Chan has been acknowledged as an international superstar since the 1990 s when his Hollywood movies became box-office hits in the western film market. Therefore, his movies, especially his Hollywood movies, appeal to the scholars who study popular culture. The fact that the cultural identity of Hong Kong and the image of Chineseness in Chan's Hollywood movies is somewhat different from that he portrays in his Hong Kong films arouses the interest of some scholars such as Kwai-Cheung Lo and Jun Wang. In this section, I will attempt to explore how 
other scholars approach Hong Kong's cultural identity portrayed in Jackie Chan's Hong Kong and Hollywood films and whether their findings are consistent with the views of scholars who study Hong Kong culture discussed in chapter III.

In Double Negations: Hong Kong Cultural Identity in Hollywood's Transitional Representations, Kwai-cheung Lo, by examining Jackie Chan's Rush Hour, attempts to illustrate how Hong Kong film stars and directors present their identity in Hollywood films. According to Lo, in the 1990s, the local social reality of Hong Kong is always influenced and determined by the transnational factors rather than the local and cultural elements. He further suggests that the notion of "double negation" could be used to describe the way Hong Kong cultural identity is reconstituted in Hollywood films. He believes that the local identity of Hong Kong is constructed on the basis of the "negation of Chineseness" in Hong Kong cinema, and therefore Hong Kong filmmakers' migrating to Hollywood indicates "another negation that negates the very symbolic realm common to Chineseness" (464). "Double negation" means that the process of negation consists of two negations at the same time, and it is a "negation of negation" (464). On the one hand, in the Chinese cultural symbolic realm, the image of Hong Kong is presented in Hong Kong films as a foreign, mediated and secondary "other," which reflects what Rey Chow claims about the marginalized position of Hong Kong in Chinese discourse. To Lo, that image is constructed through negation of Chineseness 
and looks unreal and artificial, which is well reflected in his claims: "the symbolic Hong Kong subject portrays itself as something beyond Chinese national identity and then holds onto this negative position" (467). It is interesting to note that, in Hong Kong cinema, the mainland Chinese characters are portrayed by Hong Kong film stars in a comic and exaggerated way. Thus, it leads to an unexpected effect: "the audience could both identify with the characters from (an imposed) distance and ridicule them through a sense of cultural affinity" (Lo 470). In fact, the process of negation is a process of otherization through which Hong Kong identity is self-reconstructed. This process is especially acute in the early 1990 s when Hong Kongers prepared to "readdress their Chineseness" (Lo 470) in the historical context. On the other hand, in the non-Chinese cultural symbolic realm, that is, in the Western cultural discourse, the uniqueness of Hong Kong film stars is often disregarded and they are generally positioned to be the characters of mainland Chinese in Hollywood movies, resulting in the negation of the cultural identity of Hong Kong (Lo 466). In Hollywood cinema, the representation of Asians is always insignificant and it is generally considered as a way of digressing from the invariable tension between blacks and whites. When the Hong Kong subject is portrayed in Hollywood, it is "never simply a given-being but a negation of itself other than this given" (Lo 467). In Hollywood cinema, Hong Kong stars are generally cast as "aliens from China or generic Chinese whose cultural origin has no significance to the plot of the film," and what's more, they have to 
"prove themselves more Chinese than the mainland Chinese they are playing" (Lo 470). In a sum, in Hollywood, the malleability of the Hong Kong subject is denied or excluded since Chineseness is a stereotyped and static ethnic image which is assigned by Caucasians to consolidate their dominant position (Lo 470).

Generally speaking, the role a particular film star plays in a movie is often determined by the characteristics of the star himself or herself and "the star effect could have significant repercussion on the characterization itself" (Lo 471). However, in Hollywood cinema, the casting of a Hong Kong film star in a given movie is not completely determined by his or her personal traits but predominantly by the stereotyped image of Chineseness presupposed by Americans which looks strange and estranged to both American and Asian audiences. Like the replicants in Ridley Scott's Blade Runner (1982), Hong Kong film talents in Hollywood cinema encounter a similar dilemma: they may help provide "alibis for the continued domination and exploitation of the western globalizing entertainment industry" (Lo 465). After careful comparison, Lo concludes that Chineseness presented in Hong Kong cinema is an "empty notion without a specific ethnic-object," while in Hollywood movies Chineseness is an "ethnic-object without a proper notion of Chinese national identity" (472). He further explains it by examining Jackie Chan's blockbuster Rush Hour, which was released in Hollywood in 1998. In Rush Hour, "the east-meets-west dichotomy" is portrayed to be the conflict between a "buddy 
relation between an African American and Asian" rather than the "confrontation between a Caucasian and an Asian" (Lo 472). The Hong Kong superstar Jackie Chan plays Detective Lee who goes to Los Angeles to rescue the kidnapped daughter (an allegory of China's future) of Consul Han of People's Republic of China. His mission also involves protecting China's past-the antiques that would be smashed by gangsters in the final confrontation. Thomas Griffin, a former British Commander of the Royal Police Force, who symbolizes the allegorical father and is likely the boss of Lee before 1997, becomes an evil-doer. After analysis, Lo claims that Lee is more subservient and loyal to Consul Han than to the Hong Kong police department. Such a relation between a Hong Kong subject and a Consul of mainland China is a common practice in Hollywood cinema since Hollywood presumed that such a relation would exist after Hong Kong returned to mainland China in 1997. Patriarchy is one of the main clues for the development of the plot as often seen in male-dominated action films. Lee, when he and his black partner Detective James Carter (Chris Tucker) boast about their dead fathers, seems to use the "imaginary father" to "reclaim for his identity in Hollywood" since the "existing father figures are either too weak (in the case of Consul Han) or too wicked (referring to Griffin)" (Lo 474). Compared with the action films produced in Hong Kong, there are less spectacular stunts in Rush Hour. However, western film critics still regard it as Jackie Chan's film. Nevertheless, it evokes a heated debate among Hong Kong audiences on Chan's Hollywood film. 
Many Hong Kong locals hold that Jackie Chan's Hollywood film is mainly designed to cater to the taste of Americans and international audiences. It seems that his representation in the film consciously or unconsciously denies his Hong Kong subjectivity.

Another characteristic of Jackie Chan's film in Hollywood cinema is his persona image. The male roles of racial minority in Hollywood cinema are generally depicted as some kind of "symbolically castrated men" (Lo 474), which is a traditional practice in Hollywood films with racial discourses. As some critics indicate, this kind of representation of racial minority not only imposes no threat to the Caucasian hero but also confirms his sexual domination. It is apparently that, unlike many male Asian film stars involved in Hollywood film productions, Jackie Chan's image in Rush Hour is not effeminized. However, his image is presented in a passive and unfavorable way. Lo claims that "Rush Hour never hesitates to make good fun of so-called 'harmless' Chinese and African American racist jokes" (Lo 475). It is apparent difficult for Hong Kong people to laugh when Lee calls a black, "nigger," like Carter does, to show his friendliness and when Carter says that he has been looking for his "sweet-and-sour chicken ass." Lo argues that is "not for the reason that Hong Kong audiences would be offended by the racist slurs, but for the fact that they do not have a strong enough idea of racial stereotypes in American culture to understand the gags. In other words, their gazing stance could not be structured along racial and ethnic lines" (Lo 475). It is worth noting 
that Jackie Chan's martial art performances in Hollywood cinema are somewhat shifted from those in his Hong Kong films. It is true that Chan's "acrobatic skills and well-choreographed action with cinematographic enlargement are still preserved in the Hollywood production" (Lo 477). However, the death-defying spectacular stunts that help him win high reputation in Asian and Western film markets have been largely reduced. The Hollywood portrayal of Chan is "relatively low-keyed and unglamorous (he combs his hair backward and wears western suits all the time) and conforms more to an ordinary bourgeois middle-aged look, in contrast to his babyish Beatles haircut and casual outfit found in this Hong Kong film, emphasizing his agility, dynamism and vitality" (Lo 477). According to Lo, "Jackie Chan in Hollywood is tied to a body with a lesser sense of becoming-other and is dressed up as a comedian demonstrating cartoon-like kung fu, which is still legible but is arousing less emotional impacts on the spectators. The tradition of Hong Kong action filmmaking is appropriated to meet Hollywood realistic style and racial conventions" (Lo 477). After careful analysis, Lo concludes that a new Hong Kong identity will be reconstructed by encompassing the other. He believes that any foreign elements can be integrated into the local identity since it is established on the basis of an "inherent otherness" (478). He further states that "if negation has once worked for Hong Kong's subjectivization, would we believe that 'negation of negation' is a strategic move for the becoming of a new postcolonial subject leading up to and after 1997" (Lo 478). 
Lo explains that it is sufficient to "say that negation offers no magical transformation; it only indicates that Hong Kong people have to come to terms with a wicked situation, in which they are entirely being integrated into the world of Chinese nation-state and submitted to the ideological universe of the hegemonic west simultaneously" (Lo 478-9).

In Hong Kong Cultural Identity in Jackie Chan's Hong Kong and Hollywood Films, on the basis of the research done by Lo, Jun Wang attempts to justify how Hong Kong cultural identity is depicted in films produced in Hong Kong and in Hollywood by analyzing four of Jackie Chan's films. The four movies involved in his study include Project $A$ (1983) and Who am I? (1998), which are produced in Hong Kong, and Rush Hour (1998) and Shanghai Noon (2000), which are created in Hollywood. Using the method of framing analysis ${ }^{6}$, he employs seven frames including insignificance of cultural origin, exoticness, uptightness, subservience, ignorance, disrespect and downplaying heroism.

Wang holds that Hollywood ignores the cultural identity of Hong Kong, which is well manifested by having China's national flag outside of the Consul but no Hong Kong regional flag in the film Rush Hour. Since the film was produced in 1998, one year after the return of Hong Kong from Britain to mainland China, it seems that Hollywood consciously or unconsciously neglects the historical and political facts. Additional evidence to show that Hollywood ignores the unique cultural identity of Hong Kong is that, to both

\footnotetext{
${ }^{6}$ Framing Analysis: see Jun Wang's "Hong Kong Cultural Identity in Jackie's Hong Kong and Hollywood Movies" and Stephen D. Reese's Framing Public Life: Perspective on Media and Our Understanding of the Social World, $P 7$.
} 
Hong Kong people and mainlanders, it is impossible and impractical for the Consul of People's Republic of China to request a Hong Kong police to rescue Consul Han's kidnapped daughter. Apparently, Hollywood presupposes that Hong Kong and mainland China share the same cultural identity. Hollywood's disregard of the origin of Hong Kong stars involved in Hollywood film productions is also reflected in the following aspects. The origin of those stars seems of no importance to the plot of the film. The film Shanghai Noon has nothing to do with Shanghai. Such a title is given only to arouse the interest of the western audiences since it rhymes with High Noon. That fact that the name of the Chinese character Jiang Wen (Jackie Chan) is given to rhyme with John Wayne, a famous cowboy actor in Hollywood and he has been called the Shanghai Kid by his partner also indicates that the origin of Chinese character is obscure and confused in Hollywood. It seems that in the eyes of Hollywood filmmakers, Hong Kong, Shanghai, and China have the same origin and share the same cultural identity. No matter where the Chinese character in the films comes from, he or she has the same stereotyped image and nature. However, the cultural identity of Hong Kong is reflected clearly and conspicuously in Jackie Chan's Hong Kong movies. Project $A$ is adapted from a true story in Chinese history. In Who Am I, everyone on the helicopter is given a chance to tell his origin before the crash. The exoticness means that Jackie Chan is more like a Chinese in Hollywood films than in Hong Kong cinema. For example, in Project $A$ and Who Am I, he looks like his fellows and never looks unusual. 
However, in Rush Hour and Shanghai Noon, Jackie Chan's face, accent, attire, hairstyle and other features tell that he is an oriental figure, a stereotyped Chineseness presupposed by the Westerners. For example, in Shanghai Noon, the Chinese character played by Jackie Chan wears Qing Dynasty attire and a ponytail and later his ponytail still remains although he changes to wear western style clothes, which reminds him and the audiences of his exotic cultural identity. Nonetheless, the image of Chineseness in Hollywood apparently neglects the uniqueness of Hong Kong and distorts the cultural identity of Hong Kong.

Uptightness is another feature in Jackie Chan's Hollywood movies. In both Rush Hour and Shanghai Noon, Jackie Chan is concerned with only how to rescue his Chinese fellows and never knows how to relax himself. He seldom changes his ridiculous suit and hair style and looks nervous all the time. However, in his Hong Kong films Project $A$ and Who Am I, Jackie Chan is a funny, humorous and witty guy. He knows how to relax himself and entertain the audience. For example, the bike-chasing and nude soldiers' bathing scenes in Project $A$ showcase his humor.

The fourth feature of Jackie Chan's roles in Hollywood films is subservience. In Hollywood movies, Jackie Chan always presents a subservient attitude towards his superior or authority. For example, in Rush Hour, he dares not insist on his warning of a bomb explosion even though he knows he is right. He is even more submissive in Shanghai Noon when he 
kowtows to the twelve-year-old emperor and the princess while in Hong Kong movies Jackie Chan is always a brave, independent and fearless figure. He never hesitates to refute his authority even when it means he will be punished for his behavior which is well demonstrated in Project $A$ when he yells to Colonel Mei, his superior, the highest Hong Kong police authority, also the representative of the British colonizer. Wang assumes that Jackie Chan's challenge to his superior may symbolically mean a challenge or resistance to the Western hegemony.

Ignorance is another word Wang uses to describe Hollywood's portrayal of Jackie Chan's roles. In Hollywood movies, the Chinese character played by Jackie Chan is often slightly ignored. The insignificance or ignorance is well manifested by the embarrassed or awkward situations caused by his incompetent language and lack of western culture, especially when he tries to befriend the black by saying "What's up, nigger," which he learns from his black partner Carter in Rush Hour. Yet in Hong Kong films such as Project $A$ and Who Am I, Jackie Chan's roles are depicted as sophisticated, witty and agile figures.

The sixth feature of Jackie Chan's roles depicted in Hollywood cinema is disrespect. Hollywood films always make fun of racial minorities which is well exemplified by O'Bannon's mispronunciation of the name of Jiang Wen (Jackie Chan) in Shanghai Noon and Carter's calling Lee "sweet-and-sour-chicken ass." However, in Hong Kong movies, Jackie Chan often shows respect for 
other cultures as demonstrated in Who Am / when he shows his understanding and respect for the natives' respect for the dead.

The last word Wang uses to describe Hollywood's portrayal of Jackie Chan's roles is downplaying heroism. He claims that in Hong Kong movies Jackie Chan is generally portrayed as a hero and his death-defying stunts are fully exhibited. For example, in Project $A$, the role he played is the center of the story, and he accomplishes a tough task by himself. However, in Hollywood film, his brilliant and adventurous stunts are somewhat downplayed in order not to pose a threat to the Western's dominance and masculinity. What's more, there are almost no beautiful girls around him in Hollywood films, which is unusual in his Hong Kong movies.

From the discussion of the aforementioned research on the cultural identity of Hong Kong reflected in Jackie Chan's films, we can safely draw the conclusion that the film resources used by these scholars in their research are limited and insufficient. Thus they fail to give a comprehensive analysis of Jackie Chan's films produced both in Hong Kong and Hollywood. Furthermore, they fail to consider the influences of such factors as the time of the production of the films as well as cultural, economic and political situations in the society. These factors may have some connections with the way Hong Kong local cinema and Hollywood cinema represent or construct the cultural identity of Hong Kong. However, the most important insufficiency in the above research is that those scholars fail to take into consideration the historical transition-the 
return of Hong Kong from Britain to mainland China in 1997. There may be some differences in the representation of Hong Kong cultural identity in Jackie Chan's films produced in Hong Kong and Hollywood films since cultural identity is changing all the time. 


\section{CHAPTER V}

\section{JACKIE CHAN'S HONG KONG FILMS}

Since his debut in Hong Kong cinema in the 1960s, Jackie Chan has produced or participated in more than one hundred films. In fact, his success in the Hong Kong film industry began in the late 1970s when he was involved in two of Yuen Woo-ping's films released in 1978 Snake in the Eagle's Shadow/Shexing Diaoshou and Drunken Master/Zui Quan, after the director Luo Wei failed to feature him as "a Bruce Lee clone" in the movies such as New Fist of Fury/Xin Jingwu Men (1976), The Magnificent Bodyguard/Feidu Juanyun Shan (1978) and Dragon FistLong Quan (1979) (Teo 123). Since then, Jackie Chan's popularity has been phenomenal in Hong Kong, mainland China, Japan and other Asian countries and areas, mainly because of his emphasis of "versatility in play-acting, displaying facets of both clown and master" in his martial arts movies (Teo 122). It seems no one doubts the success of Jackie Chan in Hong Kong cinema. Stephen Teo believes that Jackie Chan's success in martial arts movies lies in his "unique way of keeping the genre interesting and relevant to audiences" as well as his "adhering to a mainstream generic formula" (122). He further argues that "Chan's movies in 
the 80 s were practically alone in preserving Bruce Lee's tradition of kung fu as an instinctive but disciplined art linked to a cultural and national identity" and Chan continues to follow Bruce Lee's "espousal of kung fu" as the "overtones of nationalism" (122).

In this chapter, I will attempt to explore how the cultural identity of Hong Kong is reflected in Jackie Chan's Hong Kong films. The films discussed in this chapter are categorized into two groups: group I includes films produced before 1997 and group II is composed of the films produced after 1997.

\section{JACKIE CHAN'S HONG KONG FILMS PRODUCED BEFORE 1997}

Generally speaking, the films included in Group I are relatively more light-hearted and attach more importance to the entertainment function and visual effect than those included in Group II. The major theme of these movies is "good predominates over evil" and "justice outdoes injustice." In the Drunken Master series, Jackie Chan successfully creates a kung fu kid image. In these films and also in his other films, Jackie Chan is "really showing that kung fu is timeless and that when practiced with humour, charm and precision, it is a force unto itself" (Teo 133). Another feature is that movies about police and gangsters or related to this theme are always Jackie Chan's favorites. For example, in both the Project $A$ series and Police Story series Chan acts as a policeman. In Project $A$ II, Jackie Chan, a captain of marine force in the late 
Qing dynasty, leads his fellow men valiantly and stalwartly to struggle with a gang of vengeful pirates. Although the plots and settings of the above films are apparently different from each other in many respects, and the figures in these movies represent different professions with different personalities, Jackie Chan always presents to the audiences a masculine, brave, intelligent, confident, courageous, and sometimes humorous figure with skillful martial arts and swift action. Moreover, there are more often than not charming girls or ladies around him. When confronted with divarication with his superiors, even his British officer, for example, in Project $A$ II, he will confidently and fearlessly speak out his own ideas and even defy them without worrying about being punished. He knows what to do and how to do things, and always behaves justly, appropriately and heroically. The most import point is that the heroes of the films in Group I invariably never think about or worry about their identity.

Drunken Master I (1978) is believed to be the first film that brought Jackie Chan great success and high reputation and laid a firm foundation for his position as a superstar in Hong Kong cinema. In this film, Chan plays the young Huang Feihong ${ }^{7}$. Huang is such a naughty boy and troublemaker that his father invites his old friend Su Huazi (Yuan Xiaotian) to discipline his son. At the beginning, however, Huang is reluctant and even feels scared to learn kung fu from the grizzled old drunk. So he tries every means to make fun of the old man and escape from learning or being punished. But later, when he finally

\footnotetext{
${ }^{7}$ Huang Feihong: a legendary character of old Cantonese movies. Born in Canton in 1847, Huang was sort of a Chinese Robin Hood--a master of Hung Gar boxing, a teacher, and a physician, dedicated to helping the poor and downtrodden (See Chan and Yang 335).
} 
understands that it is impossible for him to punish the villains with his kung fu, he begins to seriously learn Su's techniques of drunken kung fu which is styled after the Eight Immortals. When Huang's father knows the local villain $\mathrm{Li}$ Wanhao plans to secretly sell a local colliery to the Japanese, Li hires a killer to kill him. In the final duel, Huang, making full use of all the styles in his drunken kung fu, eventually defeats the mercenary killer. In this film, Chan is encouraged to go overboard with his fool characterization. Therefore, the persona Huang Feihong is presented to the audiences by Chan as a clown-like and mischievous kung fu kid who is "relied upon in dire situations to save the day," a persona which he portrays for several years in his later movies such as "The Fearless Hyena/Xiao Quan Guaizhao (1979), The Young Master/Shidi Chuma (1980) and Dragon Lord/Long Shaoye (1982)" ( Teo 124).

Fourteen years later, Jackie Chan, realizing his failure of shifting from comic personae to dramatic ones, reprises the mischievous and troublemaking kung fu kid in Drunken Master II/Zuiquan /I (1994). Chan still focuses on Huang Feihong's drunken kung fu fighting in the new film and presents to the audiences the same persona, a young mischief-maker Huang Feihong, with almost no variations in his new interpretation of the character. The story tells about how Huang prevents a gang of kung fu ruffians from smuggling the antiques, a seal of the emperors and other national treasure, colluding with some foreign consular officials. The seal of the emperors accidently fell into the hands of Huang, who decides to try his best to protect the item with historic 
importance from falling into the hands of the foreigners and those Chinese kung fu ruffians. It is worth noting that Huang always wears a Chinese robe while the ruffians wear Western suits, which I assume to symbolize the ruffians' betrayal of Chinese culture even by looking at their appearances and Huang's loyalty to Chinese culture. In the final duel that takes place in a steel factory, Huang, who symbolizing a typical Chinese with traditional ideology and patriotism, defeats those Western-inclined ruffians by combining masochism and ballet skills with his drunken kung fu. The kung fu kid in the Drunken Master series brings Chan success and high reputation, which lasts for many years. As Teo says, by playing Huang like the clown in Drunken Master I (1978), Chan "may have resorted to playing it safe, but the formula of broad comedy, echoed in Anita Mui's performance as Chan's comic sidekick, and spectacular kung fu stunts have maintained Chan's star in Hong Kong cinema for nearly two decades." He further argues that the formula of broad comedy that Chan retains in his performances may be or has been criticized by critics; however, his "personal style and his attempts at dramatic characterizations are mitigating factors distinguishing a genre all too often consigned to the trash bin of cinematic criticism" (Teo 133).

In Project A/A Jihua (1982), Jackie Chan portrays Sergeant Ma Rulong of the Hong Kong Marine Police who leads his fellow policemen to wipe out pirates active in Hong Kong's outlying islands. With the police vessels destroyed by the pirates and no boats and support from the government, the 
Marine Police have to regroup into the ground force. Although there are always competition and conflicts between the land force and the marine force, they finally cooperate with each other to destroy the pirates. Project $A$ can be said a turning point for Jackie Chan's performances and his career development. On the one hand, Chan tries to challenge his previous performances. In Project $A$, which is believed to be a male-dominated and ingenuously patriotic film, Chan attempts to integrate kung fu with narratives, which is a little bit different from his previous films. He still portrays the character as a clown-like and mischievous person, but the difference between his new way of performing is that he makes the hero an optimistic one, who persistently tries to participate in Hong Kong's social development. On the other hand, Chan's career moves to a new level. With Project $A$, Chan shifts from a kung fu actor to "multi-hyphenated film-maker (actor-stuntman-director-stunt coordinator-kung fu choreographer)" (Teo 126).

In Project A II/A Jihua Xuji (1987), sergeant Ma Rulong, now the head of the Western District Police Department, together with his fellow policemen, has to be faced with a tough task: wipe out the crime and corruption in the police department and maintain social security. Instead of a male-dominated film, Project $A$ II, in addition to some survivals of the pirates defeated by Chan's marine and land forces, has some pretty patriotic young women who are trying to raise money to overthrow the Qing Dynasty. A corrupt Hong Kong police inspector is hired by the agents of the Qing government to prevent the patriotic 
young women from establishing a revolutionary base in Hong Kong. In the end, Ma helps those revolutionary young women escape from the persecution of the agents of the Qing Dynasty. In fact, Project $A$ // strengthens Jackie Chan's position as a superstar in Hong Kong cinema in the 1980s. His success lies in the following achievements he accomplished in this film. Compared with Project $A$ / and Chan's other previous films which focus more on mere martial arts, Project $A / /$ is more narrative and the plots are more complicated and twisted. Another achievement of Chan in this film is that he creates a new screen persona. He is no longer a mischievous troublemaker, but a hero with confidence, honesty and loyalty. Moreover, in this film there are political statements interpreted allegorically by using historical events, which is unusual in Jackie Chan's previous films, indicating that Jackie Chan begins to attach importance to the contents and depth of the films. Teo believes that Project $A$ /I is a film that well demonstrates "the clearest perspective" of "Chan's own personality" and his loyalty to Hong Kong" and his "attachment to China" $(127-8)$. On the one hand, he never swerves his sworn allegiance to Hong Kong under His Majesty's Government, as is reflected in the film when Sergeant Ma resists the temptation of those beautiful girls and the corrupted police inspector and refuses to join the revolutionary cause for a better China because of his conviction that politics is not his line. On the other hand, he knows how to stand on the right side of the history, which is manifested by sergeant Ma's saving those revolutionary girls to show his support for the 
anti-Qing revolutionaries. Chan's fluctuation between his loyalty to Hong Kong and his attachment to China demonstrated in Project $A$ II, a film which Teo believes to be Chan's "love letter to the territory," works as "allegory of Hong Kong's 1997 dilemma" (Teo 127-8).

In the Police Story series, which includes Police Story (1985), Police Story II (1988), Police Story III-Super Cop (1992) and Police Story IV-First Strike (1996), Jackie Chan successfully creates a police hero, Chen Jiaju. The Police Story series are more narrative and dramatic and have more complicated plots than those of his previous films. The plots, the characterization of the protagonists and the stunts of the four films are also different from each other, with increasing intricacy, detailed narrations and dramatic climaxes, and exciting and dangerous scenes. And the settings of the films are increasingly internationalized. The first two Police Story films center on the story between sergeant Chen Jiaju and the drug kingpin Zhu Tao, including his minions and the settings of the films are in Hong Kong. In Police Story III-Super Cop, sergeant Chen Jiaju's task involves infiltrating a drug kingpin's operation in China, Thailand and Malaysia. However, in Police Story IV-First Strike, sergeant Chen Jiaju is assigned to investigate an international nuclear weapon dealer, and the settings move to Ukraine and Australia.

In Police Story (1985), Jackie Chan continues to present to the audiences a similar but more mature persona he creates in Project $A l$. The plot centers on how Sergeant Chen Jiaju protects the witness Salina, a secretary of the 
drug kingpin Zhu Tao. After Zhu is freed from the court because of insufficient proof, he frames up against Chen who later becomes a wanted fugitive because of the murder of a policeman. Chen finally helps the police arrest Zhu and proves his innocence with the help of Salina. Police Story is widely accepted as a masterpiece of Jackie Chan's works. It is also regarded as a milestone for the action films of Hong Kong cinema. The success of this film lies in that Jackie Chan shifts from the comic and mischievous kung fu kid to an image of police hero and integrates more emotional elements into the narrative. For example, Chen shows excessive confidence and optimism when protecting Salina. When he brings her home, he boasts in front of Salina to show his attractiveness and androcentrism without knowing the presence of his girlfriend, May (Maggie Cheung), which results in the misunderstanding between them. Moreover, the plot of the film is more narrative and dramatic, which is reflected in several unexpected climaxes such as the unexpected release of Zhu and Chen's becoming a wanted murder. The film also becomes a start for Jackie Chan to do dangerous stunts all by himself in his later films, which is his unique way of film production. One of the dangerous but exciting scenes is "a breathtaking stunt in which Chan slides down a cable wired up with bulbs and light displays-which explode from the force of the slide," and "lands many floors down to capture the chief villain, " which is "incumbent" for "any critic to point out that Jacky Chan did all his own stunts" (Teo 128). The stunts in Police Story are so impressive that some American action stars such 
as Sylvester Stallone copy some scenes from this film "practically shot for shot" (Chan and Yang 343). With this film, Jackie Chan won the Best Picture, Hong Kong Film Awards and other awards in 1985.

In Police Story II/Jingcha Gushi Xuji (1988), Sergeant Chen Jiaju (Jackie Chan) is forced to resign his job because of his brutality against Zhu's followers, but is summoned back to deal with a terrorists' bombing case when he is leaving for holiday with his girlfriend May. In this film, Jackie Chan makes some changes in his presentation of the persona: he attempts to pay much attention to the innermost thinking of the sergeant Chen Jiaju as well as to caricature the character. Police Story II inherits Chan's style: the plot of the film is simple and the film still focuses on the exciting and dangerous fighting and chasing.

Jackie Chan makes great achievements in producing his third Police Story series. In Police Story III: Super Cop (1992), sergeant Chen Jiaju has to disguise himself as a criminal to win the drug dealers' trust, which makes himself in a danger all the time. In this film, Jackie Chan performs his most daring stunts. The exciting yet dangerous stunts range from speeding cars or motorcycles to moving trains and flying helicopters. What makes it amazing is that the stunts are coordinated with one another other with great precision and seamlessness. Although Chan gives "all this usual verve and aplomb" without offering any surprise in the "interpretation of his old character," Police Story III is still regarded as a "contemporary kung fu classic," and a film that makes the 
"action effects and stuntwork come of age in Hong Kong cinema" (Teo 132). The film proves that "Hong Kong's action genre, in the right hands, is not only the most dynamic of all action genres in the world" but also "the most graceful, the most balletic" (Teo 132). Jackie Chan wins "the Best Actor award in Taiwan for this film—a first for an action film star," which indicates that he is "acknowledged for more than" his "fighting and stuntwork" (Chan and Yang 351).

Jackie Chan's Police Story-First Strike (1996) centers on sergeant Chen Jiaju's investigation on a group of nuclear weapon dealers. At the very beginning, both Chen and his partner believe that it is a very simple task that enables them to enjoy the exotic sceneries. However, it turns out to be an

unexpected dangerous one. Jackie Chan continues to follow his style of making action films: he takes great pains to win and cater to the audiences, without worrying about his safety. Compared with his previous Police Story films, this film's settings are moved to other countries, which add more exotic elements in the film.

\section{JACKIE CHAN'S HONG KONG FILMS PRODUCED AFTER 1997}

However, the plots, the personalities of the heroes and the relationships between the figures in the films of Group II are more complicated than those in the films included in Group I. The heroes in these films are often perplexed by 
various factors such as the uncertainty or anxiety of their social status, values, their life and future, especially their cultural identity. Among them, Who Am I can be said the most representative one.

In Who Am I (1998), Jackie Chan plays a member of a multinational commando team working for the ClA. After Jackie and his team accomplish their mission in the African Jungle, they are betrayed by CIA operative Morgan. Only Jackie survives and saved by a native tribe. But he is suffering from total amnesia and doesn't know who he is. He repeatedly asks "Who am I?" therefore he is called "Who am I" by the tribe. The discovery of the helicopter wreckage makes him start a journey to find his true identity. Struggling to piece together his disjoined memories, Chan has to be faced with the assassination of Morgan and fight with local thugs. During his journey to search for his true identity, he repeatedly cries out "Who am I?" as he feels lonely, anxious and helpless, especially when he is in the wild forest and among the aborigines and nobody can be counted on or trusted.

Gorgeous (1999) marks a conscientious change of Jackie Chan after he succeeds in Hollywood. Gorgeous (1999), a romantic love story, tells about the journey of a Taiwanese village girl A Bu (Shu Qi) to seek true love. After she finds a romantic message in a bottle, which says "I'm waiting for you. A Bai," $A$ Bu decides to fly to Hong Kong to look for her Mr. Right. When she is in Hong Kong, she is disappointed to find out that A Bai is gay. Bu she still wants to stay in Hong Kong to make her dream come true. One day she accidentally saves a 
Hong Kong businessman and playboy Chen Ziwu (Jackie Chan) who is chased after by his rival in business. After several twists and turns, Chen finally gives up his playboy lifestyle and falls in love with A Bu. Gorgeous, a label for Jackie Chan's conscious change, is the first Chinese film he made after Jackie Chan successfully marches into Hollywood. It is not a typical Jackie Chan action movie but a romantic comedy with some fight scenes. With this film, Chan expects to have a break through in his career.

Chan's New Police Story (2004) seemingly tells about fraternity love and romantic love. This film is not Chan's action comedy style, but a feature film with actions. In this film, Chan plays a personified policeman, Chen Guorong, a figure which is totally different from his previous "super hero" image. Chen is a legendary figure of the police whose case-solving rate is up to $100 \%$. A group of five young criminals is headed by $\mathrm{Zu}(\mathrm{Wu}$ Yanzu), whose father is a Chief Inspector of the Northern Section of the Police. After robbing a bank, they press the alarm voluntarily to challenge the police. Chen has to be fight back within three hours with nine elite policemen. However, they are all killed by the young gangsters, including the brother of Chen's girlfriend. From then on, Chen gets drunk everyday. Feng (Xie Tingfeng) is an out-and-out big talk king. Though he is not eligible to be a policeman because his family has a criminal background, he dreams of acting as the incarnation of justice all day. Finally, with the help of Feng, who pretends to be the new partner appointed by Chen's superior, Chen resumes his fighting spirit, the true quality of a hero. 
The Myth (2005) is also a love story and a new challenge for Jackie Chan because he has to fight on a horse, which is unusual for him. In this film, Chan plays a modern archaeologist and a general of the Qing Dynasty respectively. The archaeologist and his partner enter an ancient tomb, finding a portrait of a princess (Jin Xishan). He is shocked to see that the princess resembles the woman constantly appearing in his dream. In order to figure out the relation between the dream and the reality, the archaeologist begins his journey to seek for the dreamland. He miraculously finds the site of the legendary tomb for the emperor of the Qing Dynasty. The general in his dream is Mengxin whose mission is to protect the princess to the Qing Dynasty. But on their way to the palace, Mengxin and the princess fall in love with each other. When Mengxin learns that the emperor is seriously ill and the princess will be probably put to death while entering the palace, he risks his life to look for elixir to save the princess but unexpectedly fights dead in a battle. The princess tries the elixir and succeeds, but the treacherous court official gives the emperor a false medicine. After the death of the emperor, the princess is imprisoned in the tomb of the emperor. When the archaeologist enters the tomb, the immortal princess, who has been waiting a millennium, finally meets her reincarnated lover.

Chan's Rob-B-Hood is produced in 2006. It tells the story of Renzituo (Jackie Chan) who is smart and swift-handed but misuses his talent. Renzituo steals and robs, having no goals in his life, indulging in gambles all day and 
being estranged with his family. Unexpectedly, a baby, the only grandchild of the richest woman in the city, a ready source of money for Renzituo and other two gangsters, brings him into trouble. But that also becomes a turning point of his life, since the three thieves' consciences are awakened when they get along with the baby. 


\section{CHAPTER VI}

\section{JACKIE CHAN'S HOLLYWOOD FILMS}

The success of Jackie Chan in Hong Kong cinema draws the attention of the Western filmmakers and wins popularity with Western audiences. But Chan is not so successful with his Hollywood films produced in the 1980 s in the Western film market. In Hong Kong cinema, as he once described himself to his western interviewer, "In Asia, I am Jurassic Park. I am ET" (Dannen and Long 3), Jackie Chan, who is used to improvising actions or stunts in all his performances, directs his "own stunts," and always has the "freedom to shape the intricate dance that made up a fighting sequence" even when he is not the director or action choreographer. However, in Hollywood cinema, the stunts and actions are designed by western action choreographers. For example, the director, Robert Clouse, scripts and storyboards "every scene in advance," "deciding exactly where the cameras would be placed and how the action would move." Clouse's way of directing works well with Bruce Lee, whose martial arts is "tightly controlled" but not with Chan, whose style is "wider, more open, and acrobatic" (Chan and Yang 257-8). Chan is also not satisfied with these films. Therefore, Chan refocuses on the Hong Kong cinema. 
However, Chan's extraordinary success in Hong Kong cinema in the 1990s reignites Hollywood's interests in Chan's action films. Rush Hour (1998) is his first strike after his failure in the Western film market a decade before. When talking about Rush Hour, Gail Mihara says:

In 1985 a disastrous film known as "The Protector" accomplished something that twisted limbs, cracked ribs and a hole in the head couldn't do-it caused Jackie Chan to give up. The failure of that film led him to write off the American market and leave Hollywood, vowing never to return. He did return, of course, in 1996 with the release of "Rumble in the Bronx." However, despite this and subsequent successes, Jackie has yet to become a household name. No doubt that will change in light of the $\$ 33$ million opening of his first American film in over a decade, "Rush Hour" (qtd. in Kooper and Mike 41).

Chan's winsome, inimitable and unequaled stunts and actions were showcased to best advantage in his leading role in Rush Hour released in 1998, which turned out to be the box-office hit of that year. Thereafter, Chan successfully enters the international market, involves more film productions than before and finally becomes a transnational superstar. 


\section{JACKIE CHAN'S HOLLYWOOD FILMS PRODUCED BEFORE 1997}

Chan's first attempt in the American film market is Battle Creek Brawl/The Big Brawl (1980). A Long (Jackie Chan), whose father runs a restaurant in Chicago in the 1930s, is forced to fight in a Texas freestyle brawling contest by the local godfather Dominic (Jose Ferrer) because Dominic kidnaps the fiancée of Chan's brother. Chan's Chinese kung fu is thus contrasted with Western pugilism and wrestling in this film. Unfortunately, it seems that Chan's mischievous and funny actions were not accepted by American audiences, who expected to see Bruce Lee's vigorous and valiant style.

Jackie Chan plays "bumbling Japanese" race car driver, a small and ridiculous role, in Cannonball Run (1980) and Cannonball Run I/ (1983), which are based on the real "Cannonball Sea to Shining Sea" race (Chan and Yang 337). These two films achieve box-office hit in America and Japan but not in Hong Kong, because Hong Kong audiences don't want to see him "as part of an ensemble of American stars" and they also don't want to see "Chinese people being made to look ridiculous" (Chan and Yang 265).

The Protector (1985) tells about a Chinese-American cop, Billy Wong, going to Hong Kong with his American partner to rescue an American girl who is kidnapped by a group of Hong Kong drug dealers. The film "looks surprisingly like a made-to-order Hong Kong kung fu action movies" and Chan's "do-it-yourself stunt work is remarkable." However, like other 
Hollywood thrillers, the film is full of guns and chasing scenes, indicating that "Western directors still could not understand the premise of kung fu action" (Teo 130).

Jackie Chan didn't earn the same success in the film market of the United States in the 1980s as he did in Asia, but he did impress Hollywood in some aspects, as Teo commented:

Try as he might, Chan could not duplicate Lee's success in becoming a household name in America. But his influence and that of Hong Kong cinema's kung fu genre on certain contemporary action stars in America are not negligible, as can be seen in the performances of Jean-Claude Van Damme or Steven Seagal (123)

\section{JACKIE CHAN'S HOLLYWOOD FILMS PRODUCED AFTER 1997}

The release of Rush Hour in 1998 brings Jackie Chan high reputation and box-office success in the Western film market, which leads to productions of his Rush Hour II (2001) Rush Hour III (2007) and other Hollywood films such as Shanghai Noon (2000), Shanghai Knights (2003) and Tuxedo (2002).

Rush Hour series are involved in the investigation carried out by Hong Kong inspector Lee (Jackie Chan) and a black LAPD detective named Carter (Chris Tucker). In Rush Hour (1998), Lee is summoned to rescue the daughter of the Chinese Consul Han (Tzi Ma), who is kidnapped by Juntao, a vicious 
crime lord. The LAPD detective Carter is called on by the FBI to keep Lee from meddling in the case. However, Lee and Carter finally cooperate with each other and crack the case themselves. The settings of Rush Hour II (2001) move to Hong Kong and then back to U.S. While they enjoy their wonderful vacation in Lee's hometown, Lee and Carter soon have to engage in an investigation of bombing case. The U.S. consulate is blown up and two U.S. customs officials are killed in the explosion. The reason may be because they are responsible for a case of smuggling surprisingly realistic but fake US currency. Lee soon devotes himself into the investigation. However, his investigation is interfered with by agents of the U.S. secret service who believe that it is their case. When knowing that Triad bigwig Ricky Tan (John Lone) and the deadly Hu Li (Ziyi Zhang) might have something to do with the bombing, Lee and Carter begin to chase after the mobster. After successfully teaming up in cracking two transnational cases, in Rush Hour III, Carter and Lee head from Los Angeles to Paris to track down Chinese triads. One of their missions is to protect a French woman named Geneviève since she knows the triads' secret leaders. It turns out that the names of thirteen triads' leaders have been tattooed on the back of the head of Geneviève. But Lee has to exchange Geneviève for Soo-yung, consul Han's daughter, who is captured by Kenji, Lee's Japanese stepbrother.

However, in Shanghai Noon and Shanghai Knights, Chan's partner is changed from a black to a white and Chan's identity is changed from a modern 
policeman to an imperial guard to the emperor of the Qing dynasty of China. In Shanghai Noon, Chan plays Chon Wang, who goes to the American west to rescue the princess kidnapped by Lo Fong (Roger Yuan). Lo is the previous head of the imperial guards, who is regarded as a traitor by the Chinese. He contrives a plot to kidnap Peipei (Lucy Liu), the Princess of the Qing Dynasty, from the Forbidden City, and takes her to the desolate American west. The Chinese emperor has to pay a huge ransom. Wang insists on going to the American west with other imperial guards to rescue the princess. On his way, he gets to know a bandit named Roy O'Bannon (Owen Wilson) and reluctantly teams up with him to the west. In Shanghai Knights, when Chon Wang learns that his father is killed and the Imperial Seal of the Qing Dynasty is disappeared, he rages and promises to revenge for his father and get the Imperial Seal back. With the help of his sister Lin (Wenfang Fan), Wang learns that the killer is hidden in England. Therefore, Wang and Roy head for the unfamiliar land. However, they are shocked to learn that the two traitors of Britain and China allies to overthrow the emperors of Britain and China. Wang decides to stop the plot while Roy only thinks of pursuing Wang's sister.

Chan plays Jimmy Tong, a chauffeur for millionaire Clark Devlin, in Tuxedo. After Devlin is unexpectedly injured in an explosion, Tong unwittingly dons Devlin's tuxedo and finds that he has extraordinary power with this suit. However, it also thrusts him into dangers and adventures, especially with a female partner who is even more inexperienced than himself. 


\section{CHAPTER VII}

\section{POSTCOLONIAL AND NEW HISTORICAL READINGS OF JACKIE CHAN'S HONG KONG AND HOLLYWOOD FILMS}

Through an analysis of all twenty three Jackie Chan movies listed in Groups I, II, III and IV, although some similarities may exist, I find that the cultural identity of Hong Kong reflected in these films exhibits different features.

In all of Jackie Chan's Hong Kong films produced before 1997, he endeavors to exhibit and disseminate traditional Chinese ideology, arousing and fostering nationalism and patriotism by creating such images as a mischievous but righteous kung fu kid and a valiant Hong Kong policeman. However, compared with his films produced before 1984, the cultural identity of Hong Kong reflected in Chan's Hong Kong films produced after 1984 and before 1997 take on some different features. The representative personae include the troublemaking kung fu kid Huang Feihong in the Drunken Master series, the sergeant Ma Rulong in the Project $A$ series, and the heroic Hong Kong policeman Chen Jiaju in the Police Story series. Needless to say, he has to strike the correct balance when he makes films with such a purpose. On the 
one hand, he has to satisfy the tastes of the audience to achieve financial success. Therefore, in general, Chan's Hong Kong films produced before the handover, which are included in Group I, mainly focus on traditional entertainment functions. The plots are simple, and the characterization of the protagonists is designed mainly to cater to the tastes of the audience to attain box-office success. The most representative example is Drunken Master (1978). The naughty persona in this film, the young Huang Feihong, is particularly designed by Yuen Woo-ping for Jackie Chan to capture the attention of the viewers after Lo Wei failed to clone him into another Bruce Lee. The kung fu kid created by Jackie Chan in this film is so mischievous that he teases his fellow apprentice, flirts with a girl in the street in a funny and unexpected way, avoids punishment smartly and even makes fun of his kung fu master. The film became a box-office hit as expected and contributed significantly to Jackie Chan's reputation as a superstar in Hong Kong cinema and later in the international film market.

On the other hand, however, Chan carries forward and eulogizes traditional Chinese ideology and cultivates a Chinese spirit and nationalism directly or indirectly through the images of the kung fu kid and Hong Kong policeman. For example, Huang Feihong is also a righteous hero who wins respect and popularity among people, because he often defends others against injustice and helps the weak and those who do just things for society or country. In Drunken Master (1978), when the young Huang Feihong sees a 
man bullied by a villain, he offers his help without hesitation.

In Project A /I (1987), when the female revolutionary says:

…满清政府的腐败无能已经海的我们国家民穷财尽，使得中国人变成 世界上的“二等民族。”要想救中国，要在外国人面前抬起头来，要想 所有的中国人都有好日子过, 就一定要支持革命、推翻满清政府...[The corrupted and impuissant Qing dynasty has led to the poverty of our country and our people and degraded the Chinese to a "second-class nation." In order to save China and stand proudly in the face of foreigners, and to guarantee every a comfortable life, we should support the revolutionary cause and overthrow the Qing Dynasty]"

The sergeant Ma Rulong is so moved by these words that he voluntarily buys the "爱国花[patriotic flower]" from the female revolutionary to show his support for the revolution. His behavior influences his fellow policemen immediately who also buy the flowers to show their support. There is no doubt that such scenes will deeply impress the audience and arouse their nationalism and patriotism.

Furthermore, in Drunken Master II, when Huang figures out that the British consulate tried to loot the imperial seal of China and exhibit it in the British Museum, there is a long conversation between a male revolutionary and Huang. When Huang says: “中国历代到现在有几十个玉胥，少个玉尔有什 么大不了的[there are dozens of imperial seals from the dynasty in ancient 
China to the present, so it doesn't weigh much if we lose one]," the revolutionary answers as follows:

玉䨟是中国王朝的象征。今天抢玉胥，如果你不制止，明天就会拆你 的长城...八国联军攻入北京，就是想要中国这块肥肉。弱肉强食，你 自己不振作，人家还跟你客气什么。有强权没公理这是必然的。有骨 气人家才会尊重你，人必自污而后人污之...[the imperial seal is the symbol of the Chinese dynasty. If you do not stop them when you see them looting your imperial seal today, then they will destroy your Great Wall... The goal of the Eight-Power Allied Forces ${ }^{8}$, invasion into Beijing is to occupy China, a fat prize for them. We should remember the law of the jungle-if you do not stir yourself, nobody will respect you. It will happen consequentially if "might is right" still exists. You will be respected if you have honor. Otherwise, you will be looked down upon if you look down upon yourself].

Undoubtedly, what the male revolutionary says educates and enlightens Huang, and makes him realize the significance of getting back the imperial seal of China, which means nothing or little to him at the very beginning. Consequentially, the audience identifies with the main characters when hearing such impassioned and impressive statements. The patriotism and nationalism underlying these words will be disseminated among them and

\footnotetext{
${ }^{8}$ Eight-Power Allied Forces: In 1900, the troops of the Eight Allied Powers, including Germany, Japan, Britain, Russia, France, the United States, Italy and Austria, killed, burned and looted in China. They razed Tanggu, a town of 50,000 residents, to utter ruins, reducing Tianjin's population from $1,000,000 \mathrm{one}$ million to 100,000 . They killed countless people when they entered Beijing. (See Overseas Chinese Language and Culture Education Online 中国华文教育网)
} 
rejuvenate their national spirit.

As mentioned above, Jackie Chan's post-1984 films exhibit defining and unique features. The plots of these films are more complicated, narrative, dramatic and well organized, and the stunts are more kinetic, exciting and realistic. But what matters most is that, in addition to "preserving Bruce Lee's tradition of kung fu as instinctive but disciplined art linked to a cultural and national identity" (Teo 122), Chan integrates social, political and cultural factors into his films. This change indicates that Chan consciously or unconsciously focused more on social development, political and cultural changes in the society than ever before. It also implies that the changes in social, political and cultural aspects attracted more attention from the Hong Kongers.

First of all, Chan's Hong Kong films produced after 1984 and before 1997 reflect the nostalgia of Hong Kongers' yearning for the glorious past in light of the upcoming return of Hong Kong to mainland China in 1997. One of the representative films is Drunken Master // (1994). The film emphasizes the superiority of the Western world, which seems to be away from Hong Kong and Hong Kongers after 1997, as many Hong Kongers perceived. When Huang Feihong enters the exclusive train carriage for the staff of the British consulate to get his belongings back, he is surprised to see a different world: the carriage is quiet, clean, comfortable, spacious and well decorated, and the ladies and gentlemen are elegant, neatly dressed, and well-behaved; however, the carriage for the Chinese is crowded, noisy, dirty, uncomfortable, poorly 
decorated, and the people there are dowdy and rude. The sharp and clear contrast between the Westerners and the Easterners makes him stand there agape with wonder and takes his breath away. When Huang is attacked by the hired roughneck of the British consulate, he accidentally drinks XO (extra old French brandy) instead of the traditional Chinese alcohol which he uses to perform his unique kung fu technique. He asks his stepmother what alcohol it is and she shouts loudly to him and the crowd, and at the end of the fight he once again mentions the $\mathrm{XO}$ with praise. All the above scenes unavoidably impress the audience with the superiority of the Western world over the Eastern, implying Hong Kongers' yearning for a golden colonial past.

Chan's Hong Kong films of this period also integrate some political opinions, indicating Hong Kongers' political consciousness. In Drunken Master II, after Huang helps the revolutionary escape the persecution of the agents of the Qing dynasty, the revolutionary invites Huang to join him in saving the Chinese nation. Huang refuses immediately, even while saying that he admires and respects them and knows that millions of people will need to sacrifice themselves to overthrow the Qing Dynasty. However, he really doesn't know what the result would be if he risks his life to do so. Therefore, he would instead like to be a Hong Kong policeman. The revolutionary doesn't force him to join. Instead, he says that different people have different positions but they work not for themselves but for the Chinese people. Drunken Master II also reveals that hegemony of Westerners over Easterners is ingrained 
ideology in the minds of Westerners. This ideology is manifested in the statement of a British consulate staff member speaking of the imperial seal of China. The member says that "The imperial seal of China is an equivalent of the crown of the British Queen." When he boasts that the imperial seal of China will be exhibited in the British Museum, it seems an announcement to the world of the might and triumph of the West over the East. This example undoubtedly reveals Westerners' perception of their superiority over Easterners and their desire for domination over the East. Since Drunken Master // was released in 1994, just a few years before the handover of Hong Kong from Britain to mainland China, it seems that their portrayal of the attitudes of the British consulate toward the Imperial Seal of China aims at awakening Hong Kongers' awareness of nationalism and patriotism. The conversation between the male revolutionary and Huang indicates Hong Kongers' somewhat detached attitude toward the relationship between Hong Kong and mainland China and their preference for freedom and independence. It also implies mainland China's respect for this detached attitude, freedom and independence.

In the ending scene of Police Story III-Super Cop (1992), Hong Kong policeman Chen Jiaju (Jackie Chan) and mainland policewoman Yang Jianhua (Michelle Yeoh) discuss how to deal with the illegal money of the drug dealers:

CHEN：...我也想拿，不过这属于我们香港政府的...让我们香港政府 暂时保管[... also want to take away the money, but it 
belongs to our Hong Kong government... let our Hong Kong government keep it for a while]

YANG：不对，是属于我们全中国人民的... [you are wrong. It belongs to we Chinese people].

CHEN：九七之后我们也是中国人，到时也是你们的嚓。[We are also Chinese after 1997, then it will also be yours.]

I assume Chen's insistence on Hong Kong government's keeping the money reveals the consciousness of a relative independence in Hong Kongers and seemingly indicates that, to Hong Kongers, their government is somewhat independent from the control of the central government of mainland China. The statement also implies that Hong Kongers do not think they are the same as mainland Chinese, at least before the handover.

There is also a tendency in Chan's Hong Kong films of this period pay increasing attention to social problems and issues concerning the safety or peace of the world. Police Story IV-First Strike is a good example. The film is about the head of a Soviet KGB using nuclear weapons to exchange rights in the petroleum trade with middle-eastern nations. The dialogue between Hong Kong policeman Chen Jiaju and the suspect Xu Jie is as follows:

CHEN：...你应该把这个核弹头马上交给警方 [... You must give the nuclear warhead to the police immediately.]

XU：...你知道那些所谓的军事强国已经卖了多少核子武器到全世界?

[... do you know how many nuclear weapons the so-called 
military powers sold to the world?

CHEN：我知道这是事实，我们不能改变...我们人类已经做太多的事情 来伤害这个地球...虽然我们没有能力阻止，也不能助长他们[1 know it is the truth, but we can change nothing...we human beings have done a lot to destroy the world... although we are incapable of stopping them, we cannot encourage them]

From the above conversation, we can see that Chan's films begin to pay attention to the safety of international society and the stability and peacefulness of the globe.

However, the cultural identity of Hong Kong reflected in Jackie Chan's movies produced in Hong Kong after 1997, which are included in Group II, have different characteristics. First of all, the movies produced in the first years of the post-1997 era reflect more of the ambivalent or confused values and cultural identity of Hong Kong and its residents. The most representative one is Who Am I? In this film, by portraying an agent who suffers from amnesia and searches for his true identity from the beginning to the end in an unfamiliar land and culture, Jackie Chan well demonstrates the confused or perplexed emotions of Hong Kongers about their cultural identity in the early post-1997 era. The character, who has no name, because of the long-term amnesia, is totally bewildered as to his identity. He doesn't know who he is, where he comes from, or why he has six passports with six different identities each with the same face. He desperately wants to know his real identity, no matter 
whether he is in a wild forest, unknown native tribes or large cities. The feeling of a loss of identity reaches a climax when he accidentally steps into the land of a wild forest and encounters the aborigines. He is mysteriously and inexplicably involved in a crazy pursuit by the aborigines. He is completely lost, as he cannot understand their gestures, language, tribal customs, and everything is unfamiliar and weird to him. He screams again and again in the cockles of his heart and on the top of hills "Who am I?" He is alone and lonely. As a result he is called by the aborigines "Who am I" and even he himself has to accept the new identity and introduces himself to others with this new "name." Since this film was produced and released in 1998, the year following Hong Kong's return to China, it has been regarded as the most representative film manifesting and reflecting the confused state of Hong Kongers about their self and cultural identity. Hong Kong culture has always been claimed as marginal, since it is believed that it has "never got close enough to the mainstream Chinese culture situated in the political center" and, on the other hand, it, together with the ideology of Hong Kong residents, has "been modified by its colonial history" for more than one hundred years (Tang 4). The ambivalent position of Hong Kong's cultural identity is believed to be the source of the internal, perplexing reflections of Hong Kongers, and helps explain their cultural imagination and informs their employ artistic forms, especially the visual arts, in their expressions and explorations of their innermost feelings, thoughts and confusions about their cultural identity. 
The second characteristic of Hong Kong's cultural identity reflected in Chan's Hong Kong movies released in this period is the nostalgic mood of Hong Kongers. Like the nostalgic films in the 1980s and 1990s of the Hong Kong cinema discussed in Chapter 3 , Hong Kongers' yearning for the golden past is also manifested and portrayed by the love stories of Jackie Chan's films. However, what makes them different from some of the nostalgic Hong Kong cinema in the 1980 s and 1990 s is that Jackie Chan's films not only portray Hong Kong people's yearning for the golden and memorable past, but also exhibit their hopes and expectations for a bright future. The representative ones are Gorgeous (1999) and The Myth (2005). Gorgeous is initiated by a glass bottle, which represents hope and love. When $\mathrm{A} \mathrm{Bu}$, a village girl, finds a piece of paper with a love message in the bottle, she readily decides to start her journey to Hong Kong to seek true love with only the name and address written in the message. To $\mathrm{ABu}$, Hong Kong is the future, hope and where her true love is. Since the film was released in 1999, just two years after the handover, it seems to picture a hope and bright future for the audience, although there may be some twists and turns in the process of their seeking for happiness, just like the village girl encounters in the process of her seeking her true love.

The Myth is also a love story, which is rare in Jackie Chan's films. The film develops the love story through the dreams of an archaeologist (Jackie Chan) and his journey to his dreamland, which itself is very beautiful and 
unforgettable. Miraculously, the archaeologist finally figures out the legendary site of the tomb of the Qin Dynasty and sees the beautiful princess who is imprisoned in the tomb. The film ends happily: the immortal princess who is waiting for her lover for millenniums in the tomb at last meets her reincarnated lover. Unlike Gorgeous, this film once again demonstrates the nostalgic mood of the Hong Kong people. The reason may lie in the film's date: it was produced in 2005, two years after the first July 1 rally in 2003, mentioned in Chapter 3. Hong Kongers were not satisfied with the political and social situations in the first years of the post-1997 era, which resulted in their yearning for the golden past. However, like Gorgeous, Myth also has a happy ending, which presents to the audience a hopeful and much-to-be-longed-for future.

The third characteristic of the cultural identity of Hong Kong reflected in Jackie Chan's Hong Kong films of this period is the ambivalent attitudes of Hong Kongers toward their relationship with mainland China. On the one hand, Hong Kong people enjoy their relative freedom and independence in economic and political activites. On the other hand, there is a strong and inseparable cultural bond and affiliation between Hong Kong and mainland China, although sometimes they still feel somewhat estranged or neglected. This ambivalent emotion is vividly portrayed in New Police Story (2004), the only one of the Police Story series produced after 1997.

In this film, the name of the heroic policeman is changed from "陈家驹 
/Chen Jiaju" to “陈国荣/Chen Guorong." The change from "家/Jia [family]" to "国/Guo [country]" indicates a broader symbolic meaning: What matters most for the police is the safety of the country (China and the Chinese), not only the safety of Hong Kong and its residents. "荣/rong" signifies "flourish," "honor" and "glory." Therefore, "国荣/Guorong" not only symbolizes the prosperity, honor and glory of the country, but also expresses the good wishes and expectations of Hong Kongers for China and the Chinese nation. Moreover, the change of the name implies Hong Kong people's identification with mainland China, which is consistent with the research findings of pollsters mentioned in the fourth section of chapter 2. The findings show that the number of Hong Kong people who identify themselves as Chinese or Hong Kong Chinese has been increasing in the post-1997 era. The cultural affiliation between Hong Kong and mainland China has been remarkably strengthened rather than diminished in the post-1997 era, as is argued in O'Neill's article discussed in chapter 3.

The film New Police Story allegorically illuminates the complicated and ambiguous relationship between Hong Kong and mainland China, which is exemplified in the following aspects. The criminals that Chen Guorong encounters are raised in families of high-ranking officials. The reason for their destructiveness in society is that they seldom enjoy the warmth of family. The most typical one is the head of these young gangsters, named Joe (Wu Yanzu). Joe's father (Sun Chun), who presents to the audience a patriarchal image of law-executor, is the Chief Inspector of the Police for the Northern Section. An 
abominable black-and-white flash-back scene in the film shows that the young Joe was handcuffed by his father. It also gives Joe a chance to explain to the audience that he was not born a bad guy and how much he desires to be loved by his parents, especially his father. This victim image is sharply strengthened in the final scene, when Joe uses an unloaded gun to aim at the police and force them to end his life. It undoubtedly and directly tells the audiences that he himself is a victim of the patriarchy and lack of family warmth. Joe's father is a figure whom I assume symbolizes mainland China. The following factors-the north section of the police that Joe's father is in charge of, the patriarchal image of Joe's father, and especially the actor who plays Joe's father, a mainland actor-all remind the audience of associating the patriarchy with mainland China. Geographically, mainland China is to the north of Hong Kong. To Hong Kong audiences, the patriarchy image symbolizes the central government of the People's Republic of China. As discussed in chapter 3 , some scholars such as Eliza W.Y. Lee and Rey Chow believe that China has the absolute final say on the sovereignty of Hong Kong, and therefore they believe that Hong Kongers are deprived of their right to self-determination or a voice in the negotiation process. China's relationship with Hong Kong is just like that of Joe's father with Joe. Joe's father scolds and blames Joe for everything he is not satisfied with and seldom gives Joe the care and love he needs, but he really loves his son in his heart, which can be seen in the final scene. When Joe resists the police with his empty gun, Joe's father cries. In 
some sense, therefore, the character Joe symbolically refers to Hong Kong, a victim of the patriarchy-an image of Hong Kong described by the scholars such as Chow. Joe desires to feel warmth from his family, just like Hong Kong desires the attention of the central government of mainland China. However, like Hong Kong, he also enjoys freedom and independence. Like the relationship between Joe and his father, which is linked by inseparable kinship, the relationship between Hong Kong and mainland China is connected by a strong historical, cultural bond. Neither of them can live well without the other. On the one hand, both the father and the son need respect and love. On the other hand, the father wants a certain amount of control or domination over the son; at the same time, the son also needs some freedom and independence. Compared to the patriarchal love from mainland China, it seems that understated, practical, meaningful and sometimes psychological help will be more suitable, acceptable and comfortable for Hong Kongers. This kind of help is allegorically expressed by the help that Feng (Xie Tingfeng) gives to Chen (Jackie Chan), previously discussed in Chapter 3. Feng, who pretends to be Chen's partner and whose identity is not revealed until the end of the film, gives Chen practical and meaningful help, contributing significantly to Chen's pulling himself together. It turns out that it is the help Chen gave to Feng when he sent him off to the mainland years ago that affected Feng. Therefore, it seems that Feng's only purpose after he grows up and comes back from the mainland to Hong Kong is to help Chen. From beginning to end, he appears as 
a policeman who helps Chen. It seems the way that Feng helps Chen-the way that a boy coming from the mainland helps a Hong Kong policeman-is more acceptable for Hong Kongers.

Compared with Jackie Chan's Hong Kong films, the cultural identity of Hong Kong reflected in his Hollywood films has distinct features. First of all, the cultural identity of Hong Kong is portrayed on the basis of the tastes of American audiences and their perception of what Chinese people should be like. In his Hollywood films produced before 1997, Chan's actions and performances and the roles he plays are designed by Western directors or producers. Battle Creek Brawl/The Big Brawl (1980) is a good example of Jackie Chan's Hollywood films designed to cater to the tastes of the viewers and gain financial benefits. In this film, a new kung fu kid persona, A Long, is presented by Jackie Chan to Western audiences. But this figure is designed to showcase Chan's talents by a western director, Robert Clouse, who is adept at "synthesizing Western and Eastern action" (Teo 130) to attract western audiences. Clouse scripted and storyboarded every scene in advance. Chan was unable to decide what to speak or perform or how to do the stunts. Unfortunately, Jackie Chan failed to achieve equivalent success in Hollywood with this film. The main reason is that what Western audiences expected to see was Bruce Lee's serious style of martial arts. In Cannonball Run (1980) and Cannonball Run // (1983), he even has to act as a "bumbling Japanese" (Chan and Yang 337), a role he is averse to. Although reluctant, he had to 
accept it because of the contract (Chan and Yang 339).

However, the most important feature of the cultural identity of Hong Kong reflected in Jackie Chan's Hollywood films, especially those produced after 1997, is a distorted and predetermined image of Chineseness. In his Hong Kong films, Jackie Chan is depicted as virtuous, invincible, masculine, brave, active, persevering, confident and charismatic, a man with many other positive qualities. However, in Hollywood films, Jackie Chan is portrayed on the basis of the Westerner's perception of Chineseness, an otherized and presupposed Chineseness. He is portrayed as a passive, asexual, submissive figure, which is believed to be "not only unthreatening to the white hero but also confirming [of] his sexual domination" (Lo 475). It seems that the oriental male figures are to some extent feminized or degenerated, created to cater to Western audiences and to confirm their "masculine selves." As Lo indicates in his Double Negations: Hong Kong Cultural Identity in Hollywood's Transnational Representations, the inconsistent or conflicting presentation of the character justifies a kind of social control over the Asian detective who could evidently be "assimilated to fit into the mainstream American culture." The Asian male is synchronously "excluded from, and included inside, a western-Orientalizing discourse which [makes] him stranger and friend at the same time" (Denizen 91; qtd. in Lo 475). On the one hand, in Hollywood movies, Jackie Chan plays a rational, mature and quick-witted character who is sharp at cracking criminal cases and tackling urgent situations, such as the detective in the Rush Hour 
series and the imperial guard to the emperor of the Qing dynasty in Shanghai Noon and Shanghai Knights. On the other hand, his oriental traits, such as his accent, comical language, and alien appearance, make of him a funny, strange image among the Westerners, which is exemplified in his communications with his black partner in the Rush Hour series, and the white bandit in Shanghai Noon and Shanghai Knights, as well as his stiff, goofy and mechanic behavior in The Tuxedo. Of all Jackie Chan's Hollywood films produced after 1997, the Rush Hour series would be most representative. In Rush Hour (1998), when Chan goes into a place where African Americans gamble together with his partner, he greets the men by saying "Hi, my nigger," the same words his black partner says to his fellow men. Because of this, he is inevitably chased after and beaten violently by a group of strong and large African Americans. In all the films of the Rush Hour series, Jackie Chan is inevitably despised and belittled by his black partner, although sometimes they cooperate very well with each other. It is true that the black also does not enjoy high social status in the United States. In Rush Hour (1998), Lee's (Jackie Chan) suggestions or warnings of rescuing victims from a bomb-ridden building are ignored by his fellow policeman and his senior, i.e. by the white people. As a result, a team of his fellow white policemen lose their lives in the explosion. However, it is worth noting that in Rush Hour II, in which the setting is Hong Kong, his native land, Jackie Chan appears normal. He acts as an active, brave, acute, sensible, dignified and masculine man who is always on the scene where there is 
something emergent and dangerous.

In Shanghai Noon, Jackie Chan acts as an imperial bodyguard named Chon Wang who bears a secret love for the princess of the Qing Dynasty. When the princess intently and zealously learns English with a westerner in the palace, Wang also picks up a little English. It seems that, to them, and especially to the princess, the West is a dreamland. Later when he learns that the princess is kidnapped by a traitor of the Qing Dynasty and imprisoned as a hostage in the United States, Wang offers to accompany the other imperial guards to rescue the princess from the kidnapper and is even ready to do so at all costs, including his life. When he finally finds the princess toiling with many commoners, subjects of the emperor, servants or slaves, he himself and all the others kneel down and bow to the "encaged" princess. Ironically, the princess is played by an American Chinese-a westernized Chinese, who allegorically represents the occidental, or at least a Westernized Oriental. Therefore, what the scene conveys to the audiences is that the oriental kneels down and bows to the occidental, which metaphorically or implicitly implies the superiority of the occident over the orient.

The cultural identity of Hong Kong reflected in Jackie Chan's Hollywood movies is portrayed sometimes in an inconspicuous way. The most representative example is The Tuxedo (2002), which is exceptional when compared with his other Hollywood films. Asians, especially the Chinese, in modern times as well as in ancient China, are inevitably depicted as wicked, 
treacherous, criminal and internecine. Hong Kong, particularly in Rush Hour II, is vividly depicted as a place full of material desires, prostitutes, criminals, gangsters and terrorists, an ideal place for the westerners' entertainment, including the black-the ethnic group who has no better social and economic status than people of yellow race origins in western countries. In The Tuxedo, compared with Chan's other Hollywood films included in Group IV, the tendency to deface or feminize the image of oriental males is more inconspicuous and subtle. At first glance, the film seems nothing strange, just a very popular commercialized film for entertainment. But on second thought, it is not difficult to detect the underlying intention or ideology of Westerners' degenerating and depreciating the image of the oriental. In The Tuxedo, Jackie Chan's persona is a soft-spoken and timid taxi driver who is unexpectedly appreciated and employed by Clark (Jason Isaacs) as his private lowly chauffeur. Clark is a Playboy millionaire whose real identity is a secret agent. When Clark is seriously hurt and loses consciousness in an explosive "accident," Jackie Chan curiously and unknowingly puts on Clark's tuxedo and then magically becomes a superman with a special gadget-laden tuxedo. Consequently, he is mystically involved in a dangerous world of international intrigues and espionage. Whenever he dons the magical suit, he feels well-dressed and behaves manly, confidently, skillfully, intelligently and invincibly. However, when wearing his plain suit, he is awkward, timid, knuckleheaded, goofy, and not masculine, which helps enhance the positive 
image of the Playboy millionaire Clark, the supposed symbol of Caucasians.

An indisputable and impressive fact is that in the above-mentioned Hollywood films, Jackie Chan, a symbol of the oriental, a representative of Chineseness, is otherized; in other words, he is depicted as alien, weird, feminized and asexual. No matter how many pains he takes, he is different from those occidentals and can never melt into Western society, a fact which is incisively and vividly manifested in The Tuxedo in a crafty way. His funny and awkward language and behavior, together with many other negative and pejorative traits and images imposed on him, serve as a foil to whites and further boost their positive traits such as masculinity, humor, intelligence, burliness and popularity among women.

Chan's Hollywood films reflect another characteristic of Hong Kong's cultural identity-hybridity. The character he plays in his Hollywood films travels a lot in the world and interacts with people from different ethnic groups and nations. In his interaction with these people, he learns a lot about his own self and the others. Moreover, he not only assimilates different cultures but also disseminates his own culture. Chan's diaspora experiences are much like a narration of the life of Hong Kongers who have traveled a lot or migrated to Western countries since the 1980 s, as discussed by scholars such as Siumi Maria. For example, in the Rush Hour series, Chan plays a Hong Kong policeman who has to travel everywhere. In Rush Hour (1998), he is summoned by Consul Han to the United States from Hong Kong to save Han's 
kidnapped daughter. In Rush Hour II, he enjoys his holiday with his black partner in his hometown first, and gives an opportunity for his black partner and also the Western audiences to learn more about Hong Kong. Then he travels to the United States to track down the criminals. In Rush Hour III, he goes to Paris to investigate an international crime. Most of the settings of the Rush Hour series, Shanghai Noon and Shanghai Knights are in Western nations. It seems that, at the very beginning, when he is in unfamiliar cultures, it is difficult for Jackie Chan, the symbol of Hong Kongers and Chineseness, to communicate with people of other ethnic groups. But with increasing communication and contact, both Jackie Chan and people from other ethnic groups gradually comprehend each other, even understand each other emotionally, although sometimes they cannot read, write or speak each other's language. The best example of this is Shanghai Noon. In this film, Jackie Chan accidentally steps into the land of a Native American tribe. When he sees a girl pursued by several sturdy Native American men on horseback, he saves her because he thinks that she is in danger. However, he fails to notice what is happening. Although he cannot understand the language and customs of the Native Americans, he finally understands that he misunderstands them. It turns out that the girl he saves is the younger daughter of the Chief of the Native American tribe and those men chasing her are actually playing with her. Despite his ignorance and misunderstandings, he wins the favor of the Chief, who voluntarily marries his elder daughter to Chan without his permission. 
Chan's relationships with his black partner, Carter, in the Rush Hour series and with the white bandit Roy in Shanghai Noon and Shanghai Knight, although different from that with people in the Native American tribe, also go through different stages. At the very beginning, because of their different racial and cultural backgrounds, they are unfamiliar with each other; therefore, they are more often than not misunderstanding and sometimes even distrustful and antagonistic toward one another. But with increasing communication and familiarity, they can understand each other and even establish a friendship. For example, in Shanghai Noon, the white bandit Roy deceives Chan into believing his assistance in rescuing the princess Peipei is out of friendship, not for the sake of gold. When a prostitute asks him why he has a Chinese friend, Roy says that he never considers Chan a friend because he is Chinese. From his facial expression and tone, it is obvious that he denigrates Chan because of his racial and cultural background. However, in the end of this film, especially in Shanghai Knights, Chan and Roy truely understand each other and become good partners and friends. It seems to me that Chan's experience of traveling in the West, encountering people from other ethnic groups and merging cultures with them, is an analogy of Hong Kong's hybrid culture.

From the above analyses of Jackie Chan's Hong Kong films, one can see that the cultural identity of Hong Kong in its cinema is a contrasted reconstruction, which is against Lo's negation of Chineseness. No evidence could support the claim that Hong Kong's cultural identity is constructed by 
way of negating Chineseness. It is true that the cultural identity of Hong Kong is somewhat different from that of mainland China, which is exemplified by films produced before 1997 such as Drunken Master (1994) and Police Story IV: First Strike (1996), as discussed above. Undoubtedly, these two films emphasize the characteristics of Hong Kong's cultural identity such as its unique colonial history, the nostalgia of Hong Kongers for the golden past and the freedom and independence that Hong Kong enjoys. These features are also discussed, portrayed, and explored in the scholarly works of Rey Chow, Ping-kwan Leung and Phshek Fu, Hong Kong films from the 1930s to 1990s, journalism by Chris Patten and Deborah Herd and the popular songs of Dayou Luo. Chan's Hong Kong films deal with no less than these writers, journalists or films and songs. Although he has been searching for his true identity from the beginning to the end of Who Am I?, there is still a scene which can shed some light on his identity: when the nationalities of the anonymous secret agents are exposed, the Flag of Hong Kong is sharply contrasted and displayed with the other flags.

However, Chan's films also highlight traditional Chinese culture, especially Chinese kung fu and morality and the justice associated with it. Chan's Hong Kong films produced after 1997 emphasize more of Hong Kongers' yearning for the golden past yet looking ahead with promising hope, a theme well developed in Gorgeous and The Myth. Who Am I? deals more on Hong Kongers' search for an identity, while New Police Story us concerned 
with Hong Kongers' ambivalent attitude toward mainland China. Chan's films never deny the cultural identity of Hong Kong as Chinese. On the contrary, they carry forward and foster Chinese nationalism, patriotism and traditional Chinese culture as discussed above, especially by way of Chinese kung fu. They also show that Hong Kongers identify themselves with China, as is especially stressed in the ending scenes of Police Story IV: First Strike.

Similarly, the cultural identity of Hong Kong in Jackie Chan's Hollywood films is not constructed on the basis of Lo's negation of negation. On the contrary, some of Chan's films expressly stress the cultural identity of Hong Kong. The best example of this is Chan's Rush Hour series. In these films, Chan's identity remains a Hong Kong inspector. In addition, in the beginning scenes of Rush Hour (1998), Consul Han and other officials toast the future of Hong Kong, which especially impresses Hong Kong identity upon the audiences. Further, the scenes of the first half of Rush Hour I/ are set in Hong Kong, in which Chan shows the culture of his hometown not only to his black partner but also to Western audiences. Undoubtedly, the cultural identity of Hong Kong in some of Chan's films, especially those produced before 1997, is distorted or even denied. However, this doesn't mean that the cultural identity of Hong Kong is constructed based on the negation of negation. In fact, it is mainly constructed on the basis of Westerners' perception of what a Hong Konger, Chinese or Asian should be like. Therefore, the cultural identity of Hong Kong in Hollywood films can be said to be a stereotyped or presupposed 
reconstruction. The most representative examples are Battle Creek Brawl (1980), Cannonball I (1980) and Cannonball II (1983). These films are Chan's first attempts in Hollywood after he achieved great success with his kung fu kid image created in Drunken Master (1978) in Hong Kong. However, in these films, as mentioned earlier, Chan has to do what Western directors and producers require. For example, in Battle Creek Brawl, the director and action choreographer is American director Robert Clouse, who designs everything in advance and is good at synthesizing the East and West to meet the needs of Western audiences, as discussed above. Chan has no choice but to act as Clouse requires him to do. In Cannonball I and Cannonball II, he even plays a Japanese driver, which well manifests Westerners' perception of Chineseness and the cultural hegemony of the Western over the Eastern. It seems that, to Westerners, Asians are the same, or at least there are not many differences. This perception is also exemplified by Chan's Hollywood films produced after 1997. For example, in Rush Hour, when Chan and his black partner, Carter, boast of their fathers' feats, Carter says "My daddy'll kick your daddy's ass all the way from here to China, Japan, wherever the hell you from and all up that Great Wall too." In Shanghai Noon and Shanghai Knight, Roy and other whites, such as the police sergeant in the films, insist on calling Chan "Shanghai kid" without bothering to know where he comes from.

However, it seems that Chan has been trying his best to strike a balance in presenting Hong Kong's cultural identity in Hollywood cinema since he 
returned to Hollywood with Rush Hour. On the one hand, the cultural identity of Hong Kong is still constructed based on a stereotyped or presupposed perception of Hong Kong people or Chineseness. Occasionally, the Chinese are portrayed as ingenious, diligent and swift. But more often than not, Chinese and other Asian minorities are negatively portrayed as timid, clumsy, goofy, feminine, asexual, and sometimes even treacherous figures. For example, Chan is depicted as a strange, asexual and clumsy guy as well as an extraordinary man with martial arts techniques and the capacity to deal with tough cases or problems in the Rush Hour series, Shanghai Noon and Shanghai Knights. However, in these films, the Chinese are also depicted as treacherous and dangerous figures. For example, Juntao in Rush Hour, Hu Li, a woman whose main joy in life seems to be beating, shooting, stabbing, blowing stuff up, bigwig Ricky Tan in Rush Hour // and Lo Fong, a traitor to China, in Shanghai Noon are all negative figures. One of the reasons for such portrayals, without doubt, is to cater to the tastes of Western audiences to attain box-office success. The contrasting of such a stereotyped image with the Hollywood image of the heroic, masculine, gentlemanly and humorous westerner consequentially produces comic effects that please and amuse Western audiences. But the most important reason may be illustrated explicitly by such theories as Foucault's "power-knowledge" relations, Said's Orientalism and neo-Gramscian hegemony theory, which are discussed in Chapter 2. After thinking about Hollywood films approach to the Vietnam War, 
it is easier to understand why and how Hollywood approaches Hong Kongers or the Chinese in such a way. It is cultural hegemony that determines such a representation of Hong Kongers and Chinese.

There may be other reasons or explanations for such a stereotyped or predetermined image of Hong Kongers and the Chinese in Hollywood films. By examining both the news articles published by New York Times and Hollywood films from the $19^{\text {th }}$ century to the present, I find that the portrayal of China and Chineseness in both positive and negative light has a long history. On the one hand, the Chinese, as well as other Asian minorities are regarded as a "model minority" by the American media. On the other hand, however, they are portrayed as evil monsters. In a typical news story titled "Sense, and Sensitivity, About Asians" issued by The New York Times in 1992, Asian-Americans were regarded as people undergoing "two equally unfair stereotypes. They're considered a 'model minority,' industrious and resourceful, but also seen as insular and threatening-and not quite American." American media frequently use success stories about people of Asian descent in their reporting and emphasize the predetermined successful traits which Americans do have and value, such as diligence and perseverance. In addition, Asian Americans are portrayed as silent, docile, intelligent, and especially terrific in science and mathematics. It is believed that those American-valued virtues unmistakably contribute to an average person's academic and economic success, which in some sense also reinforces the 
merits that Americans advocate earnestly.

On the other hand, people of Asian descent are believed not to be "really" American, mainly because of their alien appearance and accent, no matter whether they are American-born Asians, early immigrants or recent immigrants. They are always treated as guests of the country, welcomed or not. In Hollywood films, however, the Chinese, as well as other Asian minorities, have been portrayed as a treacherous, evil and dangerous monsters as well as geniuses. The image of Asians in Hollywood films has been undergoing a slight fluctuation, but remains very different from, or even opposite to that portrayed by the American media. An overview of images of Chineseness represented in Hollywood films from the late $19^{\text {th }}$ century onward can help construct a clear picture. Jun Ni states that, because of the continuity of the development of American culture and ideology, the stereotyped Chinese image established by early Americans has been dominating mainstream American society over the past hundred years (无知还是恶意? [Ignorance or spite?]). In the late $19^{\text {th }}$ century, China was the symbol of depravity, fatuity and poverty, which directly made Chinese immigrants victims of American racism, and became the source of the image of China and Chineseness demonstrated in Hollywood films. The most representative case is Dr. Fu Manchu, a typical image of Chineseness as a "yellow peril," depicted in Hollywood films series adapted from Sax Rohmer's Fu Manchu as a dangerous fiendish monster. Fu Manchu became an antetype of the Oriental hellion, which was repeatedly 
depicted, demonstrated in Hollywood films with little alteration. To date, Hollywood films have strove to establish the image of China and Chineseness as a "yellow peril," and have invariably and unchangeably adopted the stereotyped "Chinese monster," Dr. Fu Manchu, with his eccentricity and fondness of gang crime. Hollywood films in the mid 1920 s to the 1930 s tried to shape a new image of Chineseness - Charlie Chan, an intelligent detective - a symbol of righteousness and justice, but it proved to be a failure, mainly because the hero was played by a white actor who used many cliché and eastern aphorisms. It was not welcomed by Westerners, even Asian Americans. There is also the image of the Chinese peasant from The Good Earth by Pearl S. Buck, a typical low-class Chinese farmer who had fortitude and was industrious and fearless when facing calamity. This impressed Caucasians greatly. However, the image of the Chinese peasant with poor living conditions aroused Americans' sympathy toward Chinese farmers. Meanwhile, it also made them believe that Chinese need Westerners' protection and salvation, which contributed to Caucasians' considering themselves supreme. In The Year of Dragon produced by Metro-Goldwyn-Mayer, Inc. (MGM) in 1985, Chinatown was depicted as a place full of violence, murder, rampant gangdom crime, and was regarded as the most controversial film concerning Chinese image. The most representative examples are Chinatown, a place full of crimes and murders, and the Chinese, wicked, malicious, treacherous and dangerous, just like the 
stereotyped "Dr. Fu Manchu."

Despite his great success in Hong Kong and other areas or countries in Asia, however, it is obvious that Jackie Chan enthusiastically seeks for his career success in the West, and involves and produces more films or blockbusters in Hollywood than in his native land. Although it seems that he never intends to abandon the domestic market, the figures in the graph and table of chapter 2 suggest that Chan has been trying to win the international film market and aiming at being a transnational superstar to satiate western viewers since the 1980s. This tendency is well exemplified in his Hollywood movies produced after 1997 included in Group IV. In these movies, consciously or subconsciously, Jackie Chan indeed provides the Caucasians with his exotic appearance, personality, way of thinking and living, his unique performances and entertainment films that visually and psychologically cater to Westerners' tastes. With his sometimes paradoxically unchangeable and mutable ethnic identity, Jackie Chan's relatively ridiculous, improper and even funny language, sometimes awkward behavior in an exotic land or unacquainted surroundings, and somewhat submissive or subordinate attitudes towards Caucasians, mostly his superiors, all manifest his attempts to meet the needs and wants of Western viewers. His performances and the characters he portrayed in these Hollywood blockbusters are presumed to be designed or created to fulfill the visual and psychological needs of western audiences, and to meet the Caucasians' expectation of what Chineseness is. 
They help define the Occidental with the Oriental's contrasting image, idea, personality and experience, i.e. "other," the binary opposing "occident," as Said illustrated in his postcolonial theories discussed in Orientalism. However, the images of the oriental in Hollywood films may be distorted or even false, which can be justified and well manifested by those positive and masculine images of Chineseness in Chan's Hong Kong movies produced both before and after 1997. The otherness of the oriental in his Hollywood films and the feminization of oriental males, which is reflected by depicting them as asexual, nonthreatening, comic, passive and somewhat submissive persona-all the negative images of Chineseness, help strengthen the supposed domination and superiority of the occident. The cultural identity of Hong Kong is in fact oppressed and denied by occident discourse hegemony, and Chineseness is gradually feminized in the course of "otherization" of Chineseness by Hollywood filmmakers, and helps strengthen the otherness of Easterners in Westerners' perception and confirms their perception of the white hierarchy over non-white others. The embodiment of this inclination is reflected in a more and more inconspicuous and understated way.

On the other hand, however, Chan has also tried his best to exhibit the cultural identity of Hong Kong and Chineseness. As discussed above, the consistent identity of the policeman as a Hong Kong detective through the Rush Hour series and the use of Hong Kong as the first half setting of Rush Hour II indicate that Chan has engaged in emphasizing the uniqueness of 
Hong Kong and its culture and exhibited it to Western audiences. However, Chan also has endeavored to disseminate and carry forward Chinese culture to the world, allowing Westerners to learn more about China, Chineseness and Chinese culture. For example, both Shanghai Noon and Shanghai Knight begin with Chinese characters, the essential characteristic of the Chinese language, which remians mysterious to Westerners. The Chinese characters further impress Western audiences with a shining golden color when they are moving back and forth and up and down on the silver screen. In Shanghai Noon, when Chan finds that the white bandit Roy is buried in the sand in a desert, he gives Roy a pair of Chinese chopsticks to help him. Since his identity in this film is an imperial guard to the emperor of the Qing dynasty, he wears the court dress of the Qing Dynasty and a braid even when he is in the United States, to show and stress his identity. Even if he doffs his court dress, he still insists on keeping the braid and protects it from cutting at all cost.

A possible explanation for the coexistence of both the cultural identity of Hong Kong and China in Chan's Hollywood films is the perception of Westerners towards Hong Kong and China combined with Jackie Chan's affection towards both. How Westerners perceive Hong Kong and China is well illustrated by an article by Greg Torode, discussed in Chapter 3. Torode's article offers some evidence of Americans' perception of Hong Kong, especially after the handover in 1997. As Chris Jackson says, Hong Kong continues to retain "a separate identity while recognising the full importance" of 
its place within "the sovereign People's Republic of China" (Torode 14). To the average American, however, Hong Kong is part of China, especially after the handover, and therefore has lost its identity.

However, it is Jackie Chan's love for Hong Kong and China that enables him to disseminate and promote Hong Kong and Chinese culture in his Hollywood films. This deep love was assuredly reflected in his first contacts with the American press. When Jackie Chan met the press for the first time in America after his debut in Battle Creek Brawl, he insisted on telling the American reporters that his name was Jackie Chan and what he does is "kung fu" not "karate." He also emphasized that he was Jackie Chan, "not Bruce Lee" (Chan and Yang 260). When he was asked whether "he'd spent most his life training in Karate," he earnestly explained to the American journalist that "Karate is Japanese; Kung fu is Chinese" (Chan and Yang 261). He was exasperated when he was asked to show kung fu on a program, and said "Here I was, the biggest star in Asia, and the host was asking me to perform like a trained dog" (Chan and Yang 262). He strikingly felt that he was a "permanent stranger" and "a foreigner in a foreign land" and couldn't understand why he went from "being a prince in Hong Kong to being a beggar in America" (Chan and Yang 263). Thereafter, he changed his attitude toward Western journalists. When a reporter said "Mr. Chan, it seems like you need to work harder to get into the U.S. market," Chan answered "I'm not interested in the U.S. market...What I'm interested in is Asia. There are billions of people in 
Asia, and how many millions in the U.S.? America is a very small market" (Chan and Yang 263). However, Western journalists were shocked by Chan's "take-it-or-leave-it attitude" and "dozens of TV and radio stations began asking for interviews" and agreed to "his demands" (Chan and Yang 263). It seems that it is this unhappy experience that made Chan go back to his Hong Kong cinema, only returning to Hollywood in 1998 with his blockbuster Rush Hour to make his dream come true.

Admittedly, it is hard to say whether or not his endeavors in striking a balance between the aforementioned aspects are effective, or how his efforts are perceived by Western audiences as well as his fellow Hong Kongers and Chinese. However, what we can see from his Hong Kong and Hollywood films, especially those produced in recent decades, is that Jackie Chan definitely concerns himself with social and cultural dimensions in his movies. In these films, he becomes a man who tackles tough problems for his friends, advocates fair competition, is concerned about the safety and peace of his country and the world, and even saves the earth. In these films, he tries to strike a balance between globalization, postcolonialism, Chinese legacies, Hong Kong culture and Western perceptions of Hong Kong and China. 


\section{REFERENCES}

Battle Creek Brawl/The Big Brawl. Dir. Robert Clouse. Prod. Raymond Chow, Fred Weintraub and Terry Morse Jr. 1980. DVD. 20 ${ }^{\text {th }}$ Century Fox. 2004.

Barthes, Roland. "Myth Today" Cultural Theory and Popular Culture: A Reader. $2^{\text {nd }}$ ed. Ed. John Storey. Hemel Hempstead: Prentice Hall, 1998.

Berry, Chris. "At Full Speed: Hong Kong Cinema in a Borderless World by Esther C. M. Yau." Book Review. The Journal of Asian Studies. Vol. 61, No. 4. 11:24, Jan. 8, 2007. Nov. 2002.

Bin, Zhihui (宾智慧). “八十年代成龙的电影风格初探[Brief Review on the Styles of Jackie Chan's Films in the 1980s]," 成龙的电影世界 [Jackie Chan's Film World]. Beijing: China Film Press (中国电影出版社), 2000.

Cairns, Alice. "Identity Parade." South China Morning Post 15 Jan. 1995, sec: Agenda; Culture: 6.

Cai, Hongheng (蔡洪声). “成龙的电影世界 [Jackie Chan's Film World],”成龙 的电影世界 [Jackie Chan's Film World]. Beijing: China Film Press (中国 电影出版社), 2000.

Cannonball Run. Dir. Hal Needham. Writ. Brock Yates. Prod. Albert Ruddy. 1980. DVD. Hbo Home Video. 2001.

Cannonball Run II. Dir. Hal Needham. Writ. Havey Miller. Prod. Albert Ruddy. 1983. DVD. Warner Home Video. 1999.

Chan, Jackie and Jeff Yang. I am Jackie Chan-My Life in Action. New York: 
The Ballantine Publishing Group, 1998.

Chan, Natalia Sui Hung. "Rewriting History: Hong Kong Nostalgia Cinema and Its Social Practice." The Cinema of Hong Kong: history, arts, identity. Ed. Poshek Fu and David Desser. Cambridge, UK; New York, NY: Cambridge University Press, 2000. 252-272

Chen, Mo (陈墨). “功夫成龙：从港岛走向世界一成龙电影创作历程述要 [Gongfu Cheng Long: From Hong Kong to the World-Brief History of Jackie Chan's Films]," 成龙的电影世界 [Jackie Chan's Film World]. Beijing: China Film Press (中国电影出版社), 2000.

Chen, Shan \& Tang, Jialin (陈山、唐佳琳). “希望与荣誉一成龙与史秦龙英雄形 象比较 [Hope and Honor-Comparison Between the Heroic Images Created by Jackie Chan and Sylvester Stallone] " Jackie Chan's), Film World (成龙的电影世界). Beijing: China Film Press (中国电影出版社), 2000.

Cheng, Andy. "Essence of City-Movers to Develop the West Kowloon District as a Cultural Hub are Premature While We Have Yet to Define Our City's Cultural Identity, Say Experts." South China Morning Post. 4, Dec., 2004. Sec: Behind the News 16.

Cheung, Anthony. "The Rise of Identity Politics." South China Morning Post 28 Dec. 2006, sec: News: 13.

Chow, Rey. Writing Diaspora: Tactics of Intervention in Contemporary Cultural Studies. Hong Kong: Oxford University Press (China) 1995.

Cooper, Richard. ed. More 100\% Jackie Chan. Titan Books, 2004

Cooper, Richard and Leeder, Mike. ed. 100\% Jackie Chan: The Essential Companion. Titan Books, 2002.

Corcoran, John. The Unauthorized Jackie Chan Encyclopedia: From "Project A" to "Shanghai Noon" and Beyond. 1 edition. McGraw-Hill, 2002

Culler, Jonathan. Literary Theory_A Very Short Introduction. Oxford University 
Press, 2000.

Dannern, Fredric and Long, Barry. Hong Kong Babylon_-an Insider's Guide to the Hollywood of the East. London: Faber, 1997.

Denizen, Norman K. The Cinematic Society: The Voyeur's Gaze. London; Thousand Oaks, Calif.: Sage Publications, 1995.

Drunken Master. Dir, Yuen, Woo Ping. Writ. Hsiao Lung. Prod. Ng See-yuen. 1978. VCD. 1995.

Drunken Master II. Dir. Lau Kar-Leung, Jackie Chan (uncredited). 1994. DVD. 1998.

Faucault, Michel. Discipline and Punish. Harmondsworth: Punguin, 1979.

Fu, Ping. "The Cinema of Hong Kong: History, Arts, Identity (review)." Asian Theatre Journal - Vol. 18, Number 2, Fall 2001, P279-281. University of Hawai Press. 2001.

Fu, Poshek and Desser, David. ed. Cinema of Hong Kong: history, arts, identity. Cambridge, UK; New York, NY: Cambridge University Press, 2000.

Gentry, Clyde. Jackie Chan: Inside the Dragon. Taylor Trade Publishing, 1997.

Gorgeous. Dir. Vincent Kut Tak-chiu. Writ. Jackie Chan and Ivy Ho. Prod. Jackie Chan and Raymond Chow. DVD. Golden Harvest (HK). 1999.

Hall, Stuart. "Cultural Identity and Cinematic Representation" Framework: the Journal of Cinema and Media 36. 1989.

---. "The Rediscovery of Ideology: the Return of the Represented in Media Studies," Subjectivity and Social Relations. Ed. Veronica Beechey and James Donald. Milton Keynes: Open University Press, 1985.

Hammond, Stefan and Wilkins, Mike. Sex and Zen and a Bullet In the Head. Powells Books Wholesale Remain, 1997

Hammond, Stefan. Hollywood East: Hong Kong Movies and the People Who Made Them. McGraw-Hill Companies, 2000.

Herd, Deborah. "In Search of Identity." South China Morning Post 3 Nov. 1996, Sec: 5 . 
Hogg, Michael A, Terry, Deborah J, and White, Katherine M. "A Tale of Two Theories: A Critical Comparison of Identity Theory with Social Identity Theory," Social Psychology Quarterly. Washington: Dec 1995. Vol. 58, Iss. 4 ; pg. 255, 15 pgs

$\mathrm{Hu}, \mathrm{Ke}$ (胡克). “成龙电影形象浅析 [Brief Analysis of Jackie Chan's Film Images]," 成龙的电影世界[Jackie Chan's Film World]. Beijing: China Film Press (中国电影出版社), 2000.

$\mathrm{Hu}$, Poshek. "Between Nationalism and Colonialism: Mainland Émigrés, Marginal Culture, and Hong Kong Cinema 1937-1941." The Cinema of Hong Kong: history, arts, identity. Ed. Poshek Fu and David Desser. Cambridge, UK; New York, NY: Cambridge University Press, 2000. 199-226.

Hung, Citi Ching-tin. "Identity Question a Key Priority: Chris Patten Needs to Address the Cultural and Historical Dimension During his State-of-the-nation Speech on Wednesday." South China Morning Post 4 Oct. 1992. Sec: Sunday Edition: 13.

Hung, Denise and Leung, Ambrose. "Civil Service Hopefuls Will Have to Brush Up on National Identity." South China Morning Post 11 Oct. 2007, sec: News: 6.

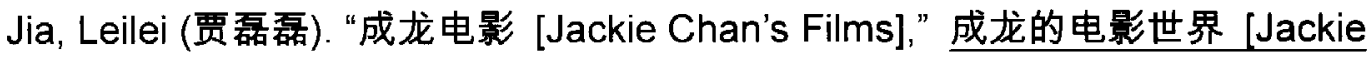
Chan's Film World]. Beijing: China Film Press (中国电影出版社), 2000.

Kan, Wendy. "Identity Crisis No Longer a Problem." South China Morning Post 2 Nov. 1997, sec: Agenda; Home And Away: 2.

--.- "The Language of Cultural Identity." South China Morning Post 16 Nov. 1997, sec: Agenda; Home And Away: 2.

Lee, Eliza W.Y. Gender and Change in Hong Kong-Globalization, Postcolonialism, and Chinese Patriarchy. Ed. UBC Press The University of British Columbia, 2003.

Leung, Ping-Kwan. "Urban Cinema and the Cultural Identity of Hong Kong." The Cinema of Hong Kong: history, arts, identity. Ed. Poshek Fu and 
David Desser. Cambridge, UK; New York, NY: Cambridge University Press, 2000. 227-251.

…. “都市文化与香港文学[Urban Culture and Hong Kong Literature]," 后殖民理 论与文化认同 [Postcolonial Theory and Cultural Identification]. Ed. Zhang, Jingyuan. Taipei: Rye Field Publishing Co. 1995.

Li，Bing (李冰)。“对手戏”模式一成龙电影走向世界的桥梁 ['Antagonist' Pattern—a Bridge to the World for Jackie Chan's Films],"成龙的电影 世界 [Jackie Chan's Film World]. Beijing: China Film Press (中国电影 出版社), 2000 .

Liu, Guojun (刘帼君). “成龙的表演艺术世界 [Jackie Chan's Performance Art]," 成龙的电影世界 [Jackie Chan's Film World]. Beijing: China Film Press (中国电影出版社), 2000.

Loh, Christine. "Hong Kong's Search for Identity." South China Morning Post sec: News: 15.

Lu, Sheldon. "Filming Diaspora and Identity: Hong Kong and 1997." The Cinema of Hong Kong: history, arts, identity. Ed. Poshek Fu and David Desser. Cambridge, UK; New York, NY: Cambridge University Press, 2000. 273-288.

Lu, Sheldon Hsiao-peng. ed. Transnational Chinese cinemas: identity, nationhood, gender. Honolulu, HI: University of Hawaii Press, 1997.

Luo, Dayou and Jiang, Zhiguang. "Huanghou Dadao Dong/Queen's Road East." By Lin, Xi. Huanghou Dadao Dong/Queen's Road East, 1991. 16:32 20 May, 2009. http://www.lrc123.com//rc/110972-58117.htm|

--- and et al. "Shoudu/Capital." By Lin, Xi. Shoudu/Capital. 1992. 17:23: 20 May, 2009. <http://mp3. baidu.com/m?f=ms\&rn=10\&tn=baidump3lyric\&ct=1509 94944\&word $=\%$ CA\%D7\%B6\%BC\& $\mid m=-1>$ 
Luo, Gang and Liu, Xiangyu. 文化研究读本 [Cultural Studies]. Ed. Beijing: China Social Sciences Press, 2000.

Lo, Kwai-Cheung. "Double Negations: Hong Kong Cultural Identity in Hollywood's Transnational Representations. Cultural Studies. 15 (3/4) 2001. P464-485. Taylor \& Francis Ltd. 8 Jan., 2006. http://www.tandf.co.uk/journals

$\mathrm{Ni}$, Jun (兒俊). “无知还是恶意? 好莱坞怎样演义“中国人” [lgnorance or spite? How does Hollywood Depict the image of "Chinese"]." Xinhuanet: 12:49:54, Nov. 29, 2003. World Knowledge: Vol. 22. 2003. 20:25 May 5, 2007. <http://news.xinhuanet.com/world/2003-11/29/content_2767795.h $\underline{\mathrm{tm}}>$

New Police Story. Dir. Benny Chan. Prod. Willie Chan, Solon So, Benny Chan and Barbie Tung. DVD. JCE Movies Limited/China Movie Group. 2004.

McLeod, John. Beginning Post-Colonisation. P40-50 New York: Manchester University Press 2000

O'Neill, Mark. "One of the Family: Hong Kong's identity is merging with the mainland even as Beijing says the SAR plays a distinctive and vital role," South China Morning Post. 8 July, 2002, Sec: Supplement 2.

Overseas Chinese Language and Culture Education Online (中国华文教育网). 18 Nov., 2008. 21: 0312 June, 2009. <http://www.hwjyw.com/zyzx/ jxsc/zgls/200811/t20081118_23608.shtml>

Page, Benjamin I. "The Mass Media as Political Actors" Political Science and Politics, Vol. 29, No. 1. Mar., 1996.

Pang, Laikwan and Wong, Day. Masculinities and Hong Kong cinema. Hong Kong: Hong Kong University Press; London: Eurospan [distributor], 2005.

Police Story. Dir. Jackie Chan. Prod. Wilie Chan. 1985.DVD. 1997.

Police Story II. Dir. Jackie Chan. Writ. Jackie Chan, Edward Tang King-sang. 
Prod. Leonard Ho. 1988. VCD. Golden Harvest (HK). Virgin (Far East) Limited 1988.

Police Story III: Super Cop. Dir. Stanley Tong. Writ. Edward Tang King-sang. Prod. Willie Chan, Edward Tang King-sang. 1992. DVD. 1998.

Police Story IV: First Strike. Dir. Stanley Tong. Writ. Stanley Tong, Nick Tramontane. Prod. Barbie Tung, Jackie Chan. 1996. 20 May, 2009. < http://kankan.xunlei.com/4.0/movie/77/3677.html?id=42>

Project A/Pirate Patrol. Dir. Jackie Chan. Writ. Jackie Chan. Prod. Leonard Ho. 1984. DVD. 2001.

Project All. Dir. Jackie Chan. Writ. Edvard Tang King-sang. Prod. Leonard Ho. 1987. DVD. 2001.

Pujadas, Carlton. "Current School System in the Grip of an Identity Crisis." South China Morning Post 14 Jul. 2001, sec: Mailbag: 5.

Qian, Xuege (钱学格). “成龙表演艺术的发展轨迹 [The Growing of Jackie Chan's Performance Art ],"成龙的电影世界 [Jackie Chan's Film World]. Beijing: China Film Press (中国电影出版社), 2000.

Qiu, Yunhua. Literary Critical Theory and Practice. 2005. Beijing: Peking University Press 2006.

Reese, Stephen D., Oscar H. Gandy and Jr. August E. Grant (ed.) Framing Public Life: Perspectives on Media and Our Understanding of the Social World. Mahwah: Lawrence Erlbaum Associates, Inc., Publishers, 2001.

Rob-B-Hood. Dir. Benny Chan. Writ. Benny Chan and Jackie Chan. Prod. Willie Chan, Solon So, Benny Chan and Wong Zhonglei. DVD. Huayi Brothers' Movie Investment Limited. 2006.

Rovin, Jeff. The Essential Jackie Chan Source Book. Pocket Books, 1997

Rush Hour. Dir. Brett Ratner. Prod. Roger Birnbaum. 1998. DVD. New Line Home Video. 1999.

Rush Hour II. 2001. Dir. Brett Ratner. Writ. Ross LaManna. Prod. Roger 
Birnbaum. DVD. New Line Home Video. 2002.

Rush Hour III. Dir. Brett Ratner. Writ. Jeff Nathanson and Ross LaManna. Prod. Roger Birnbaum, Andrew Z. Davis, Jonathan Glickman and Arthur M. Sarkissian. DVD. 2007.

Said, Edward W. Orientalism. London: Routledge and Kegan Paul, 1978.

Saunders, David. "World-watching Leaves HK with Identity Crisis." South China Morning Post 2 Oct. 1999, sec: Business Post; Lai See: 16.

Saussure, Ferdinand de. Course in general linguistics. Eds. Charles Bally and Albert Sechehaye; Trans. Roy Harris. LaSalle, Illinois: Open Court, 1986, c1983.

"Sense, and Sensitivity, About Asians" The New York Times. March 3, 1992. Copyright: The New York Times Company 1992.

Shanghai Noon. Dir. Tom Dey. Writ. Miles Millar and Alfred Gough. Prod. Gary Barber, Roger Birnbaum, Jackie Chan and Willie Chan. DVD. Walt Disney Video. 2000.

Shanghai Knights. Dir. David Dobkin. Writ. Alfred Gough and Miles Millar. Prod. Roger Birnbaum, Gary Barber and Jonathan Glickman. DVD. Walt Disney Video. 2003.

Shao, Zhou (少舟)。“论成龙电影的历史坐标 [On Historical Coordinate of Jackie Chan's Films],"成龙的电影世界 [Jackie Chan's Film World]. Beijing: China Film Press (中国电影出版社), 2000.

SCMP. South China Morning Post. 10 May, 2009 <http://scmpgroup.com/about/milestones.html>

Stets, Jan E and Burke, Peter J. "Identity theory and social identity theory" Social Psychology Quarterly. Vol. 63, Iss. 3. Washington: 2000. 224-238.

Storey, John. Cultural Theory and Popular Culture: An Introduction. Pearson Prentice Hall, 2001

Stryker, Sheldon. "Identity Theory and Personality Theory: Mutual Relevance." 
Journal of Personality 75:6, Dec. 2007. Blackwell Publishing, Inc. 2007. DOI: $10.1111 /$ j. $1467-6494.2007 .00468 . x$

Sun, Min (孙玨). “成龙电影与文化认同 [Jackie Chan's Films and Cultural Identification],"成龙的电影世界 [Jackie Chan's Film World]. Beijing: China Film Press (中国电影出版社), 2000.

Suo, Yabin (索亚斌). “醉里乾坤我最知一从两部《醉挙》看成龙电影[Conscious Drunken-Reading Jackie Chan's Films from Drunken Master I and II],"成龙的电影世界 [Jackie Chan's Film World]. Beijing: China Film Press (中国电影出版社), 2000.

Tan, Yaming (谭亚明)。“解读成龙警韭片 [Interpreting Jackie Chan's Police Stories],"成龙的电影世界 [Jackie Chan's Film World]. Beijing: China Film Press (中国电影出版社), 2000.

Tang, Suk-man. "Imagined Chineseness in Transcultural Contexts: Dynamics in Chinese Cinemas." Sinology, University of Zurich. Jan. 8, 2007. http://www.asienundeuropa.unizh.ch/research/film/china/Projektskizze 2.pdf

Tam, Siumi Maria. "Empowering Mobility: 'Astronaut' Women in Australia," Gender and Change in Hong Kong-Globalization, Postcolonialism, and Chinese Patriarchy, 177.

Teo, Stephen. Hong Kong cinema : the extra dimensions. London: BFI, 1997.

Terry, Edith. "A Reawakening Sense of Identity." South China Morning Post 19 May 2004, sec: News; Chinatown: 13.

The Myth. Dir. Stanley Tong. Prod. Willie Chan, Solon So, and Barbie Tung. DVD. JCE Movies Limited and China Film Group Corporation. 2005.

The Protector. Dir. James Glickenhaus. Writ. James Glickenhaus. 1985. DVD. Warner Home Video. 2002. 
The Tuxedo. Dir. Kevin Donovan. Writ. Philip Hay, Matt Manfredi, Michael Wilson (II) and Michael Leeson. 2002. DVD. Dreamworks Video. 2003.

Torode, Greg. "Massaging the Message-Chris Jackson Has Spent Five Years Gently Putting Hong Kong's Position Across in the US. As He Prepares to Leave, He Warns about the Dangers of the SAR Losing its Identity." South China Morning Post. 5 Jan., 2001. Sec: 14.

Tsui, Clarence. "Who are We?-An Evolving Sense of Identity is Changing the Socio-political Scene." South China Morning Post. 11 Jun., 2007. Sec: News; Behind the News 12.

Tyson, Lois. Critical Theory Today. New York \& London: Garland Publishing, Inc., 2006.

Wang, Jun. "Hong Kong Cultural Identity in Jackie Chan's Hong Kong and Hollywood Movies" Sun, 5 Feb 2006 13:23:37 -0500. 8 Jan., 2007. $<$ http://list.msu.edu/cgi-bin/wa?A2=ind0602a\&L=aejmc\&T=0\&P=1843 $\underline{8}>$

Wang, Haizhou (王海州). “成龙电影 : 英雄形象极其变奏 [Jackie Chan's Films: Heroes and Variations]," 成龙的电影世界 [Jackie Chan's Film World]. Beijing: China Film Press (中国电影出版社), 2000.

Who Am I?. Dir. Jackie Chan. Writ. Jackie Chan and Susan Chan. Prod. Leonard Ho, Barbie Tung and Jackie Chan. DVD. Golden Harvest (HK). 1998.

Witterstaetter, Renée. Dying for Action: The Life and Films of Jackie Chan. Grand Central Publishing, 1997

Wu, Fei (吴飞). 编辑学理论研究 [ Study on Theories of Editorology]. Hangzhou: Zhejiang University Press, 2001.

Wu，Guanping (吴冠平). “好莱坞认知的成龙电影 [Hollywood's Perception of Jackie Chan's Films]," 成龙的电影世界 [Jackie Chan's Film World]. 
Beijing: China Film Press (中国电影出版社), 2000.

Xu, Hui (徐辉). “成龙电影中的女性形象 [Female Images in Jackie Chan's Films]," 成龙的电影世界 [Jackie Chan's Film World]. Beijing: China Film Press (中国电影出版社), 2000.

Xu，Jinhua. 飞扬与落寞-成龙的侠骨柔情 Victory and Loneliness. Beijing: Tuanjie Press, 2006.

Yang, Enpu (杨恩璞). “好莱坞的突破与突破的好莱坞一成龙电影的国际走向 [Hollywood's Breakthrough and the Breakthroughed Hollywood-The International Trends of Jackie Chan's Films],"成龙的电影世界 [Jackie Chan's Film World]. Beijing: China Film Press (中国电影出版社), 2000.

Yau, Esther C.M. ed. At full speed: Hong Kong cinema in a borderless world. Minneapolis: University of Minnesota Press, 2001.

Ye, Weilian. “殖民主义·文化工业与消费欲望 [Colonialism, Cultural Industry and Consuming Desire],"后殖民理论与文化批评 [Postcolonialism and Culture Criticisml. Ed. Zhang, Jingyuan. Beijing: Peking University Press, 1999.

Ye, Yincong. “本地人'从哪里来? [Where are the Natives from? ]," 谁的城市： 战后香港的公民文化与政治论述 WWhose City: Citizenship Culture and Politics in Postwar Hong Kongl. Hong Kong: Oxford University Press, 1997.

Yeung, Chris. "Hong Kong's Identity Still an Open Question." South China Morning Post 22 Sep. 2002, sec: At Large: 8.

Zhang, Yan (张燕). “香港文化的银幕典范一成龙电影现象研究 [Screen 
Apotheosis of Hong Kong Culture-Studies on Jackie Chan's Films]," 成龙的电影世界 [Jackie Chan's Film World]. Beijing: China Film Press (中国电影出版社), 2000.

Zheng, Dongtian (郑洞天). “成龙形象的文化意味 [Cultural Significance of Jackie Chan's Image],"成龙的电影世界 [Jackie Chan's Film World]. Beijing: China Film Press (中国电影出版社), 2000.

Zhou, Xing (周星). “论成龙电影的东方文化显现 [On Oriental Features of Jackie's Chan's Films]," 成龙的电影世界 [Jackie Chan's Film World]. Beijing: China Film Press (中国电影出版社), 2000.

Zhu，Lili. 身份认同与华文文学研究 [Identity and Chinese Literature Study]. Shanghai: Shanghai Sanlian Press, 2008.

Zuo, Ke (左克).标题一得录 [Understanding of Headings]. Beijing: Xinhua Publishing House, 1991. 


\section{CURRICULUM VITAE}

NAME: $\quad$ Yajuan Ding

ADDRESS: Room 502, Building 25, University of Science and Technology Beijing (No.30 Xueyuan Road), Haidian District, Beijing, P. R. China, 100083

DOB: $\quad$ Beijing, China - August 16, 1969

\section{EDUCATION}

\& TRAINING: English Language Teaching

University of Science and Technology Beijing

1988-1990

English Language Teaching

Capital Normal University

1991-1993

M.A., Educational Economy and Management (formerly Administration of Higher Education) University of Science \& Technology Beijing 1999-2002

M.A. Training Program, Linguistics and Applied Linguistics Tsinghua University

2002-2005

Ph.D. in Humanities

University of Louisville

2006-2009

PROFESSIONAL SOCIETIES

2007- International Association for Intercultural Communication Studies (IAICS) 


\section{PUBLICATIONS}

Chief Editor, Tutorial for the Textbook of PETS 3 . Beijing: Beijing Foreign Language Press, 2006

English-Chinese translator, Gain the Edge! Negotiating to Get What You Want. Beijing: Guangming Daily Press, 2005.

English-Chinese translator, 15 Seconds Principle. Beijing: Guangming Daily Press, 2005.

Author, “How to Prepare English Proficiency Test II"《步入英语的殿堂》. Beijing: Foreign Language Teaching and Research Press, 2004.

Author, "Education of Paris" Research on the Education Development Strategies of Beijing. Beijing: Hongqi Press, 2003

English-Chinese translator of some articles published in METAL WORLD, No. 2, 3, 4, 5, 1996.

\section{INVITED PRESENTATIONS}

"Cultural Identity of Hong Kong Reflected in Jackie Chan's Performances and Movies," 2007 International Conference on Intercultural Communication, June 22-24, 2007, Harbin, Heilongjiang, P.R. China 